\title{
WestVirginiaUniversity
}

THE RESEARCH REPOSITORY @ WVU

Graduate Theses, Dissertations, and Problem Reports

2001

\section{Portraits of the songwriting process in elementary classrooms}

Sally dhruva Stephenson

West Virginia University

Follow this and additional works at: https://researchrepository.wvu.edu/etd

\section{Recommended Citation}

Stephenson, Sally dhruva, "Portraits of the songwriting process in elementary classrooms" (2001).

Graduate Theses, Dissertations, and Problem Reports. 2373.

https://researchrepository.wvu.edu/etd/2373

This Dissertation is protected by copyright and/or related rights. It has been brought to you by the The Research Repository @ WVU with permission from the rights-holder(s). You are free to use this Dissertation in any way that is permitted by the copyright and related rights legislation that applies to your use. For other uses you must obtain permission from the rights-holder(s) directly, unless additional rights are indicated by a Creative Commons license in the record and/ or on the work itself. This Dissertation has been accepted for inclusion in WVU Graduate Theses, Dissertations, and Problem Reports collection by an authorized administrator of The Research Repository @ WVU.

For more information, please contact researchrepository@mail.wvu.edu. 
PORTRAITS OF THE SONGWRITING PROCESS IN ELEMENTARY CLASSROOMS

by

Sally dhruvá Stephenson

\author{
Dissertation submitted to the \\ College of Human Resources and Education \\ at West Virginia University \\ in partial fulfillment of the requirements \\ for the degree of
}

Doctor of Education

in

Curriculum and Instruction

\author{
Approved by \\ Joy Faini Saab, Ed.D., Chair \\ Ron lannone, Ed.D. \\ Ardeth Deay, Ph.D. \\ Janet Robbins, Ph.D. \\ Gail Neary Herman, Ph.D.
}

Department of Educational Theory and Practice

Morgantown, West Virginia

2001

Keywords: Creative Writing, Portraiture, Arts in Education, Creativity, Qualitative Research

(c) 2001 S.D. Stephenson 


\title{
Abstract \\ Portaits of the Songwriting Process in Elementary Classrooms
}

\author{
by Sally dhruvá Stephenson
}

This study uses the qualitative research technique of portraiture to study the songwriting process in elementary classrooms. In chapter one, the author provides a theoretical framework for incorporating the arts and music in general education, and proposes to provide support for incorporating the creative process of songwriting into the elementary curriculum. Chapter two reviews the research literature on the educational and therapeutic uses of songwriting, and published examples of educational applications of songwriting. In chapter three, the methodology of portraiture is explained and four research settings are described, one each in Virginia, West Virginia, Tennessee, and Maryland. Two of the sites involve visiting songwriters-in-residence, and the other two sites involve regular classroom teachers in educational outreach programs sponsored by professional organizations (Country Music Hall of Fame and Metropolitan Opera Guild). In chapter four, the results of the researcher's observations, interviews, and review of student products are presented as portraits of the songwriting experiences (one for each site). In the final chapter, the author reflects and integrates the four portraits and draws conclusions regarding the four approaches to the songwriting process observed. Inferences from the data are discussed in sections entitled "Collaboration, Cooperation and Engagement," "Voices of the Children," and "Authentic Learning Experiences." The chapter concludes with reflections on the research with recommendations for further study. The researcher suggests that there is sufficient justification, outlined specifically in national and state educational standards, supported by research literature, and brought to life by the experiences and voices of those in the field, to incorporate songwriting into the regular elementary curriculum. Also included are fourteen excerpts from songs written by elementary students, references, and four appendices: interview questions, summary of songwriting pedagogy by site, song topics grouped by theme, and National Standards for Arts Education relating to the songwriting process. 


\section{Dedication}

This dissertation is dedicated to

my advisor, chair, mentor and colleague,

Dr. Joy Faini Saab

who patiently walked me through my doctoral program

from my first inquiry through my graduation

and in memory of my father,

Dr. Edward Almand Stephenson,

always the consummate teacher and scholar,

and mother,

Eunice Ruth Stephenson,

whose belief in me never waned. 


\section{Table of Contents}

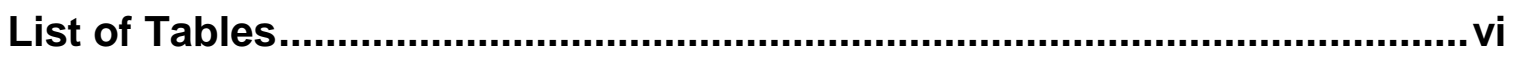

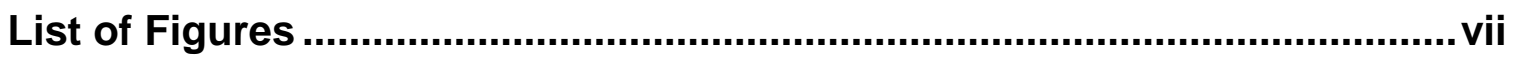

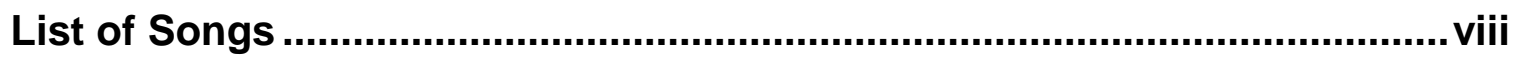

\section{Chapter One}

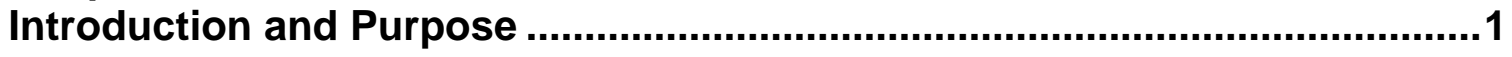

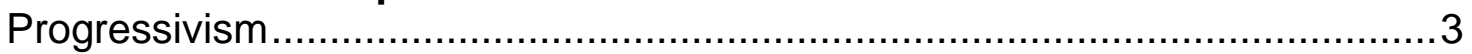

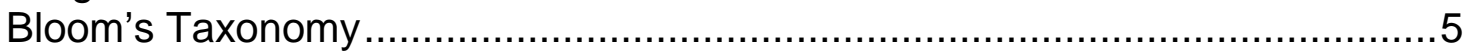

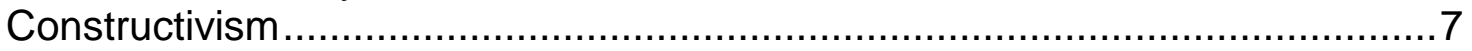

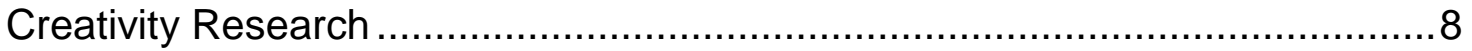

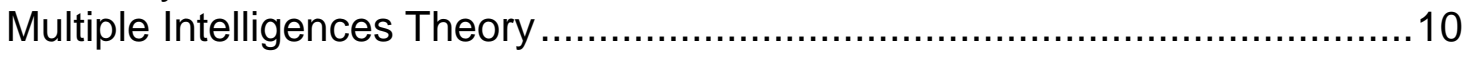

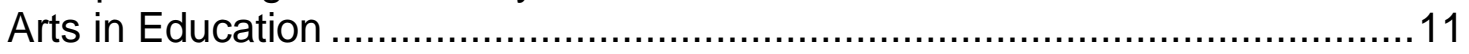

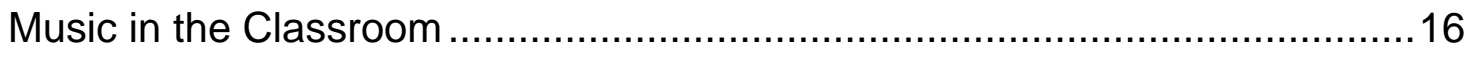

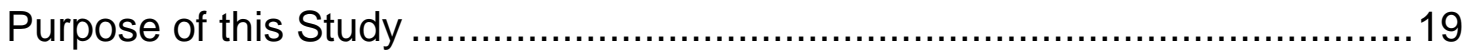

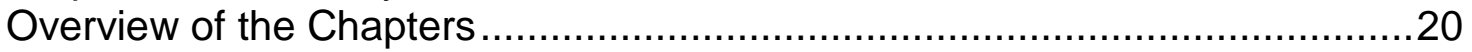

\section{Chapter Two}

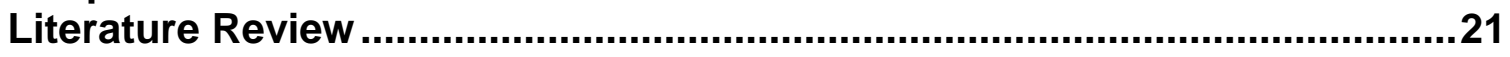

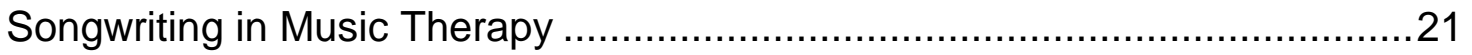

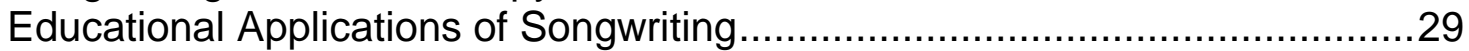

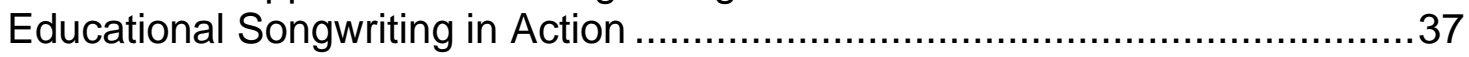

\section{Chapter Three}

Methodology: Creating the Portraits..........................................................38

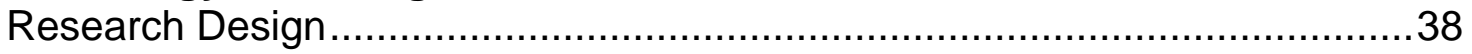

Selection of Participants ...................................................................... 41

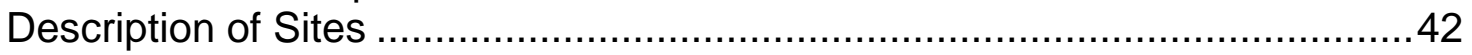

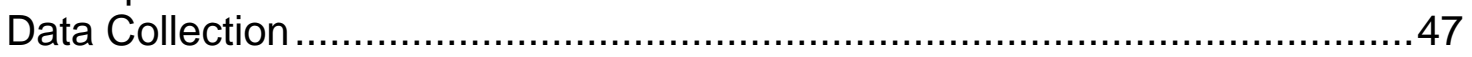

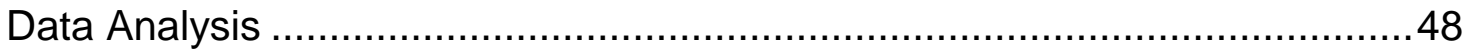

\section{Chapter Four}

Results: Portraits of the Songwriting Process.........................................52

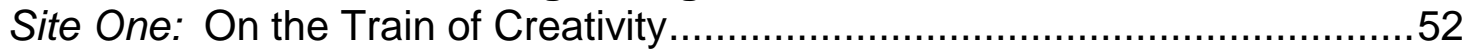

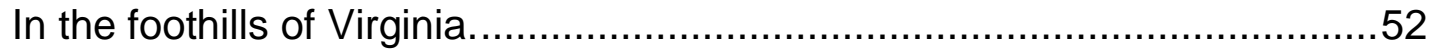

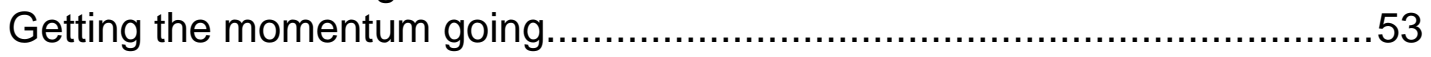

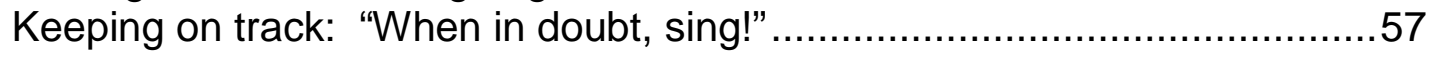

Site Two: The Building Blocks of Songwriting ..........................................6

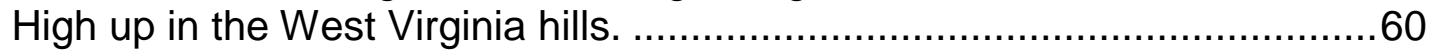

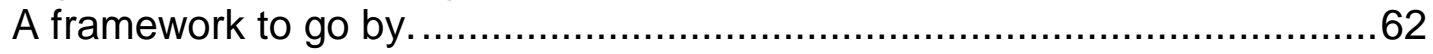

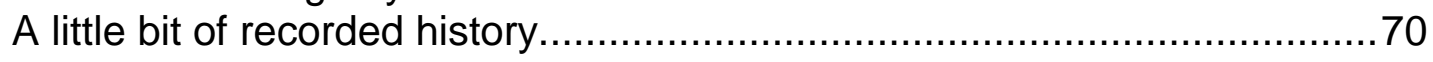


Site Three: The Country Music Songwriting Tradition ................................75

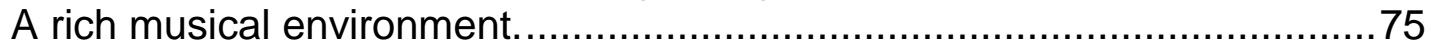

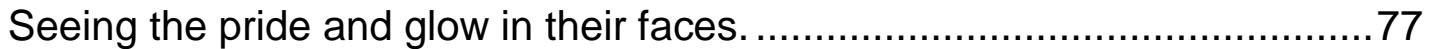

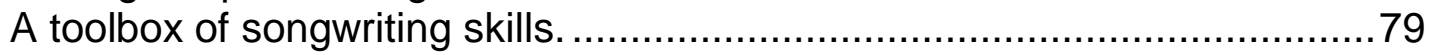

"The Children Want to Be Heard." ...........................................................94

Site Four: An Integrated Perspective in a Fragmented World ......................98

On the edge of a multicultural metropolis. ............................................98

Cooperating to make something "really big" happen. ................................99

The overwhelming responsibility of writing an opera. .............................101

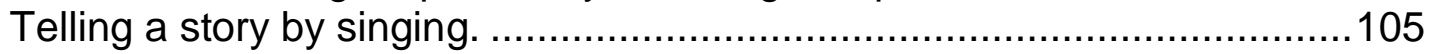

Weaving the arts into the cloth of the curriculum..................................109

\section{Chapter Five}

Conclusion: Reflections on the Portraits ..............................................113

Collaboration, Cooperation and Engagement …....................................117

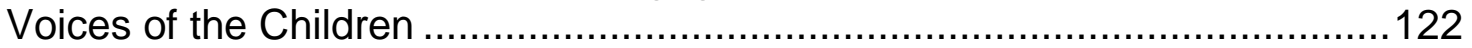

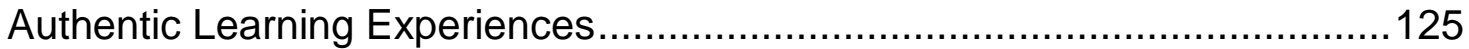

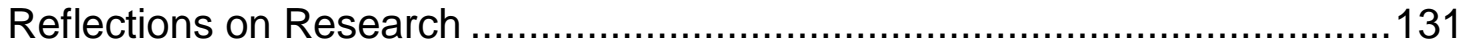

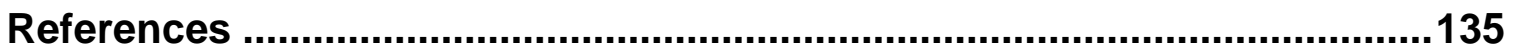

\section{Appendix A}

Interview Schedules

Interview Schedule A: Classroom teachers ..........................................144

Interview Schedule B: Songwriting consultants ...................................145

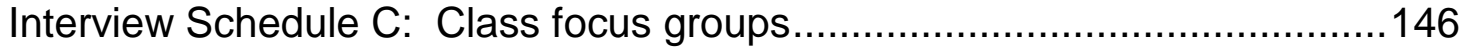

Appendix B

Summary of Songwriting Pedagogy by Site.............................................147

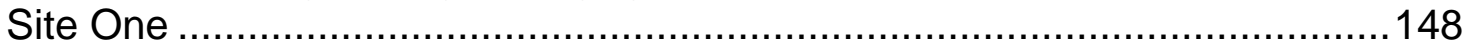

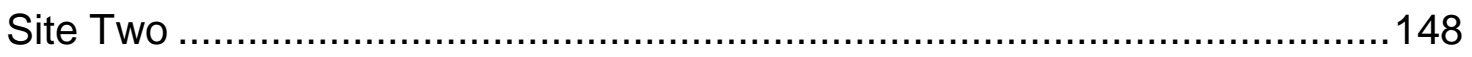

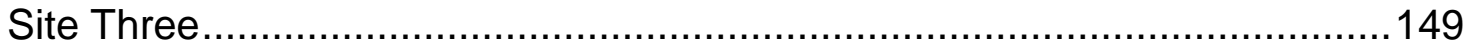

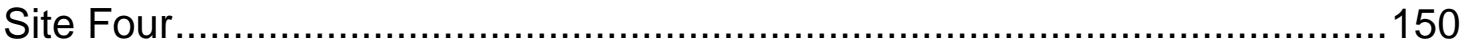

Appendix C

Song Topics Grouped by Theme.............................................................152

Table C1. Topics of group songs from two schools at Site One by theme...153

Table C2. Topics of group songs from two schools at Site Two by theme...154

Table C3. A sampling of song topics from schools at Site Three................155

Appendix D:........................................................................................156

National Standards for Arts Education Relating to the Songwriting Process

Music (K-4) Content Standard \#3 ....................................................157

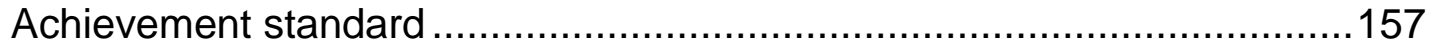

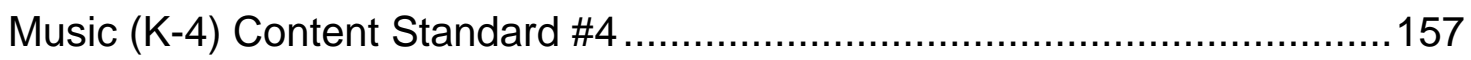

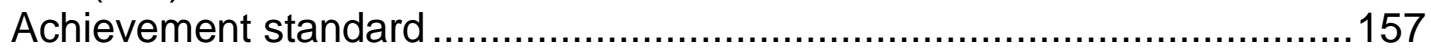

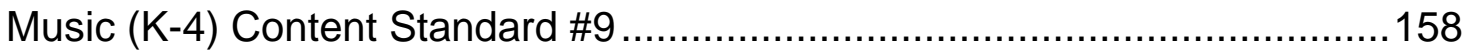

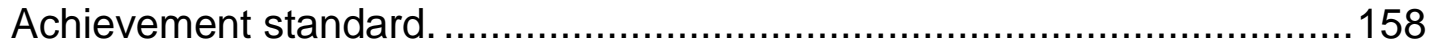




\section{List of Tables}

Table C1. Topics of group songs from two schools at Site One by theme........153

Table C2. Topics of group songs from two schools at Site Two by theme........154

Table C3. A sampling of song topics from participating schools at Site Three..155 


\section{List of Figures}

\section{Site One}

Figure 1. Notation of refrain for "My Grandma Stayed Home." ........................59

\section{Site Two}

Figure 2. Initial word lists for "Future Basketball" by fifth grade boys................64

Figure 3. A third grader's web on ideas about art. .......................................65

Figure 4. Excerpt from fourth graders' outline for "House on Haunted Hill.".......67

Figure 5. Bookmark of the "Big, Gray Wolf" drawn by third grader. ..................68

\section{Site Three}

Figure 6. Definitions of song elements from Jean's blackboard.......................81

Figure 7. Comparison chart of poetry and songs on Jean's blackboard. ...........84

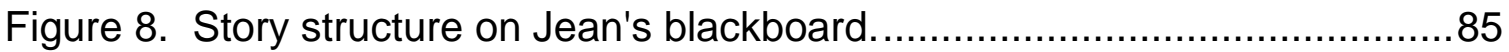

Figure 9. Example of student's chart showing beginning, middle and end........88

Figure 10. Excerpt of song, "School Drools," as submitted to songwriter. ........90

Figure 11. Excerpt from lyrics for "Pimples, Freckles, Warts, 'n Moles." ............93

\section{Site Four}

Figure 12. Exhibit display information on the job of composer......................104

Figure 13. Logo designed by students for the youth opera company..............112 


\section{List of Songs}

\section{Site One}

Song 1. Excerpt from "Swimmin' in the Nile" ...................................54

Song 2. Excerpt from "Flurries in the Night" ....................................55

\section{Site Two}

Song 3. Excerpt from "Space Art" ............................................. 70

Song 4. Excerpt from "Dinosaur Rock".....................................72

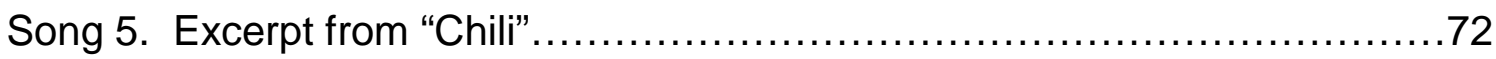

Song 6. Excerpt from "Big Gray Wolf"

\section{Site Three}

Song 7. Excerpt from "Brush Your Teeth" ......................................78

Song 8. Reading of excerpt of first draft, "School Drools"........................89

Song 9. Excerpt from final arrangement, "School Drools".........................90

Song 10. Excerpt from "Pimples, Freckles, Warts 'n Moles"........................93

Site Four

Song 11. Excerpt \#1 from "Teasing Song"...................................100

Song 12. Excerpt from "I'm Alone" ..........................................105

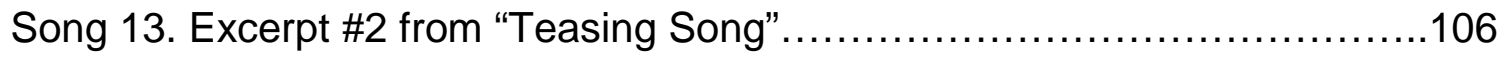

Song 14. Excerpt from "Building Song"......................................108 


\section{Chapter One}

\section{Introduction and Purpose}

Children love to sing. Every early childhood classroom is overflowing with youngsters eager to fill the air with the sounds of their voices, be they soft or loud, sweet or rough. And equally, children love to create: paper airplanes, homemade jewelry, drawings of rocket ships and houses, make-believe dramas, original dances and cheers. . . the list is endless. Unfortunately, the lock-step educational system that prevails in the United States today too often teaches children to repress these natural instincts in the sacred names of "achievement" and, ironically, "performance."

Measurable objectives and the resultant accountability have become the mandated focus of our educational process. Not all educators agree with this priority, however:

The subject matter curriculum with its characteristics of fragmentation, memorization, textbook orientation, teacher as controller, cognitive-based, and norm-testing is now being questioned. It is especially being questioned by those who feel that the modern, industrial efficiency paradigm is no longer relevant for today's curriculum. We seemed to be looking for something more in the curriculum. (Iannone and Obenauf, 1999, p. 738)

There is a significant and growing body of research that supports the fostering of creative and artistic endeavors as an integral part of a well-rounded, holistic education. Although our educational system has yet to succeed in fully integrating constructive, creative learning experiences into the curriculum, the idea is by no means new. This concept appeared in our educational literature as 
far back as the early 1900's in the philosophy and teachings of Dewey (1934), and reappeared in the landmark works on educational objectives by Bloom (1956) and the intellectual development of children by Piaget (as cited by Silberman, 1973). In the 1960's, research by Guilford (1968), Torrance (1965), Parnes (1967) and others evidenced a widespread interest in understanding and fostering the creative process.

The educational environment of the late 1900's, although heavily directed by legislative mandates on accountability and the resultant emphases on basic skills and competency testing, was brightened by the appearance of Gardner's theory of multiple intelligences $(1983,1993)$. This alternative view of intelligence provided a refreshing, multi-dimensional approach to education, including strong support for the arts and constructive, experiential learning experiences. Contemporaneously, as school systems restricted or eliminated arts programming to deal with budgetary restrictions, other research began to appear on the advocacy side of the arts (Eisner, 1990, Greene, 1990, Hanna, 1992, Hanshumaker, 1980, and McLaughlin, 1990).

As a follow-up to the national Goals 2000: Educate America Act (WV Commission on the Arts, n.d.), which directed schools to prepare all students to be "competent in challenging subject matter, including the arts," the Consortium of National Arts in 1994 outlined specific National Standards for Arts Education, from which each state adopted corresponding voluntary standards for student achievement in visual art, music, dance and drama for grades K-12. 
Chapter one of this study elaborates on the aforementioned historical and theoretical perspectives to build a conceptual foundation for incorporating the arts and creativity in an elementary curriculum. Of specific interest to the researcher is the creative use of the songwriting process. In an unpublished manuscript, Ching (1995), the Artistic Director of Opera Memphis, emphasizes the benefits of songwriting in an educational program:

Song writing is one of those arts that is at the top of an educational pyramid. It requires language skills. It requires knowledge of the world-history, culture. It requires musical skills. Because of this great blending, song writing gives us a great way to synthesize our knowledge and experience. Because of its almost magical effect on memory, song writing can be an excellent mnemonic device.... Synthesis is one of the key parts of creativity, and this creativity, once found, can be applied to songs, music and beyond, to society and life itself. (p. 6)

This particular study, the methodology of which will be explained in chapter three, utilizes the framework of arts in education as support for incorporating the creative process of songwriting in the elementary curriculum.

\section{Progressivism}

One of the cornerstones in our educational foundation is Dewey. As spokesperson for the Progressive movement which dominated the educational landscape in the early 1900's, he authored a multitude of books which are still required reading in educational coursework a half century later. Gardner (1991) describes the progressive educators' approach:

Spurning a rigidly mandated curriculum with explicit schedules during the day, and calling into questions the pervasive systems of rewards, punishments and regular examinations, progressive educators instead formed rich projects through which children could 
come to know their world, achieve a fuller understanding of themselves and begin to secure a feeling for the skills and concepts that lay at the heart of formal disciplines. (p. 193)

Dewey (1934) emphasized the importance of hands-on experiences in learning. In his view, interaction with raw materials provides integrated, complex opportunities for student learning; in fact, he states that art is "the incomparable organ of instruction" (p. 347). In Art as Experience, Dewey elaborates on how the arts engage students in authentic learning experiences:

Art denotes a process of doing or making. This is as true of fine art as of technical art. Art involves molding of clay, chipping of marble, casting of bronze, laying on of pigments, construction of buildings, singing of songs, playing of instruments, enacting roles on the stage, going through rhythmic movements in the dance. Every art does something with some physical material, the body or something outside the body, with or without the use of intervening tools, and with a view to the production of something visible, audible or tangible. . . . Art, in its form, unites the very same relations of doing and undergoing, outgoing and incoming energy, that makes an experience to be an experience. (p. 47)

Support for the success of the progressive approach is found in Kridel (1990), who writes in reference to the Progressive Education Association's eight-year study, conducted from 1932-1940: "Progressive educators of the 1920's and 1930's developed the concept of core curriculum to its most refined form. The Progressives 'proved' beyond question that an integrated curriculum (incorporating the arts) provided an equal, if not better, preparation for college" (p. 87). 


\section{Bloom's Taxonomy}

As the American educational system pulled away from the experiential approach of the progressivists and toward standardized measurement of educational objectives, a group of educators headed by Bloom (1956) brought attention to the different levels of thinking required by educational tasks in a taxonomy of educational objectives. This hierarchical outline arranges educational objectives from lower levels of fact recall (knowledge), understanding of concepts (comprehension) and generalizations (application) to higher level skills of breaking down material into constituent parts (analysis), putting together elements and parts to form a whole (synthesis) and making judgments about the value (evaluation).

This classification of learning activities has been widely accepted and emphatically taught in teacher education; however, classroom observations have repeatedly shown that the great majority of school tasks fall into the lower domains and neglect the higher level cognitive functions. The arts, utilizing creative processes, are ideal vehicles for addressing the objectives of analysis, synthesis and evaluation. Bloom (1956) explains:

Synthesis is the category in the cognitive domain which most clearly provides for creative behavior on the part of the learner. . . . In synthesis, the student must draw upon elements from many sources and put these together into a structure or pattern not clearly there before. His efforts should yield a product-something that can be observed through one or more of the senses and which is clearly more than the materials he began to work with. It is to be expected that a problem which is classified as a task primarily involving synthesis will also require all of the previous categories to some extent. (p. 162) 
Teacher-researcher Gallas (1994) conducted an in-depth study of students in her second-grade classroom, making note of conversations with and between students, playground behaviors, drawings in daily art journals, notes to friends, and observations of children throughout the school day, to determine how her students would process and communicate knowledge. Her conclusions reinforce the notion that the arts are an apt vehicle for developing higher-level thinking:

Although it is easy to assess children's knowledge in the most superficial levels, assessing higher-level thinking is more difficult. That kind of learning is not easily measured and it is more difficult to encourage. I need to provide ways for children to express the metaphoric transformation that they are clearly capable of making by offering them many expanded opportunities for expressive action: to talk, paint, dance, write, build and study together. . . . Through the arts, teachers and children build an understanding of how school concepts relate to the child's personal reality. (p. 118)

Another concern for educators is the problem of motivation and student attitudes toward school, which is documented by researchers such as Haladyna and Thomas (1979). Their study of 3,000 elementary school students notes a sizable decline in attitudes toward school as children move through the grades: "The data unmistakably suggest that children are somewhat positive about school but grow increasingly disenchanted as a function of grade level. By the grades seven and eight, they appear extremely negative" (p. 20).

Few educators teaching in the public school system would disagree with these findings and the need for including in our instructional strategies those which increase motivation and improve student attitude and engagement in the learning process. Bloom (1956) addresses the interest value of synthesis objectives: 
... tremendous motivational possibilities in synthesis activities. Such tasks can become highly absorbing, more so than the usual run of school assignments. They can offer rich personal satisfactions in creating something that is one's own. And they can challenge the student to do further work of a similar sort. (p. 166)

\section{Constructivism}

In the 1960's, Swiss psychologist Piaget drew attention to the process of intellectual development in the child through his observations of his own children and their interactions with different media and corresponding conceptualizations. His theory describes stages of development which he named sensorimotor, preoperational, concrete operations and formal operations with children moving from concrete to abstract in their processing of knowledge (Craig, 1979).

The goal in education is not to increase the amount of knowledge but to create the possibilities for a child to invent and discover. . . teaching means creating situations where structures can be discovered; it does not mean transmitting structures which may be assimilated at no other than a verbal level (Piaget as cited by Silberman, 1973).

Piagetian theory laid the groundwork for constructivism. According to DeVries (1987), the basic law of development for Piaget is that the child, through interaction with materials in the environment, constructs his intelligence and knowledge. He states:

According to Piaget, interest is central to the spontaneous actions of empirical and reflective abstraction by which the child constructs knowledge and intelligence. Thus, methods aimed at promoting this constructive process must arouse the child's spontaneous interest, which is inherent in the child's activity. (p. 24) 
Ferreiro and colleagues (1979/82, as cited by DeVries, 1987) support the constructivist conception of an active learner who produces knowledge. An active learner "compares, excludes, orders, categorizes, reformulates, confirms, forms hypotheses and reorganizes through internalized action (thought) or through effective action (according to the level of development)" (p. 223). Armistead (1996), in a paper on constructivism and arts-based programs, states:

The arts engage children, parents and teachers in the creative process. An early learning arts-based curriculum allows preschool children, teachers and families to observe and comprehend the application of constructivist principles ( $p$. 2). . . Arts-based programming promotes risk-taking. It is child and teacher interest driven, characterized by action, not skill-driven tasks or exercises. Arts engagement gives children time and support for making and correcting errors in judgment or thinking. (p. 8)

\section{Creativity Research}

As well as the work of Piaget on child development, the sixties brought an awareness of creativity in education through the works of Guilford, Torrance, Parnes and others. Guilford (1968), one of the pioneers in creativity research, built upon the earlier work of Thurstone in an analysis of intellectual abilities in the formulation of his model, "Structure of Intellect." This model classifies intellectual abilities into three categories (figural, symbolic and conceptual), five classes (cognition, memory, convergent thinking, divergent thinking, and evaluative thought) and five products of operations (classes, relations, patterns, implications, and 
transformations) (p. 5). Guilford attributed grave importance to creativity in education:

Creative education aims at a self-starting, resourceful and confident person, ready to face personal, interpersonal and other kinds of problems. Because he is confident, he is also tolerant where there should be tolerance. A world of tolerant people would be peaceful and cooperative people. Thus creativity is the key to education in its fullest sense and to the solution of mankind's most serious problems. (p. 147)

Torrance (1965), a champion of creativity training, has conducted

longitudinal studies of creative thinking which indicate that creativity needs to be "energized and guided almost from birth" (p. 12). Torrance $(1966,1967)$ developed a series of creativity tests based on the creative characteristics of fluency, flexibility, originality and elaboration as identified by Guilford (1962). Parnes (1967) also puts great emphasis on the value of creativity:

If we can develop a kind of creative education which provides its own reason for being, then the person's entire life could be built around the intense desire to learn. . . . Life would then be one continuous creative experience, a flowing and merging of what we have with what we absorb, providing fully for what Maslow calls 'self-actualization.' (p. 25)

Several authorities note the importance of the environment supporting creative activity. Hennessey (1987) reports that the social environment must allow individuals to retain an "intrinsic focus" (p. 16); Torrance (1965) recommends showing respect for unusual questions and imaginative ideas; and Parnes (1967) suggests that the environmental setting must allow for complete self-acceptance. Hallman (1967) provides an interesting definition of creative thinking: 
Creative thinking is only one of several kinds of operations included in the higher mental processes; it is usually distinguished from other kinds of thinking largely in terms of its nonrational aspects. . . . In every case it is the nonrational, the autistic, the metaphoric, the internally oriented, the spontaneous and involuntary, the integrating unbound energies which are active in producing new connections. (p. 24)

Hubbard (1996) reinforces the need for such mental processing: "The more connections and different strategies for processing information we can use, the deeper our memory formations and the more wide-ranging our neural networks will be" (p. 94).

\section{Multiple Intelligences Theory}

Guilford's multi-factor view of intelligence described above paved the way for Gardner's theory of multiple intelligences. Basing his work on the study of skill development in normal children, the breakdown of abilities in brain-damaged patients and special populations with "jagged cognitive profiles" (1993, p. 7), Gardner posed a new multi-dimensional view of intelligence. Defining intelligence as "the ability to solve problems or fashion products that are valued in one or more cultural settings" (p. 87), he identified the following seven intelligences: linguistic, logical-mathematical, spatial, musical, bodily-kinesthetic, interpersonal, and intrapersonal. Intending this set of intelligences to be the minimum, rather than allinclusive, Gardner later added an eighth, naturalistic (Checkley, 1997).

Gardner's (1991) view on creativity aligns with the constructivist viewpoint: "Those more sympathetic to a creativity stance view education as an opportunity for individuals to invent knowledge on their own, to transform what has been 
encountered and to contribute new ideas and concepts to the collective wisdom" (p. 120). Furthermore, he states (1983, p. 2), "The arts may be especially suited to encompass the range of individual intellectual profiles." Moody (1990) speaks of the impact of Gardner's theory on arts in education:

The implications of multiple intelligences provide a powerful new argument for strengthening education in and through the arts. In the main, the arts are a celebration of the human spirit; they often present an intracultural sign of the times. In addition to their cultural value, experiences with them are necessary for the development of several forms of intelligence and may be equally important in motivating learning on the part of students who do not respond well to traditional teaching. (p. xi)

Gardner is not alone in his multi-dimensional view of learners. In a study incorporating creative dramatics into the teaching of mathematics concepts, Saab (1987) states, "Students vary in temperaments, attention spans, interests and abilities. . . The use of an instructional technique which incorporates a number of modalities may result in improved achievement, attitudes toward a specific content area, and creativity" (p. 1).

\section{Arts in Education}

The arts have long held a place in liberal education. Plato himself (as cited in Howard, 1992, p. 136) is quoted as saying, "An aesthetic education is the only education that brings grace to the body and nobility to the mind. . Art is the only instrument of early education that can penetrate into the recesses of the soul."

Eisner (1990) is a leading advocate for the arts in education: "When we're talking about artistic intelligences, we're talking about ways of knowing. If the mission of the school is defined in terms of knowledge transmission, the arts as well 
as the sciences, but in different ways, can make a major contribution to the realization of that mission" (p. 34).

Fowler (1990) provides some specifics on four ways in which the arts make unique connections with the "deeper purposes of education" for students:

1. Thinking aesthetically, which transfers to other realms of life

2. Thinking creatively, which requires:

- a high order of abstract reasoning

- utilizing the intellectual skills of an artist (envisioning, setting goals, determining and exercising technique, evaluating, revising and solving problems)

- developing self-discipline in the act of creating

3. Thinking communicatively, using unique communication systems; and

4. Thinking culturally about ourselves and others (p. 164)

Fowler believes that each of the arts functions as an important and unique system of communication. He elaborates on the role of the arts in communication:

Arts are forms of thought every bit as potent in what they convey as mathematical and scientific symbols. . they are the languages of civilization through which we express our fears, our anxieties, our curiosities, our hungers, our discoveries, our hopes. . . . More importantly, they are the ways we give form to our ideas and imagination so that they can be shared with others." (p. 164)

Furthermore, Fowler states, "The arts, like athletics, can make school enjoyable to students who cannot find joy anywhere else. They can touch the spirit of students whose spirit is denied in every other quarter" (p. 164). 
Fowler's concept of the arts as important symbolic languages echoes the work of Vygotsky (1978) in understanding children's sign-using activities and symbolic processes. Sign systems such as the symbolic languages of art, music, drama, and mathematics are communication systems, Berghoff (1998) explains and adds that these systems can support literacy learning, especially for students with reading difficulties or a lack of motivation to attend to typical language forms.

Research studies have documented specific academic benefits from arts in the curriculum. Hanshumaker (1980), in a review of selected research on the effects of arts education on intellectual and social development, found positive results in many of the studies. In his review, research findings showed that:

- Music, drama/movement and visual arts activities have a significant impact on language development and reading readiness skills of preschool and primary children

- Kodaly method music instruction appears to have a significant effect on the reading achievement of primary grade children

- Art experiences used to reinforce math concepts improve attitudes toward mathematics in fourth graders

- Arts activities foster a more positive attitude toward school and the general curriculum, resulting in increased achievement as well as decreased absenteeism (pp. 21-22)

Goldberg $(1992,1997)$ makes the point that the arts can provide valuable alternatives to standard methods of assessing student knowledge. She cites teacher-researcher Gallas's (1991) examples of first-grade students demonstrating 
knowledge through drawing science pictures and creating biology "dramas." Goldberg, in her college course on cognitive development, allows her students to communicate their understandings through journals, drawings, sculptures, poems, songs, music, dances and so on. She contrasts this student-empowered approach with the "banking model" of top-down education criticized by Freire (1994) in his social consciousness work.

Hanna (1992), a U.S. Department of Education program specialist, reviews a number of programs and studies documenting the success of arts programming, citing examples of how the arts can enhance the cognitive, social, civic, personal and aesthetic growth and development of students. One study on school desegregation in 200 southern secondary schools by Crain, Mahard, and Narot (1982, as cited in Hanna) found more cross-racial interactions occurring in performing and visual arts classes than in any others.

Lee (1985) describes a model comprehensive arts in education program, geared to the overall educational curriculum. This program is made up of four segments: specialized arts instruction, arts in general education, community arts resources, and arts for special populations. He notes that in a survey of twentyseven arts in education projects and nineteen research studies, every report claimed positive effects on at least one of four basic categories: student achievement, student behavior, student attitudes, and "other" (curriculum, community, or school staff).

McLaughlin (1990), under the auspices of a Kentucky Arts Council grant from the NEA's Arts in Schools Basic Education Grant Program, compiled an 
annotated bibliography of major research on arts education. He linked each of the eighty-eight studies to one of eleven points in a case statement for arts education, abbreviated below:

1. The arts enhance creativity, creative thinking and problem-solving.

2. The arts are integral in the development of the use of both brain hemispheres; cognitive, affective and psychomotor skills; and learning styles.

3. The arts increase communication skills needed in today's society.

4. The arts enhance basic literacy skills, including cultural literacy.

5. The arts enable students to acquire aesthetic judgment.

6. The arts develop self-esteem and a positive self-concept.

7. The arts provide better cross-cultural understanding.

8. The arts improve school atmosphere and aid in improving attendance.

9. The arts provide numerous career opportunities.

10. The arts improve student performance in other areas.

11. The arts are a valuable teaching tool for special populations. (pp. 11-12) Greene (1978) stresses the importance of including aesthetic experiences in all pedagogical contexts to serve as a stimulus for perception, questioning and creating a consciousness of one's place in the larger world. She speaks of the the value of the arts in making connections between oneself and the world to reach a deeper level of meaning: "As I view them, the arts offer opportunities for perspective, for perceiving alternative ways of transcending and of being in the world, for refusing the automatism that overwhelms choice" (1992, p. 8). The benefit of educating with the arts is eloquently expressed by Greene (1990): 
To explore our own language, to try to construct a world with our own pigments or sounds or gestures or words, is to come to understand art-making in some fashion, to grasp 'making' itself. . . . We may come to realize as well the ways in which we can discover our own sensations. . . by writing them, by embodying them in language, just as we may discover the way the curve of the rock or the blaze of the red leaf discloses itself when we try to render it. ( $p$. 151)

\section{Music in the Classroom}

Music has long been an accepted part of elementary and secondary curricula, but as education budgets get successively tightened, music programs have all too often fallen victim to cutbacks that weaken or destroy their impact on students. In the words of the National Committee on Music Education (1991), "The arts have become the first sacrificial lamb to fall under the budget axe when funds grow short" (p. 9). This committee released a report designed to validate the importance of music in the curriculum, citing specific benefits to students from music study:

- developing the ability to use symbols in new contexts

- discovering power, precision and control of mathematics

- finding and directing personal creativity

- exercising the diverse skills of problem-solving

- experiencing the joy of self-expression

- growing into the liberation acquired through self-discipline

- participating in the satisfaction of shared work and challenges met

- exploring the emotional and aesthetic dimensions of experience 
- finding avenues of success and approaches to learning for students who may have problems in other areas of the curriculum (pp. 17-18)

An earlier study by Tucker (1981) reviewed twenty-nine research studies on music and the teaching of reading, and found that "the use of music in the teaching of reading may enhance the motivation and the ability of children, whether or not they are musically talented or intellectually above average" (p. 14). Several Australian researchers (cited in Music Educators National Conference, 1991, p. 21) have reported a positive correlation between music instruction and performance in:

- reading comprehension, spelling, math and learning ability

- listening ability

- primary mental abilities (verbal, perceptual, number and spatial), and

- motor proficiency

Howard (1992, p. 21) speaks of the wide range of effects of musical education: "from physical dexterity, to emotive discovery, to perceptual insight, to pattern recognition, to associative hunches, to logical argument-in no particular order and in every combination."

Many educators have welcomed and embraced Gardner's view of intelligence as justification for broadening the scope of classroom experiences, reaching children of different strengths in learning styles and modalities, and increasing student interest in classroom activities. In reference to teaching with musical intelligence in mind, Campbell, Campbell and Dickinson (1996) state: "Because of the strong connection between music and the emotions, music in the classroom can help create a positive emotional environment conducive to learning" 
(p. 133). They also outline a number of ways in which the musical intelligence can be addressed:

1. Playing background music to enhance classroom ambiance

2. To relax, invigorate, focus student attention, or ease transitions

3. Listening to a variety of musical styles and composition

4. Songs in the content areas (including science and math)

5. Music for skill building; e.g., spelling new words to music

6. Music in the study of other cultures and historical eras

7. Creating student-generated music notation systems

8. Creating curriculum songs to familiar or original music

9. Using music as a source of inspiration for creative writing

10. Making and/or playing musical instruments

11. Utilizing musical technologies in the classroom (pp. 136-154)

Other classroom teachers praise the benefits of incorporating music into their instructional strategies. Langfit (1994), a reading specialist, believes that melody can serve as a strategy for emergent readers and writers, along with the semantic, syntactic, graphophonic and picture cues normally emphasized. She integrates music into her reading and writing lessons through writing original verses for familiar songs in the creation of thematic class books. First grade teacher Smith (2000) also favors music and songwriting experiences for the development of emergent reading and writing. Again the suggestion is made for students to write original verses to existing songs, particularly those which utilize repetitive and cumulative lyrics (p. 648). 
Martin (1983), a remedial specialist, utilizes a system of recording spelling and vocabulary practice with an accompaniment of recorded background music (pre-classical or baroque due to the cadence) for students to use in practice at home. She states: "The success of working and speaking with music lies in globally engaging the right and left brain by decreasing resistance barriers. . . resulting in more effective learning internalization, comprehension, and memorization" (p. 507). Harper (1995) recommends integrating music and singing into an elementary guidance program, relating benefits in social interaction from positive involvement with others, diminishing the divisive effects of such factors as ability, disability, race and background.

\section{Purpose of this Study}

There is adequate, and growing, evidence in the research literature to create a strong case in support of the arts and music as integral components of the curriculum. As an educator, I am constantly in search of instructional strategies that will humanize the educational experience, develop students' creative potential, and engage students in constructive learning experiences. As a songwriter, I have discovered that songwriting can be a powerful vehicle for self-expression. My initial forays into the world of songwriting with children have led me to believe that this practice is a nearly-untapped potential source of engagement and active learning in the classroom.

The dearth of literature on the topic of songwriting in education creates a fertile field for a study of this nature. Consequently, I designed this research for the purpose of investigating four approaches of teaching songwriting to elementary 
students. This study employs the qualitative research technique of portraiture to depict the songwriting process in elementary classrooms.

\section{Overview of the Chapters}

Chapter two reviews the research to date on the educational and therapeutic uses of songwriting. (Many of the studies involving songwriting to date have been done in the field of music therapy.) Chapter three outlines the specific methodology of data collection and analysis used in this study. Chapter four presents the results in the form of four portraits, and chapter five concludes the report with a collective reflection on the portraits and their educational implications. 


\section{Chapter Two}

\section{Literature Review}

A search of the professional literature on songwriting produced some interesting results. Research studies on the educational uses of songwriting were scarce; however, there were a surprising number of studies on songwriting applications in the mental health field. With these results in mind, it seems highly appropriate to conduct this study to investigate the use of songwriting as a curricular tool in an educational setting.

\section{Songwriting in Music Therapy}

Music therapy began as a professional field in the mid-1940's in the United States, although man has used music for health and to affect the behaviors of others since before recorded history. For primitive man, music and dance was often used ceremoniously in healing rituals to drive away the evil spirits that were believed to cause illness. Ancient Greek philosophers Plato and Aristotle are credited as the forerunners of music therapy, as they believed that listening to inspiring melodies relieved people who suffered from uncontrollable emotions. Aristotle also advocated the use of "musical rattles as an outlet for the energy of destructive children who would otherwise smash the furniture" (Alvin, 1966, p. 47).

An understanding of the restorative effects of music led to the hiring of professional musicians during World War I by veterans' hospitals for morale 
building as "music aides." After World War II, changes in psychiatric treatments brought about more specific uses of music in therapy, and the first formal curriculum to train music therapists was established at what is now Michigan State University (Gaston, 1968).

Plach (1980) describes four advantages to using music in group therapy: ability to evoke feelings, ability to provide a vehicle for expression, ability to stimulate verbalizations, and the reliability to provide a common starting place. He states: "Besides being able to evoke specific feelings and thoughts in the individuals and the group, music is also very adept at stimulating verbalizations and socialization" (p. 6). Harper (1985) recommends including music in the elementary school guidance curriculum "to establish mood, to lessen anxiety, to encourage calmness, to ease loneliness, and to soothe irritability" (p. 218).

Ficken (1976) is one of the early proponents of patient-composed songs as a therapeutic activity. He cites Priestly's (1975) use of composition for expressions of feelings and awareness of patterns of interaction and Apprey and Apprey's (1975) use on songwriting to facilitate recovery of repressed material. Ficken provides some guidelines for techniques including lyric writing through substitution of words in popular songs, adding new verses, or composing a parody. Music writing techniques built gradually from natural speech pitches and rhythms to adding simple melodic ostinati and pentatonic scales, as suggested by composer/educator Orff (Landis and Carder, 1972). Song fragments were then completed with arrangements and accompaniments. 
Ficken also cites Hannett's conclusion that song material may have diagnostic potential. Hannett speaks of lyrics as "preconscious expressions which convey emotions and feelings which cannot be expressed directly" (1964, as cited in Greenstreet, 1990, p. 30). Building on that premise are several studies (Goldstein, 1989; Greenstreet, 1990; and Delk, 1993). Goldstein devised a scale (the Goldstein Songwriting Assessment for Hopelessness) for the assessment of hopelessness in depressed adolescents utilizing the 12-bar blues song form. Subjects diagnosed as depressed or at-risk for suicide were asked to write "fill in the blank" lyrics adapted from questions on an existing measure, the Beck Hopelessness Scale. Greenstreet also designed an instrument, the Songwriting Anxiety Assessment Scale, for the purpose of measuring anxiety in adults. With this scale, subjects compose lyrics to a pre-determined melody and harmony. The lyrics are then converted into a numerical anxiety rating, and correlated with an established measure, the State-Trait Anxiety Inventory. Delk, as well, developed an instrument, the Delk Songwriting Interview, to elicit information from adolescents that relates to their internal state. Delk reports, "In clinical songwriting, the song form provides a structure into which the adolescent may safely express both thoughts and affect through meteric [sic] patterning, condensation, sublimation, rhyming and integration of ideas" (p. 25).

Schmidt (1983, as cited in Goldstein, 1989) states, "Since songwriting is a creative act, it can be used as a way of promoting many of the healing qualities inherent in creative acts" (p. 17). In a subsequent study by Schmidt with Roscoe and Krug (1985, as cited in Goldstein), the researchers discovered that eighty-six 
percent of the high school-aged participants in the study reported writing poetry, diary entries, short stories or songs in order to express themselves. Hamer (1985) reports that difficulty with self-expression is a common problem of adolescents, especially those suffering from depression, and that songwriting provides an avenue of self-expression while increasing self-esteem.

Hamer's study measured depression and anxiety levels of depressed adolescents before and after songwriting sessions, and found a decrease in depression levels in eight of ten participants (1985). The primary songwriting technique used in this study differed from those described earlier. Composition began with improvisation of a melody on a piano, with an appropriate accompaniment provided by the researcher. This session was recorded and listened to, with instructions for the student to "let his mind wander and describe what the song sounded like, what he is reminded of and any thoughts that come to mind" (p. 33), concluding with titling the song. The next session involved selected patterns from the improved recording to organize into a melody form to which lyrics were composed by free-writing or through prompts by the therapist. A secondary technique in this study began with poetry and added guitar accompaniment.

Lindberg (1995) utilized songwriting in extensive individual therapy with an adolescent survivor of childhood sexual abuse. In 75 sessions over a 26-month period, the subject progressed from co-creating lyrics by free association with key words and phrases, to writing complete lyrics and picking out keyboard melodies while the therapist created chordal accompaniments. The therapist 
noted that the outlook of the songs progressed from focusing on loss and abusive situations to expressions of hope and strength, and personal positive traits such as humor, independence and courage.

Johnson (1978) studied the effects of an eight-weeks-long combined values clarification program with songwriting experiences on the self-concept of socially disadvantaged adolescents in a group home. The experimental group of fifteen participants reported differences in self-concept from the control group as measured by an interpersonal checklist; they saw themselves as less selfeffacing and masochistic, and as more cooperative and conventional. The songwriting component began by subjects writing individual self-reflective essays, with recurring topics developed into choruses, non-repeated topics becoming verse material, and melodies created by subjects with chordal accompaniments suggested by the experimenter.

One approach to creative group songwriting is outlined by Edgerton (1990), working with groups of emotionally impaired adolescents. In a series of six to 10 two-hour sessions, this model takes participants through the following six steps: lyric analysis and interpretation, music analysis, group theme and style selection, lyricwriting by elaboration on the selected theme, improvisational music composition, and culminating activities. The music is developed via this sequence: a drum machine player establishes the meter, a rhythm guitar player improvises a basic chord progression with open-tuned barre chords, a trap drummer develops a rhythmic pattern, a lead guitar player makes selections from simple corresponding choices, bass guitar and keyboard samples are added, and 
finally, vocalists take turns improvising melodies using the lyrics to the chorus until all vocalists agree on a melody. The researcher concluded that creative group songwriting appears to be effective in developing group cohesiveness, increasing self-esteem, and providing an outlet for self-expression.

The use of songwriting with the chemically dependent has also been studied. Freed (1987) worked with a group of individuals dependent on alcohol and other drugs, receiving a 24-day in-patient treatment. Songwriting was used with this group to encourage the expression of feelings which relate to the individual's situation and to allow them validation by others. Through the creative process, patients are encouraged to seek productive solutions to their problems while involved in a pleasurable, aesthetic experience. The "cloze" method of filling in the blanks allowed individuals to substitute their own lyrics for words in a popular song; a second technique involved writing complete verses to preexisting melodies. Beyond the actual stages of writing, however, analysis of the lyrics was a central element of therapy and the formulation or reinforcement of corresponding treatment goals.

A later study (Walker, 1995) built upon the work of Freed, emphasizing that clients completing a songwriting task feel a sense of accomplishment and become more confident, with improved self-esteem. In addition to the two techniques mentioned above, Walker adds that of writing rap songs, using an instrumental beat from a portable keyboard to which original lines of poetry are set. He suggests that clients be encouraged to create a "hook" (a short, catchy pattern used to introduce or reinforce the theme) and to add movements or 
creative sounds to their raps. He emphasizes that "the bond between music, emotions and spirituality is a strong one that can be utilized by helping professionals to assist chemically dependent clients find fulfillment in their journey toward spiritual growth" (p. 165).

Positive results using songwriting in therapy has been documented in studies with other populations, as well. In a case study of a 48-year-old multiple sclerosis patient, Davis (1998) incorporated songwriting in weekly music therapy sessions over a period of ten months to address the issues of social isolation, depression, and communication impairment. Due to the client's health condition and passive involvement, the collaborative songwriting process was comprised of the therapist taking the patient's ideas, impressions and descriptions and adapting them into song form, accompanied by solo guitar. She concluded that through this work, her client "created closer bonds with his family, found meaning in life experiences and discovered a renewed sense of hope" (p. 20).

Silber and Hes (1995) investigated the value of songwriting with a group of patients diagnosed with Alzheimer's disease. Through writing words for lyrics to accompany an existing melody, and through writing poetry to background music, participants partially and temporarily overcame apparent cognitive, memory and language deficiencies. Analogies were used to elaborate on a theme, such as love:

Since analogies are based on free expression, imagination and creativity and do not require accurate answers, it was felt that they were non-threatening and represented an additional medium for expressing images, sensations, feelings and memories in a rich and colorful style. The use of analogies appeared to be a key to 
open the door to a long-forgotten memory which may have been repressed, unexplored and unexploited. (p. 33)

In a study with HIV-seropositive adult patients with depression, songwriting was used in one of three experimental groups (the others being a game-playing group and a control group with no intervention) to compare group cohesion, a factor deemed necessary for therapeutic gains to occur (Cordobes, 1997). Although the cohesion scores for the three groups were not significantly different, content analysis of the songwriting experience demonstrated evidence for the clinical usefulness of the treatment. The songwriting process involved the selection of a theme, verbalizing thoughts on the theme, organizing thoughts into verses and a chorus, selection of minor or major keys on a xylophone and a rhythm, and approving/revising a musical arrangement sung by the therapist and played on a guitar. The study includes an in-depth content analysis of the finished song, demonstrating that songwriting provides an experience that encourages the use of coherent language, multiple perspectives, insights, problem solving and emotional reaction. The researcher concluded that issuebased songwriting allows for in-depth exploration of current areas of distress for patients.

Brunk, a music therapist, in a manual of instruction entitled Songwriting for Music Therapists, (199u, p. 3) explains three functions of songwriting in the therapy process: to create age-appropriate music to teach a specific academic concept or reinforce a particular behavior, to help students and clients express themselves, to create a musical account of a client's therapeutic journey, and for the therapist's use in creating appropriate music selections "on the spot." She 
delineates three corresponding types of songwriting: strategic songwriting, in which the songs are composed in advance with a specific purpose in mind; process songwriting, done with a client or group in one or more sessions; and spot songwriting, spontaneously composed, usually with a group. She adds that "often the process of composition is as important therapeutically as the final product" (p. 3). She includes in her guide the songwriting forms of "piggybacking," in which new words are written to familiar melodies (p. 12) and the "fill-in-the-blank" method, in which parts of lyrics to existing songs are blanked out, leaving a formula into which clients add their own ideas (p. 27).

Brunk states, "If you are interesting in using music in therapy, songwriting is one of the most useful tools you can have" (199u, p. 3). The studies cited in this section have evidenced an interest in the mental health field for the use of songwriting as a strategy in diagnosis and therapy with a variety of client groups. The next section will examine the role of songwriting in education as documented to date in professional literature.

\section{Educational Applications of Songwriting}

Few actual research studies of educational uses of songwriting were identified in this review of the literature. A number of articles written by teachers were located, elaborating on songwriting activities in various educational settings, helping to fill in this scanty picture a little better.

One researcher, Ungerleider (1987), selected collaborative group songwriting with three groups of adults as a tool for raising consciousness about the threat of nuclear war. In a three-hour workshop, each group listened, sang 
and discussed several topically-related songs and were led through a guided visualization activity before collaboratively writing an original song. The songwriting process began with each participant creating a brief lyric expressing a personal thought or concern; writers then combined these to form complementary lyric pairs, and followed this by combining pairs to form groups of four to create verses. The facilitator then led the group in ordering verses, selected a musical style, and volunteering melodies: "Everyone gets a lyric in the song, but in general, not everyone participates in the creation of the music. Bold or talented members of each group tended to initiate the melodic structure of each song" (p. 100). Participants responded to pre- and post- pictorial tests designed to measure their consciousness levels according to Freire's terms of magical-conforming, naïve-reforming, or critical-transforming (1973, as cited in Ungerleider, pp. 18-22). Evaluation of the study's results showed that overall consciousness scores did increase significantly, and that it appears possible to raise consciousness in a three-hour workshop. Participants reported group process developments including a sense of group solidarity, accomplishment, interpersonal relationships, equal participation, and enjoyment.

In the same vein as Ungerleider's study, Arnold and Burke (1983) include songwriting as one strategy in a "toolbox" for building a popular education program in Canada in their manual, A Popular Education Handbook. This approach is modeled after Freire's literacy training work in Brazil, with a methodology associated with organizing efforts and political action undertaken by grassroots organizations. The songwriting approach involves the selection of a 
theme (generally, of a political nature), writing down main points to be communicated and adapting them into lyrics, and selecting a well-known melody for ease in singing along. Arnold and Burke note that songwriting can be used "to help summarize and prioritize the most important points in the discussion of a theme" and "to encourage creativity and another perspective on the arts and culture," as well as "empowering people" through a creative initiative (pp. 44-45). They also note that the finished products may be used to communicate actual messages in printing, in public events, and in performances.

Elsila (1998) writes of his experiences teaching music and songwriting to incarcerated prisoners. Like the authors described above, Elsila is also a proponent of "liberatory pedagogy" and gradually transformed his "banking style" music theory class to a "dialogical" songwriting workshop over a two year period (p. 6). The group songwriting process he developed begins with brainstorming topics and voting on one, followed by each participant writing a few lines on separate pieces of paper which the teacher collects, types, and redistributes. The lyrics are then revised in a group editing process, and set to music with individuals offering melodic and rhythmic ideas. Elsila concludes: "Maybe in prison, songs are an action; a creative action, a liberating one. . The 'actions' that the music workshop engenders may be internal; such actions may consist of personal healing, confidence, analysis, and mental survival" (p. 7). His satisfaction with the class is echoed by quotes from two prison students: "Music gave me confidence that I could achieve in whatever endeavor I directed my 
attention" (p. 6) and "The class gives us freedom in a sense. Freedom to write, create, play and sing. To unmask us from the inner self. . ." (p. 2).

A more academic study was undertaken by Satterwhite (1991) to explore creativity in secondary education composition classes through songwriting. After establishing a definition of creativity, the researcher describes his creative writing curriculum which is based on analyzing country music songs. Elements studied included theme, song form and structure, and the uses of poetic devices and figurative language: denotation-connotation, imagery, metaphor, simile, personification, synecdoche-metonymy, symbolism, paradox, irony, allegory and analogy. As each element was studied, students applied their new knowledge in the creation of song lyrics. In conclusion, the researcher states his belief that student products created through his songwriting curriculum met his criteria for creativity. Furthermore, he emphasized the positive effect of creative assignments on the students:

It was as if students had been sleepwalking through school and finally found a reason to wake up and participate. ... Some of these students had never achieved any level of distinction in school and were now creating poems, songs, song lyrics, short stories, plays and descriptive essays which were pleasant reading, entertaining, and, in short, of value. These students showed more interest in school in general (p. 33).

Working with third grade students, Carpenter (1999) conducted a study utilizing songwriting as one element in an aesthetic approach to teaching social studies concepts. She references Rosenblatt (1991, as cited in Carpenter) in describing aesthetic experiences as those which hold meaning for students because they participate in its construction. Through the use of content-related 
original songs written by the researcher, dramatization of concepts and performances, Carpenter found that although not all students reached the desired levels of achievement, all students found the experiences enjoyable, motivating, and rewarding: "The singing and performances throughout the unit gave all students in the classroom one undeniable opportunity. It gave them the opportunity to experience and enjoy their own learning by making meaning of it for themselves" (p. 39).

Campbell et al. (1996) suggest the creation of "curriculum songs" with students to accompany units of study, beginning with the technique of writing original, "curricular-appropriate" lyrics for familiar musical selections (p. 149). "When an entire class sings curriculum songs, not only is subject matter learned and creativity released, but the affective atmosphere of the class also improves," they report (p. 150).

In Music as a Way of Knowing (1995), Page relates improvising in speech and action to the process of writing songs and raps. He outlines five steps in the songwriting process:

1. Identify the theme or topic

2. Brainstorm related words and phrases, accepting all suggestions

3. Create the words and rhythm, beginning with a rough order of phrases

4. Create melodies or background beats, considering melodic shapes

5. Revise, edit and record the song

Page notes: "When the ideas start flying, the process is truly amazing. It's like watching the creative evolution of nature, but sped up to a breath-taking speed" 
(p. 23). He also provides some basic information on composing music with a sequencer and/or computer software.

Gantz (1998) created a teacher's guide for songwriting with high school students for his Master's thesis. In a sequence of nineteen units to be presented over a period of five weeks or more, he provides instructional materials with which to teach students to analyze popular songs, apply this knowledge to the creation of original songs, and perform the songs in class. Through this process, he teaches such concepts as song form, types of rhyme, melody structure, and figurative expressions (metaphor, simile, personification, etc.). He encourages students to draw from their own experiences for song topics: "We write songs about what we are feeling, something we feel strongly about, the human condition, an important or everyday occurrence, an observation or a realization. In one word: Life" (p. 47).

Ching (1995), the Artistic Director of Opera Memphis, describes a threeyear partnership with three Memphis high schools in which students imagined, wrote, composed, rehearsed and produced their own opera/musical theatre piece. Training began with students viewing Opera Memphis performances to discover different operative models, but from there, Ching bases his process on teaching students to write songs by "deciding what is worth singing about" (p. 4), creating the hook to express the essence of the song and developing the chorus around it, then analyzing the key lyric line for its natural accents to establish the rhythm. Once the class has agreed upon this, the final step is to add the melody and continue in such a way until the song is completed. 
Much, if not most, of the songwriting instruction that takes place in the classroom occurs as a result of an arts partnership or residency with a visiting artist. Cockburn (1992) is one such artist who presents workshops on different grade levels utilizing folk music and songwriting correlated with curricular topics and areas of interest to the class. In a typical three-session residency, Cockburn introduces traditional and contemporary songs relevant to classroom themes, including songs in other languages. Students are encouraged to collect folk songs from their homes and share them. The group, often with prior preparation by the regular teacher in understanding song form, will then begin writing lyrics on a topic selected from the curriculum or of interest to the class. Students are encouraged to think of interesting details and sensory images to enrich the song, as well as academic facts and observational impressions. The melody can later be adapted to the lyrics, by using a familiar tune or an invented melody. Cockburn states:

Writing folk songs is an effective tool for teaching language arts, for developing skills of observation and problem-solving, and for inspiring confidence in creative expression. The universality of folk song can also be used to develop an understanding of and appreciation for a variety of cultures, and as an aid in bilingual education. (p. 65)

School counselor Miles (1993) offers songwriting to students as a way for the children to share their feelings, concerns and troubles in a non-threatening manner. He reports that the use of songwriting can promote communication, trust and acceptance for the student, especially those who are reluctant to disclose their feelings. Miles quotes Bowman (1987): "The song is a powerful tool that can capture attention, elicit forgotten memories, communicate feelings, 
create and intensify moods, and bring people together" (p. 28). Newcome and Thompson (1994) feel that music and songwriting are powerful resources for the elementary school counselor, and that songwriting can promote self-awareness, provide and emotional release, and aid in future planning (Hanser, 1984, as cited in Newcome and Thompson). They recommend activities ranging from "fill-inthe-blank" songs, to composing lyrics from an existing melody, to the total process of composition.

Special educator Monogan (1989) draws simple ideas and melody notes from his high school students, all developmentally disabled and most dealing with behavior problems. With his support in eliciting details and creating a chordal accompaniment, the class wrote a collection of songs that was released in 1989 by Rounder Records as "Special Music by Special Kids." Monogan writes, "The kids have experienced a boost in self-esteem and a feeling of accomplishment all too rare in their lives" (p. 20).

Skaught (1987), a teacher of the gifted, recommends using songwriting as a way to teach the principles of creativity. He notes that, although akin to poetry writing, "Lyric writing requires a special set of skills that enables the creator to visualize not only the descriptive words, but the musical feeling to be presented as well" (p. 40). He suggests starting with a familiar song and using the "SCAMPER" technique (Eberle, 1973, as cited in Skaught) to substitute, combine, adapt, modify, put to another use, eliminate, or rearrange ideas to come up with variations on the song. He also emphasizes the benefits of humor and satire: "By encouraging the outrageous and ridiculous, as well as the 
thoughtful and sensitive, numerous songs will emerge from just one session" ( $p$. 41).

Some music teachers have also discovered the benefits and joys of including songwriting in their curriculum. Bryan (1980) describes a "songmaking" project with fifth and sixth grade students in which students analyze their favorite songs, writing lyrics without following any formal rules of poetry, finding natural rhythms in the lyrics and inventing a "melodic setting that further enhances meaning and mood" (p. 131). In contrast to the traditional performance-oriented music curriculum,

Songmaking provides students with that vital experience [of creating their own songs and expressing themselves], allowing them to join company with the troubadours, minnesingers, slaves, cowboys, and millions of unheralded nobodies who throughout history have expressed their deepest troubles and greatest joys in song. Songmaking is truly a student-centered learning experience. (p. 131-132)

\section{Educational Songwriting in Action}

As seen in the literature, educators and therapists who have engaged in songwriting activities with their students and clients attribute a wide range of positive effects from the practice. This study involves observations of songwriting in the classroom in four different educational settings. Through the technique of portraiture, the researcher will share with the reader a glimpse into the process of songwriting with elementary school students. The next chapter elaborates on the specific research methodology of this study. 


\section{Chapter Three}

\section{Methodology: Creating the Portraits}

\section{Research Design}

Educational research falls into two domains: quantitative, which employs experimentally-structured, statistically-driven methods, and qualitative, which depends on careful observation and thoughtful reflection to draw inferences from the environments and individuals under study. One could claim that quantitative studies fall within the realm of "scientific" research, and that, conversely, qualitative studies reflect the "artistic" side of research. Eisner, a highlyrespected proponent for the arts in education, argues that "educational activity, whether teaching, evaluating, or curriculum planning, is much like the artistic activity a painter engages in as he or she copes with emerging visual configurations on a canvas" (1979, p. ix).

In order to capture the multi-faceted complexities of educational enterprise, Eisner (1979) challenges the researcher to expand his or her vision with skills more frequently discussed in the study of aesthetics: criticism and connoisseurship. Criticism, he explains, is "not the negative appraisal of something, but rather the illumination of something's qualities so that an appraisal of its value can be made" (p. 193), and defines educational connoisseurship as "the art of appreciating what is educationally significant" ( $p$. x). Approaching the research question from this perspective not only allows but encourages the researcher to employ artistically-influenced, expressive language that conveys knowledge of feeling and brings a sense of immediacy of 
experience, thus enhancing the reader's understanding of the area of study (1988, p. 18). Eisner and Peshkin, in their closing commentary as editors of Qualitative Inquiry in Education: The Continuing Debate, argue that "a willingness to explore the possibilities of forms of inquiry that typically do not appear in the conduct of educational research is precisely what creative scholarship requires" (1990, p. 366).

Bogden and Taylor (1975) explain that qualitative research aims to refocus the attention which traditional, quantitative research places on the hypothesis and variables within a study to a holistic view of the subject in the perspective of the larger research issues. Their description of qualitative methodologies as "research procedures which produce descriptive data: people's own written or spoken words and observable behavior" (p. 4) supports the suitability of this approach for a study involving children's creative expression--indeed, one in which the voices of the children are paramount. Furthermore, qualitative research is the logical choice for a study in which understanding a process is central: "Qualitative researchers are concerned with process rather than simply with outcomes or products" (Bogden and Biklen, 1992, p. 31).

None has taken up Eisner's challenge of connoisseurship more eloquently than Sara Lawrence-Lightfoot. Acclaimed for her astute descriptive analyses in The Good High School: Portraits of Character and Culture (1983), she has refined and defined her processes of qualitative research as "portraiture": 
I seek to combine systematic, empirical description with aesthetic expression, blending art and science, humanistic sensibilities and scientific rigor. The portraits are designed to capture the richness, complexity, and dimensionality of human experience in social and cultural context, conveying the perspectives of the people who are negotiating those experiences. (Lawrence-Lightfoot and Davis, 1997, p. 3)

In further describing the distinctive nature of portraiture, Lawrence-

Lightfoot and Davis (1997) reflect, "Ethnographers listen to a story while portraitists listen for a story" (p. 13), and in keeping with this humanistic view, replace the clinical term "interviewees" with a more descriptive one, "storytellers," and refer to individuals being observed as "actors in the setting" rather than the customary "subjects in the field" (p. 9).

These authors detail the salient features of portraiture as follows:

(a) the shaping of context as a frame for the action with a possible foreshadowing of themes to be developed (p. 59), (b) careful selection of the modality of the researcher's voice reflecting his or her stance and perspective (p. 103), (c) navigating the boundaries of the relationships between researcher and those researched, blurring the traditionally separatist viewpoint (p. 137), (d) discovering and constructing emergent themes through synthesis, convergence and contrast (p. 193), and (e) the weaving together of the elements to create an aesthetic whole (Lawrence-Lightfoot and Davis, 1997, p. 247).

In a qualitative study of this nature, the veracity of the findings is supported not by the familiar reliability and validity standards of quantitative research, but by more subjective processes of verification. Eisner (1979) suggests in his model of educational criticism that consensual validation is 
determined by (a) "structural corroboration," indicating that the pieces of evidence validate each other, fit together consistently, and when put together, create a cohesive whole (p. 215); and (b) "referential adequacy," the process of "testing the criticism against the phenomenon it seeks to describe, interpret and evaluate" (p. 218).

Lawrence-Lightfoot and Davis (1997) elaborate that "objectivity is not the standard for validity as it is in quantitative research" (p. 245) but instead pursue the goal of "authenticity" in which the rich portrayal of the aesthetic whole resonates with three audiences: the actors reflected in the story, the readers of the portrait, and "the portraitist herself, whose deep knowledge of the setting and self-critical stance allow her to see the 'truth value' in her work" (p. 247).

With this description of portraiture as my framework, I will next outline the particulars of my study of the processes of teaching songwriting to children.

\section{Selection of Participants}

As songwriting is not customarily addressed in a typical school curriculum, locating research sites was a challenge. This study does not purport to utilize the quantitative approach of random sampling (representative of the population) or comprehensive sampling (all possible examples) but rather employs purposeful sampling of "information-rich cases which are studied in depth" (Wiersma, 1995, p.298). In this procedure, subjects are selected "because they are believed to facilitate the expansion of the developing theory" (Bogdan and Biklen, 1992, p. 71). Schwandt defines the criteria for selecting qualitative research sites as "availability, accessibility, and theoretical interest" (1997, pp. 140-141). 
After making inquiries of state departments of education and arts councils in the region, songwriting associations, educational and musical discussion groups on the Internet, and personal contacts with educators and professional songwriters, I initially identified three potential research sites (one each in West Virginia, Virginia and Tennessee). The sites were selected with consideration of professional qualifications of the programs and/or participating songwriters, and representation of some variety of geographic and demographic characteristics. During the data collection period, I added a fourth location (in Maryland) after hearing a public radio broadcast featuring their school's project, which related to my topic of study.

Of the four sites I visited, two of them involved the whole school, class by class, in songwriting activities with a professional songwriter in the role of visiting artist. The other two schools were affiliated with well-established arts organizations and participated in structured programs which involved specific teachers in the schools and a smaller number of students. The individual sites and programs are described below.

\section{Description of Sites}

Site One: An elementary school in rural central Virginia, grades 1-6. The student population is a mixture of children from humble, rural backgrounds and those of "comfortable" families, many of whom chose to re-settle in this historic "old farming" area of Virginia. "Paul," the professional songwriter working with this site, is a composer, performer, and nationally-recognized songwriting teacher. He conducts workshops across the country for songwriters to improve their skills as well as occasional presentations in schools. The songwriting program at Site One 
consisted of one-hour sessions with Paul, every class meeting with him at least once, during which session the group collaboratively writes a song. Some of the songs were tailored to relate to current topics of study or written to fit the theme of an upcoming interdisciplinary arts performance, but many of the topics were chosen based solely on student interest.

Paul identified the following goals for his residency:

- Students will become excited about creative writing and have fun writing

- Students will gain experience with the rhythm of music and language

- Students will gain experience with metaphor and figurative language

- Students will work in a creative situation with a group

Site Two: An elementary school in a small city in a mountainous region of north central West Virginia, grades K-6. The student population here is comprised mostly of children born and raised in the area, which is home to timbering, some tourism, and a small college. "Pam," the songwriting instructor at this site, is a certified elementary teacher currently working as a substitute teacher, performing musician/songwriter, and visual artist. She is active in community arts programs and experienced in working with schools as a visiting artist. In Pam's songwriting residency, she met with each class and introduced them to different styles of music (country, blues, jazz, rock and folk) and art (graphic art, modern art, realism and impressionism). With her guidance, the younger grades wrote a group song on topics of their choice, and upper grades worked in small groups to write several songs per class. Each song was recorded and students created a cover design for 
the personal copy of their tape, which they received at the conclusion of the project. A school performance of the children singing their original songs also served as a culminating activity.

Pam's goals for her residency included:

- Fostering creativity through language, art and music

- Providing opportunity for self-expression

- Providing opportunity to learn about various styles of music and visual art

- Developing positive self-concept and confidence in students through attaining the goal of creating an original product

Site Three: A K-5 elementary school in Nashville, Tennessee, a major urban area with a strong presence of the music industry. This school participates in the "Words and Music" program, a long-standing educational outreach sponsored by the Country Music Hall of Fame. For over twenty years, the CMHF has provided curricular materials and lesson plans on song structure and lyric-writing to interested teachers of grades four through twelve. With these materials, classroom teachers guide students through the lyric-writing process in four to six one-hour class periods. Student writings are then forwarded to one of a large pool of participating professional songwriters, who selects several from each class to set to music. The unit culminates with a class visit to the CMHF for a session with the songwriter, who performs the collaboratively written songs for the group and a live recording is made. At the end of the year, the museum presents a public performance of a selection of such songs performed by the student and 
professional co-writers. The program for the final performance in May 2000 credits participation by 67 songwriters, 48 schools and thousands of school children.

Through a series of communications with the coordinator of the "Words and Music" program, arrangements were made for me to visit and observe participating fourth and fifth grade students in a gifted program in a suburb of Nashville. "Jean," the teacher, had spent several prior sessions introducing the songwriting concepts of theme and storytelling, song elements such as chorus, hook-line and bridge, and rhyme. During my observations, she concluded the instructional sessions and guided the students through the writing of original lyrics, most of them working individually. This visit was followed by a second one three weeks later, at the time of the class' visit to the Country Music Hall of Fame for the session with their professional songwriter. (I also had the opportunity to observe other classes' songwriter sessions on both trips.)

Goals of the "Words and Music" program include:

- Expanding creative writing and/or music skills

- Interaction of students with a professional songwriter

- Student experience with basic elements in the language arts curriculum such as rhyme scheme, meter, alliteration, assonance, consonance, onomatopoeia, simile, metaphor, and hyperbole

- Reinforcement of student understanding of basic musical elements such as beat, meter, tempo, rhythm, pitch, form, phrasing, harmony, and expression 
Site Four: An elementary school in the metropolitan D.C. area of Maryland with a very diverse student population, grades K-5. My original plan for this study included only the three sites described above. To my good fortune, during the research period, I happened to hear a public radio broadcast while driving my car on this school's participation in the "Creating Original Opera" program of New York's Metropolitan Opera Guild. I was able to locate and contact the school, and obtained permission to attend the final performance of their original opera later that week, and interview groups of students and teachers involved. The production was the culmination of a year-long project in which fourth and fifth-grade students learned all aspects of opera writing and production with program guidance and teacher training provided by the Met. (Although this was my first encounter with this educational outreach project, I learned that nearly four hundred schools participate nationwide!)

Goals of "Creating Original Opera" include:

- each school will write, produce and perform an original opera

- students will utilize and enhance skills in all curriculum subject areas

- students will learn planning and problem-solvings for real-world problems

- each student will develop skills in an opera-related specialization (as writer, producer, publicist, electrician, etc.)

- students will develop skills in responsibility, communication and collaboration 


\section{Data Collection}

After receiving formal permission to conduct research in each of the above schools, I planned and carried out my site visits. The length of time spent at each site varied as follows:

- Site One: Two full days, during which time I traveled from class to class with Paul and observed him working with individual classes;

- Site Two: One trip of two days of similar observations with Pam working twice each with seven different classes, a later one-day trip to second school in her residency, and a third trip to attend a final performance by student songwriters;

- Site Three: One trip of three and a half days, during which I observed the classroom teacher teaching lyric-writing techniques to several groups of her own students and also observed museum sessions of other classes, meeting with the professional songwriters who finished their songs; and a second trip of two days during which time the class I had observed met with their songwriter at the museum, and a public program was presented as a culmination of the year-long program; and

- Site Four: One two-day trip, during which time I attended the school's public opera performance, examined their educational display for the public, and met with a group of participating students and their teacher.

Although the actual duration of the visits and activities varied somewhat, my procedures at each site were basically the same: I observed the school activities as noted above, made field notes, audio-recorded the class songwriting activities 
for the purpose of later transcription and analysis, and interviewed a classroom teacher, an anonymous group of students, and the participating songwriter, if there was one (see Appendix A for interview questions). I examined samples of student work in progress and (in the case of the museum) previously collected student work and news releases maintained in the library, which is available for research by the public. The songwriting activities studied were all existing instructional components of the regular school curriculum; none were arranged or presented by the researcher.

Anonymity of subjects, in accordance with the requirements for research with human subjects of the Institutional Review Board of West Virginia University, was assured and is reflected by the use of pseudonyms in the results which follow. Permission was requested from each site to publish songs, lyrics, drawings and/or excerpts of student products for the purposes of this study. It should be noted that although material is herein credited anonymously, all writings, drawings and musical compositions remain the intellectual property of the copyright holders (generally the creator or creators of the works).

\section{Data Analysis}

The research method of portraiture has several features in common with other forms of qualitative research, and some characteristics of its own. With its emphasis on colorful depictions of the research findings, successful portraiture demands that the researcher make careful choices in navigating the boundaries of relationships, framing the context, utilizing voice in perspective, and seeking 
emergent themes in order to create an aesthetic whole in the final narrative. Lawrence-Lightfoot and Davis (1997) begin their discussion on emergent themes by describing the portraitist's initial intellectual foundation, "the result of a review of the relevant literature, prior experience in similar settings, and a general knowledge of the field of inquiry" (p. 185). To this anticipatory framework, they add "the researcher's template," the lens of inquiry," the lens of inquiry which may take the form of explicitly-stated "relevant dimensions" or the more informal "guiding preoccupations" (p. 186). These provide the bases for the perspective-taking, data collection and analysis through which the themes depicted in the final portraits emerge.

As in all qualitative or ethnographic studies, the uncovering of emergent themes requires extensive review of the data. Glaser and Strauss (1967) provide a model of data analysis in their "constant comparative" method. This method involves the following four stages:

1. Coding each incident in the data into as many categories of analysis as possible, and comparing subsequent incidents to determine applicability to the categories;

2. Integrating categories through constant comparisons of the diverse properties of the categories;

3. Delimiting the theory through reduction as the categories become more select and focused and the theoretical saturation of categories occurs; and

4. Writing the theory by collating reflections on the data, summarizing, analyzing and returning to the coded data to illustrate points. 
Bogdan and Biklen (1992) describe the coding process: "Codes categorize information at different levels. Major codes are more general and sweeping, incorporating a wide range of activities, attitudes, and behaviors. Subcodes break these major codes into smaller categories. ... This involves scrutinizing sentences carefully and judging what codes the material pertains to" (p. 177).

The constant comparative method described by Glaser and Strauss (1967) can be applied, in the same study, "to any kind of qualitative information, including observations, interviews, documents, articles, books, and so forth" (p. 104). Rubin and Rubin (1995) describe a similar process in analyzing interview data:

When the coding is complete, the data are grouped in categories that allow us to compare what different people said, what themes were discussed, and how concepts were understood. Through examining the information within each category, we come up with overall descriptions of the cultural arenas or explanations of the topic we are studying. We then seek out the broader significance by asking if our data support, modify, or contradict an existing theory or policy. (pp. 228-229)

Lawrence-Lightfoot and Davis (1997) elaborate on the construction of the emergent themes through listening for repetitive refrains, resonant metaphors and the messages of cultural and institutional rituals. In addition, they suggest looking for patterns and using triangulation "to weave together the threads of data converging from a variety of sources" (p. 193). Triangulation is a well-recognized tool of the qualitative researcher, "a means of checking the integrity of the inferences one draws" (Schwandt, 1997, p. 163). Lawrence-Lightfoot and Davis describe triangulation thus: "The researcher employs various strategies and tools of data collection, looking for the points of convergence among them. Emergent themes arise out of this layering of data, when different lenses frame similar 
findings" (p. 204). The final product resulting from the data analysis is the portrait, "a retrospective holistic view that might be accomplished explicitly through the portraitist's reflection" (p. 264).

These processes-coding of observational data via the constant comparative method, similar analysis of interview and document data, triangulation of sources, and the discovery of emergent themes-were followed in analyzing the data from the site visitations described above. The results of this data analysis and supporting examples will be related in the next chapter entitled "Portraits of the Songwriting Process." 


\section{Chapter Four}

\section{Results: Portraits of the Songwriting Process}

\section{Site One: On the Train of Creativity}

\section{In the foothills of Virginia.}

The drive to Site One passes through rolling countryside at the foot of the Blue Ridge Mountains. This area has not been dissected by interstate highways and their inevitable strip mall offspring, but instead retains the flavor of Old Virginia. Modest horse farms with wooden fencing and swinging signs proclaiming the year established (some in the 1700's), and stalwart, historic brick homes remind the traveler that these unassuming villages were indeed part of the framework of our country's birth. "Old money" has made room, however, for the quiet arrival of a new generation, many of them artists and professionals, who seek the strength and serenity these fields and farmscapes bring.

I arrive on a frosty late winter morning at the county's consolidated elementary/middle school which houses grades K-7 and meet up with Paul, the visiting songwriter. Well into a residency of several weeks, he is quite the popular figure in the school, and smiling children greet him by name as they pass us in the hallway on their morning errands. Although the multi-disciplinary arts grant that brought him here provides for visitations to individual classrooms, this day begins in the music room where he first meets with a group of volunteer singers from several different classes. Their goal is to rehearse and record a few 
of the school's original songs for a final program involving visual arts, music and dance creations on a common theme.

A semi-circle of blue chairs in the center of the room awaits the arrival of the students. Musical paraphernalia line the room on three sides: an upright piano with a small guitar resting on top, one dishpan full of recorders and a second one filled with xylophone mallets, and stacks of purple and blue music books, among other materials. "Keep your mind open, " reads one of the "Rules for Today's Music" on the wall. Paul and his vocalist assistant, Diane, take their seats at the front of the circle, as I settle into my observer's post off to one side.

\section{Getting the momentum going.}

The songs on the morning's rehearsal agenda are but a few of the dozens that have been written in recent weeks by Paul and various classes. In this residency, Paul is working as a "fast-track" songwriting teacher, guiding classrooms of students through the process of crafting original ideas into songs, usually completing them within a single 45 -minute session. The children who begin the session uncertain of the outcome emerge from the process as proud co-writers of a living creation.

"What do you want to write about today? Anybody have an idea?" he generally begins, as he coaxes song topics from the class, timid and reticent at first. "Something funny," a seventh grader suggests. Chocolate and pizza are the favorites in a fourth grade room; pets are popular among the younger set. In

a band class, he combines a student's idea with the teacher's suggestion for a song about instruments: "Let's figure out a way to put chickens in a song about 
instruments." The resulting synthesis is a new take on a familiar theme, "Old MacDonald Had a Band." Families may be the focus, as in "Riptide Mike and Hurricane Frances" about the trials of being a sibling. Occasionally with a younger group, Paul will provide a seed idea, such as a song about wishes, or he may decide to focus on a current holiday.

The collection of songs Paul has written with students here and at a nearby Waldorf school include several relating to topics being studied by the students. "Jamestown" relives the drama of the trip across the Atlantic ["The sky's on fire! The sky's on fire! Three boats, sailing to America"]; the serious "Afghanistan" reflects on the plight of women under the Taliban regime ["She sees the world through dark cloth edges, Though a small flame burns inside, no one hears her cry"]; and the upbeat "Swimmin' in the Nile" brings Ancient Egypt back to life (song 1):

Swimmin' in the Nile, we were swimmin' with the crocodile Swimmin' in the Nile, we were swimmin' with the crocodile Piranhas and pyramids, blood and sand, Mummies and pharoahs dancing hand in hand Swimmin' in the Nile, swimmin' with the crocodile. . .

After the topic for a particular songwriting session is selected (often with a quick vote to finalize the choice), Paul springs into action to begin creating the musical montage, drawing details from the students, which Diane hastily scrawls on a blackboard or large paper chart. The "wish" theme brings out the secret dreams of the first graders: ten horses, a four-wheeler, a trip to the skating rink. 
The fifth grade band students abound with creative combinations for their song: the long-necked trombone reminds them of a giraffe, the clip-clopping of the wood blocks brings a horse to mind, and the gentle plucking of guitar strings reflects the scampering of a mouse. Diane can't resist contributing a "tuba-tootin' elephant" and Paul adds "in green underwear," to the children's delight.

The joy of word play is a favorite pastime of Paul's, and one which quickly infects the students with whom he is collaborating. The fourth-graders' "favorite foods" song takes a turn for the bizarre, as minds are challenged to imagine "weird stuff that nobody would think of," and the children eagerly rise to the task: "pink pickled peppers on ice cream" and "eyeball stew" which gives them the "higgly-wiggly blues." With a little chuckle and a whisper of conspiracy, Paul shares with the class a songwriter's secret: "One of the great things about songwriting is that it doesn't have to be true." This knowledge frees up their imaginations to soar to new heights.

"The words," Paul tells the children, "are such an important part of the song," and through brainstorming words and phrases with which to build the lyrics, the class experiences first-hand the metrical and poetic rhythm of language. "We start clustering," Paul explains in describing his process, "and then we find some words we really like in the clusters, and we start bumping them up against each other and find ones that make interesting metaphors." And as we chat in his studio, surrounded by recording equipment, he plays for me on the computer a charming example, "Flurries in the Night" (song 2): 
A waterfall of sound with roses all around

We're surfing in the pool of sunshine in this town

Paddlin' my canoe on a river of blue balloons

We sparkle like stars as the notes come raining down

We are the waves of the ocean

We are the clouds in the sky

We are the trees in the forest

We are the dolphins jumping high

We're flurries in the night. . .

One of Paul's aphorisms is that "every song has a story" and he suggests that stories can provide good material for song topics. The concept of journey provides a structure for some of the songs, such as the one written by second graders that begins simply as wanting to write about their pets. By the completion of "Spike the Tiger Guard Cat," forty minutes later, Spike, a threelegged cat, has won a race and beaten a dog who thinks he's "faster than a cheetah and a dirt bike," leaving him in disgrace. Sometimes, the theme of the story involves a change or transformation, as it does in the song in which the school's fight song, lost for twenty years, is re-discovered in the principal's filing cabinet. This event inspires the student body to change from "lazy bums" who just "watched TV like a bunch of slugs, twiddlin' our thumbs" to throw out their TVs, finally "undefeated with our basketball team."

Beginning with the identification of the topic or central theme and continuing with the development through supplying the supporting details, the 
students work in tandem with Paul in the songwriting process, who begins to piece their ideas into a lyrical whole. He describes it as "pulling together strands of what is happening around me." Together they experiment with phrasing, trying a line first one way and then another. The humorous Valentine image suggested by a second-grader, "Be my chocolate covered pig wearing a George Washington wig" becomes shortened to "Be my chocolate covered pig wearing a wig," which better matches the rhythm of the other lines.

Rhyme is an essential element of songs, and in crafting the rhymes, the children also contribute. Paul explains that in singing, the vowel sound is the most critical aspect in rhyming: "It doesn't have to be a perfect rhyme, because in singing, you hold out the vowels." The novice songwriters learn that words having the same vowel sound and similar-but not exactly matching-ending consonants can still work as rhymes in a song. Paul asks first graders for a rhyme with "wrestling," and they offer "ring," "drink," and "chicken wings." The fight song writers, in seeking a rhyme for "team," reject one student's suggestion, "We were all full of beans," in favor of "It was beyond our wildest dreams." Good ideas frequently spark excited praise from Paul, as this one did: "Oh, perfect! Excellent-you're a professional. We've got a song here, I think-let's sing the third verse."

\section{Keeping on track: "When in doubt, sing!"}

In this real-world way, Paul teaches the children song form. "Let me tell you about a chorus, " he explains, "A chorus is when you sing the same words and the same music every time. That's so people can remember it. A verse has 
the same music every time, but the words are different. So if the words are different each time, you can tell a story with them, right?" And in no time, the developing song lyrics have a tune to go with them.

Before the lyrics are even finalized, Paul applies his expertise in composition to begin improvising an accompaniment. As soon as there is a rough form of the first verse or so, Paul picks up his guitar and begins "noodling," as guitar players say, experimenting with melodic phrases or chord patterns in one or more musical genres. "What kind of song is this, do you think?" he asks the "weird food" group. "How about a blues song? Do you like the blues?" He demonstrates on his guitar the feel of the blues, which seems perfect for this quirky topic. When he asks a group of seventh graders what style of music to play for their funny song, they reply, "Do a fast one. Like a hillbilly song," and Paul obliges by playing a quick finger-picking rendition for them. The gentle melody that he first attempts for the silly Valentine song elicits groans of "Oooh!" and "Too mushy!" from the giggling second graders, so Paul tries again. Although the first-graders writing about their wishes cry out for "Rock and roll!" Paul's assistant suggests using a familiar tune for this one, and they settle instead on an adaptation of "Twinkle, Twinkle Little Star."

Thus every lyric meets its music, with Paul seeking approval from the group for his musical ideas and working in melodic suggestions from students, whenever possible. If a student starts to sing a line, Paul tries to incorporate it into the tune. For the most part, however, the music is written by Paul, who explains that, due to the time constraints of teaching introductory songwriting in 
45-minute sessions, he has to "eliminate some variables, and that is the variable that I think should be eliminated first, because that's the hardest thing for them to do unless they have some sort of musical background." Although Paul generally devises the melodies, his student co-writers quickly pick up the tunes and sing along. A cluster of ideas, a few lines scribbled on the board, and Paul with his guitar is coaching them, "Let's sing what we've got so far." Although Paul makes note only of the chord structure during the writing sessions, the music teacher who organized the songwriting residency later writes several of the songs out in music notation for future use in practicing and performing the songs (figure 1).

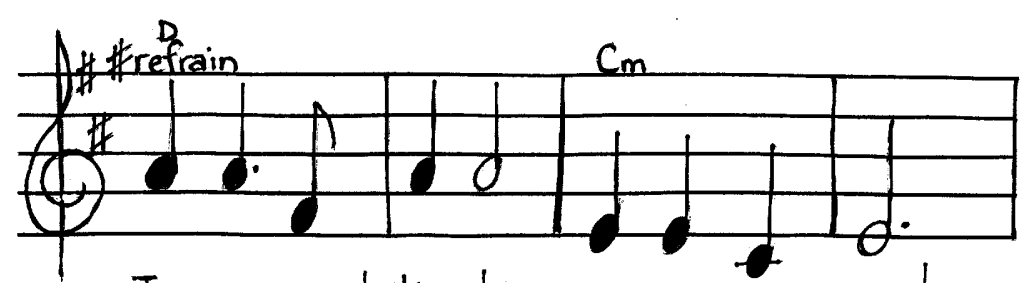

Ice cream and trac-tors, mer-ry-go-round,
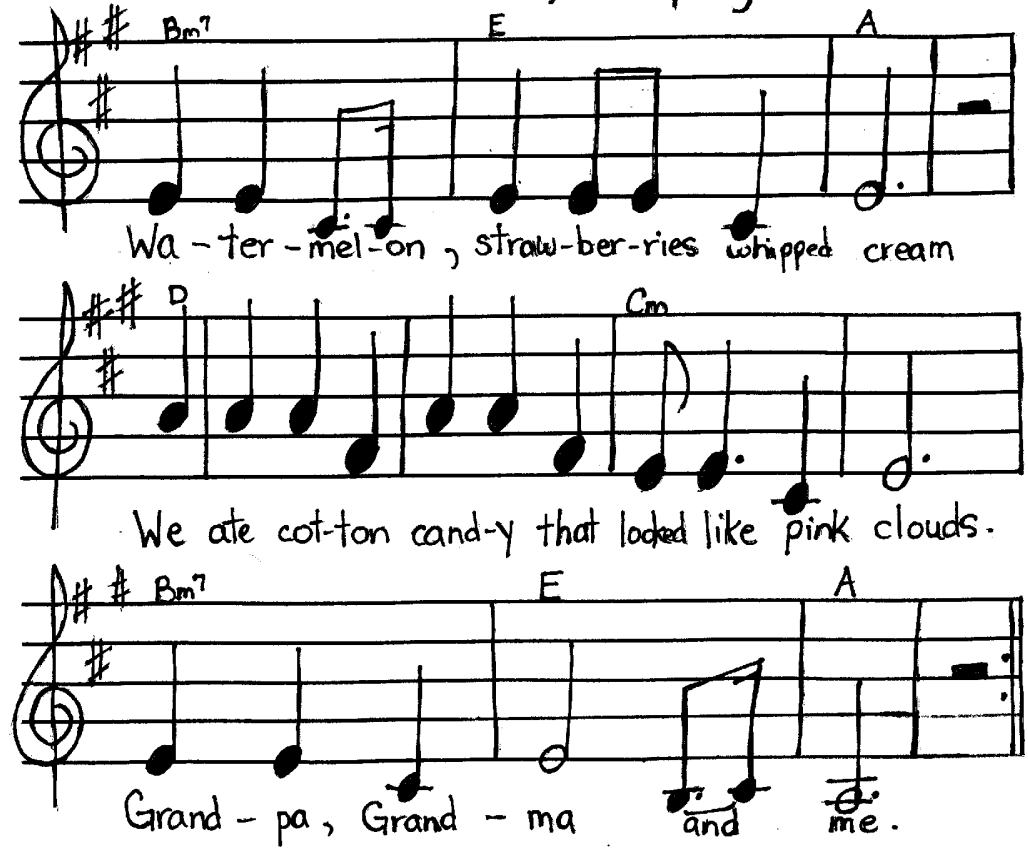

Figure 1. Notation of refrain for "My Grandma Stayed Home." 
The process continues with testing the melodies, continuing the story line in new verses, and gaining familiarity by singing the repeating chorus. Working together as a team, their energy creates a group momentum which Paul directs and keeps moving. Their creative songwriting process brings to life the writing stages depicted on a colorful train-car display over one of the blackboards: "Prewriting, drafting, revising, proofreading, publishing."

As the songs take shape, Paul encourages the students to have fun with them, adding animal noises, ad-libbed comments, or sound effects as appropriate, such as a choir of trumpet mouthpieces playing, kazoo-like, the introduction to the fight song. All students are encouraged to participate at their own levels of ability-even a severely speech-disabled child who presses the button on his voice synthesizer to add "The end" at the finish of one song.

By the end of the session, students who were tentative at first, unsure of their own little-used voices as well as the unfamiliar territory of the tune, are competing enthusiastically for positions around the microphone to record their masterpiece. "We're famous!" exclaims a fourth grader, who adds, "We're the littlest school in all Virginia, and our county's so small compared to others, and they came to our little bitty county!"

\section{Site Two: The Building Blocks of Songwriting}

\section{High up in the West Virginia hills.}

Site Two is located in a high mountain valley in north central West Virginia. The roller-coaster roads that wind past hillside farms, community 
churches and limestone quarries finally begin to straighten out in a broad expanse with a breathtaking view of the surrounding peaks. This traditionally remote area, becoming ever-more accessible as highway development hurries to bring the skiing income in and take the timber profits out, is home to generations of loggers, subsistence farmers, and (as is so often the case in Appalachia) unemployed "welfare families." The presence of a few local industries and a small college nearby does little to affect the demographics of the two rural schools that I visited, whose student populations are predominantly middle-to-low income and white.

The county is host, however, to a growing community of supporters of the arts who have built a network of collaborative support for arts enrichment in the schools, working cooperatively with the local school administration to bring practicing artists into classrooms. This is the avenue by which Pam, one of the five artists featured that year, was able to introduce nearly a thousand children in forty-two classes at three different elementary schools to the art and craft of songwriting.

In Pam's introductory lessons, she shares examples of recorded music by other West Virginia artists, and thus it happened that I was already "famous" when I accompanied her to my first observation, midway through her residency. "Are you the singer?" one admiring little girl asks me as I enter the room with Pam, who had informed them that I would be visiting. I smile and respond as Pam gathers the children around her to begin the day's session. 


\section{A framework to go by.}

The structure of Pam's residency allows her the luxury of spending seven 45-minute sessions, more or less, with each class. With this much time allocated for the songwriting experience, she is able to work at a less intense pace than Paul in the previous portrait, and to take the time to point out connections between songwriting and other subjects in the curriculum, especially music in general, visual art, and the creative writing process.

Although the actual songwriting process she follows varies slightly according to grade level, her initial sessions are fairly consistent. I observe an introductory session with a group of Kindergarten students, who, under the direction of a very organized teacher, sit neatly in two rows on the carpet in front of us. Pam begins by asking the children why they enjoy music. "It makes you feel good," offers one of them. "Because you can dance," says another, and a third, "It can sing you to sleep." One little fellow pipes up, "I like music because my dad wears funny glasses and dances outside!" All of their answers are right, of course, and Pam next demonstrates different styles of music by playing samples of rock, blues, country, jazz, bluegrass and other musical genres from recordings by West Virginia artists, which she makes a point to tell them. Immediately she incorporates a visual awareness by showing them tape and CD cover art, and asking them how they think each one was designed.

This leads her to explaining her objectives for the students: The class will write a song together (upper grades working in small groups), the song(s) from each class will be recorded and a copy duplicated for each student, who will 
individually create a tape case cover design for their personal copies. In an afterschool interview, she shares with me some of her instructional goals, expressing that she hopes to build self-esteem in the children through giving them the belief that they can write a song, and confidence in their ability by teaching them a sequential process, as well as creating an enjoyable activity for them.

The first session concludes with asking for suggestions of song topics. The Kindergarteners, predictably, come up with typical ideas for that age group, such as mommy, baby sister, horses, cats, dogs and puppies, and a few unusual ones (skunk, rock stars, and "snake in the barnyard,"). Voting, a new experience for many of these youngsters, finalizes the topic as "puppies." A second Kindergarten class, filled with ideas about animals, decides to write about a trip to the zoo. A review of fifty songs (about half the total) written during Pam's K-5 residency reveals pop culture topics (music, television and movie themes) were most frequently chosen, with pets, sports and space aliens running close behind in popularity.

Once the class (or small group, in the case of grades 3-5) settles on their topic, Pam, like Paul, elicits descriptive words and details. "Think about little baby puppies. What do they do, what do they feel like, what do they smell like, what are their noses like, what do they look like?" she coaches the littlest songwriters. "Puppy's soft." "They have a black nose." "Lick." "A puppy chew up my shoe one time." A handicapped girl in a pretty pink dress signs, "Play." "They roll around everywhere." All these ideas and more go on Pam's list. The 
zoo group offers suggestions on swinging monkeys, hopping kangaroos, longnosed crocodiles and a zookeeper named Jack.

With the older groups, Pam explains each step of the process to the class and then turns them loose to work in groups, visiting each section in rotation. A group of fifth grade boys who are planning a song about a basketball game between the Robots and the Aliens writes one list of typical terms used in the game, and another one with futuristic ideas (figure 2).
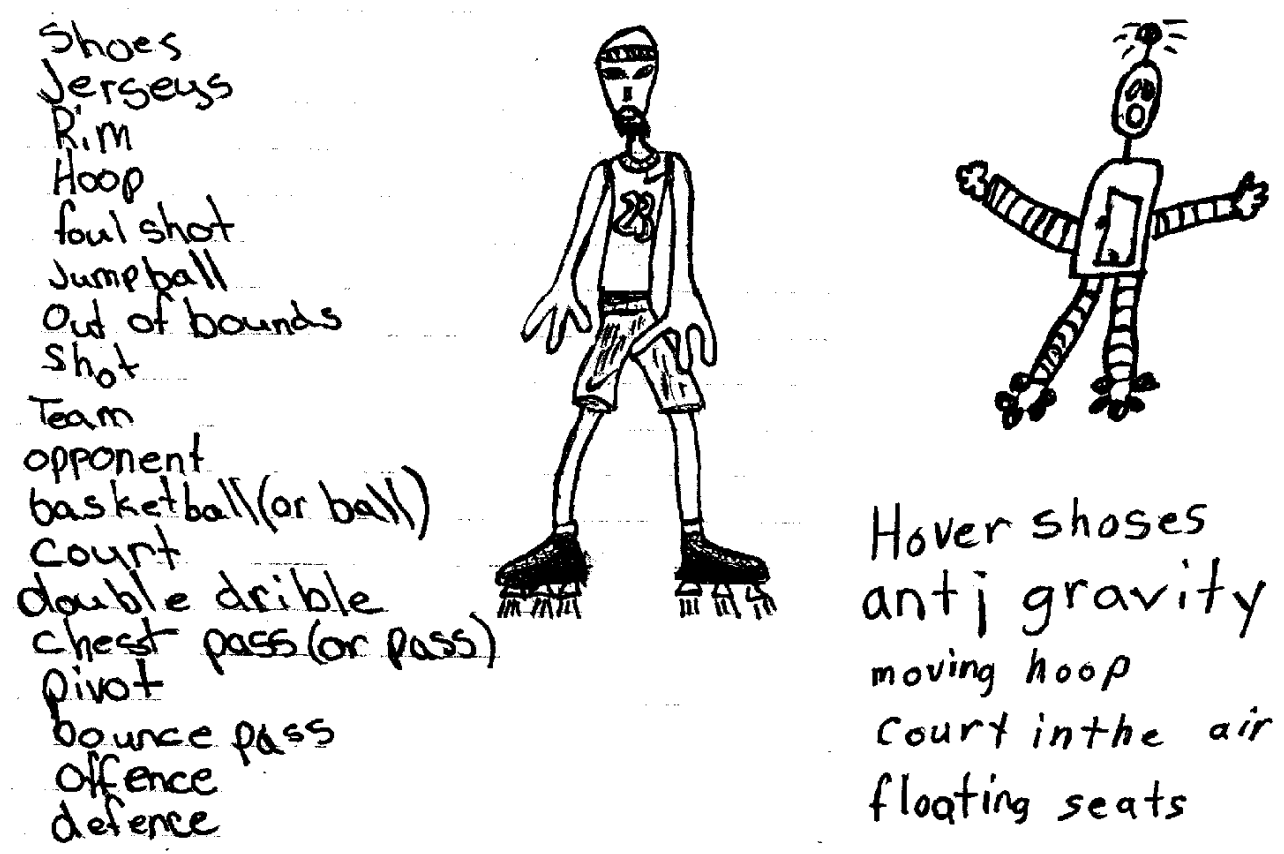

Hover shoses ant; gravity Ball moving hoop court in the air floating seats

Figure 2. Initial word lists for "Future Basketball" by fifth grade boys.

Once the students have begun creating word banks with descriptions and details, Pam has them expand this collection by finding rhymes that go with these words. When we visit the first grade class that has chosen to write about a horse, she explains this step to me: 'We put the word 'horse' in the middle; we 
put all the describing words around it to make a web. And then we take these describing words and think of rhyming words to go with them." She reviews the lists: "Halter, Walter, shelter-that's a close rhyme; run, sun, tons, bun," and then picks up the rhyming where they left off-“Did we do black? No, we didn't," to which the children respond with "track," "snack," tractor," and "pack." A second-grade group writing about a party in space comes up with the clever rhymes "planet—can it" and "Jupiter—stupider."

Pam explains that in grades Kindergarten through 2, the class writes one song, but in grades 3 through 5 , she breaks them into three, four or even five groups per class. Another one of her objectives, she tells me, is for the students to work cooperatively. "And I want the older ones to do more work on their own, so they'll have a little more individuality," she adds. The groups follow the same steps as the classes in selecting their topics, elaborating on them with related ideas, sometimes in web form (figure 3), and looking for initial rhymes.

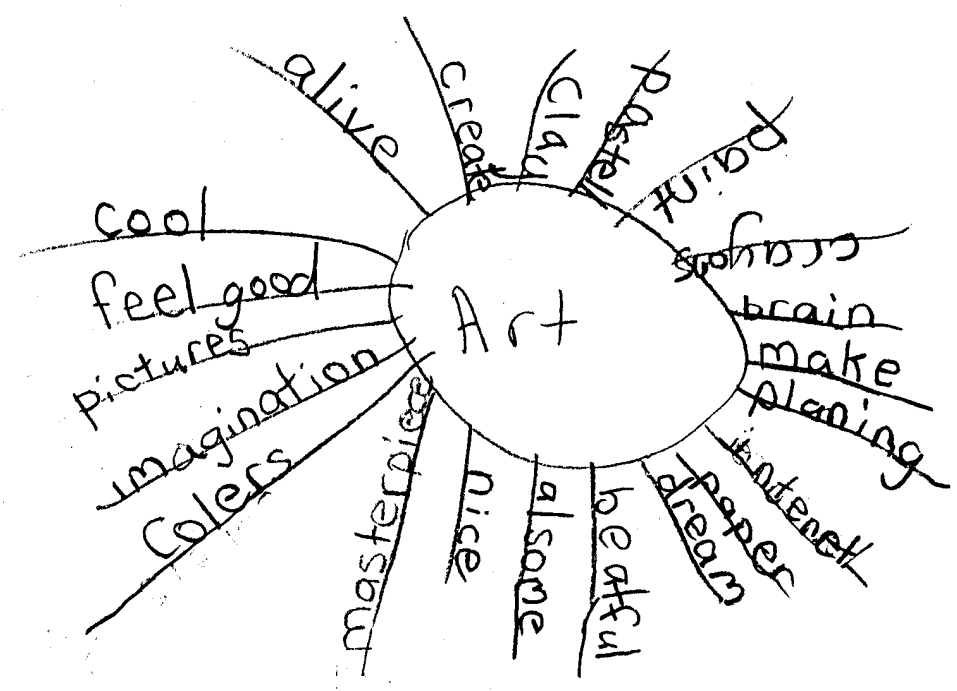

Figure 3. A third grader's web on ideas about art. 
The next step in Pam's lyric-writing process is formulating action ideas. The last class we visit that day is a second grade room in which the desks are arranged roughly in a horseshoe. The windowless room is hot, and the children are tired, some resting their heads on their arms. Pam reviews with the class: 'We have the ideas 'wolves' and 'camping in the mountains.' We just have a lot of words so far; we don't really have any action ideas yet. That's what we're going to cover today. What could we make happen in our song? We're going to write a little story that's going to make a song. So what could happen? We need some ideas."

Only a few raise their hands with ideas in the beginning: "Set up a tent," "Gather firewood," and so on. The group begins to perk up when someone offers, "You might run into poison ivy," and someone else suggests, "Mountains can have avalanches." Soon the students are caught up in the flow of imagining all kinds of exciting possibilities, many voices calling out answers at once. Pam focuses their attention on drawing out some imagery, the "wolf's eyes glowing like the light of the fire" and "the avalanche was like a ghost in sheets, " repeating their ideas in a dramatic, storytelling voice. She reminds them that they are still in the pre-writing stage, however: "These are just the ideas; these are not really the words of the song yet."

To help them organize their thoughts, she asks the groups to create a list for the sequence of the action. "Decide what's going to happen first, the setting maybe, where it takes place, and what happens second, and so on. ... So when you start writing your song, you'll keep that order in mind. And I will come 
around to every group and show you how to start the rhyming process, if you haven't already." Some groups take these instructions to heart and create a sequential list of events (figure 4); others, who have an internal sense of what they want to have happen in their song, simply jump into composing the lyrics.

10, bats fly out of the window

II wear wolves start howling

12. owls in the trees start hooting

13. Max Miller starts screaming
because he can see the ghost.

14. He was walking down the road with his pale face and red eyes and scared people
away.

Figure 4. Excerpt from fourth graders' outline for "House on Haunted Hill."

The length of time spent on each step in the process varies from class to class, according to each group's attention and interest level that day. A certified, experienced elementary school teacher, Pam is alert to the signs of restlessness and off-task behaviors that mark a loss of concentration. When she notices their focus wandering too far off-course, she sometimes interrupts her own instruction to lead the children in a creative dramatics activity related to their songs. Students in the "puppy" class pretend they are baby puppies. "Feel your noseit's wet, cold, and black. You see a shoe on the floor, and it's got a big, long 
shoelace coming out from it. What are you going to do?" They giggle and scamper around like pups. The writers of the horse story "prance" and "whinny" around the room (learning new vocabulary words from the teacher at the same time) and the campers narrowly escape a "rolling carpet of snow" down the mountain, leaving their imaginary gear behind them but making it home safely in their make-believe cars. Other times, Pam will use an art activity as a change of pace, providing them with a blank bookmark to decorate as practice in designing their tape case covers (figure 5). I notice in several rooms that when the children have something with which to occupy their hands, they settle down again and the songwriting process can continue simultaneously.

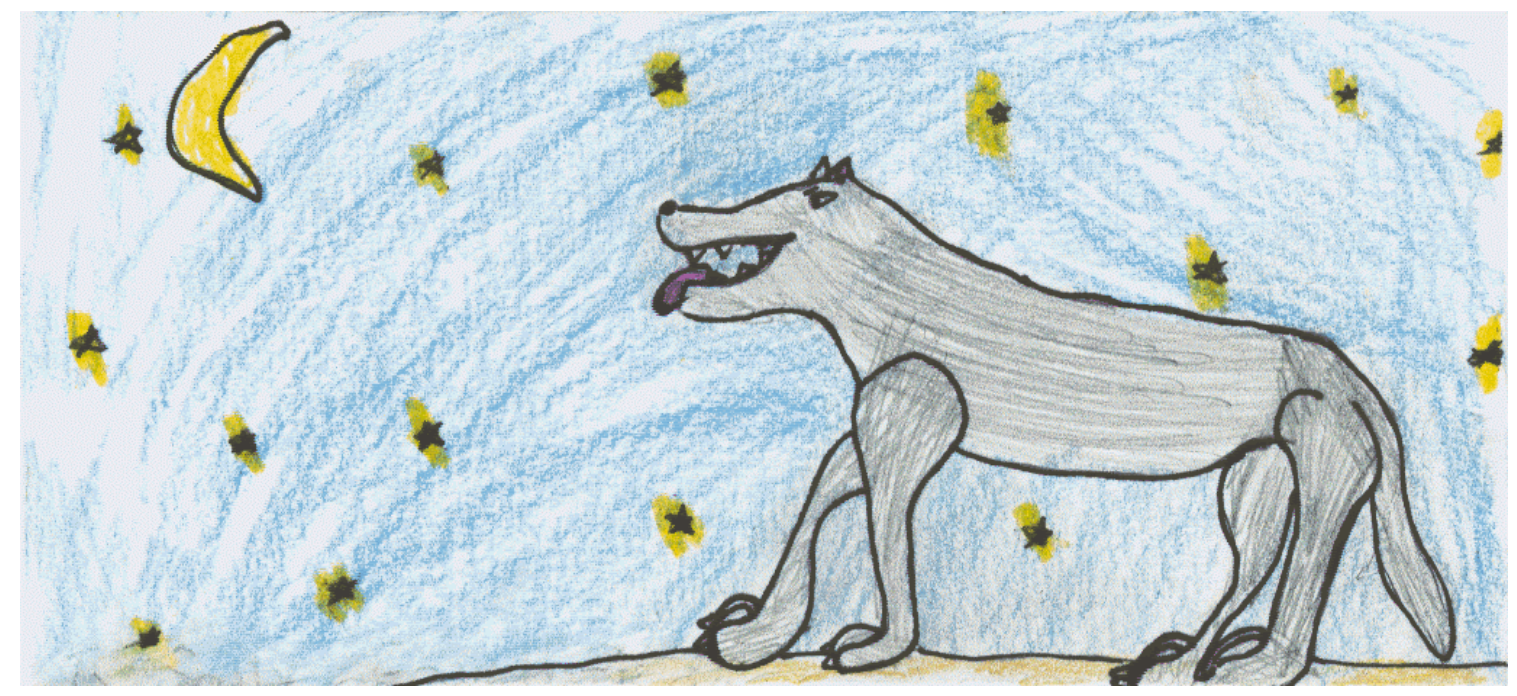

Figure 5. Bookmark of the "Big, Gray Wolf" drawn by third grader.

Before long, Pam decides that there is sufficient material with which to begin actually writing the lyrics. "These are ideas that are going to give us something substantial to pick from to write our song," she says, reviewing the 
lists of words and action ideas. "Okay, guys, we're going to start writing this song now. I need someone to give me the first line of our song."

"Lightning ran through the field. . ."

"I'm getting ready to pack my bags. .."

"Once there were some aliens fighting. .."

“Fire in the desert, we are goin' camping. .."

"Everybody get ready, 'cause we're coming steady. .."

She uses their suggestions exactly as offered, making them the seeds from which the following lines grow. The final example above gets the ball rolling for "Future Basketball." "That's a good first line, "Pam reflects. "Ready and steady. Then you need another two lines that rhyme here. You might want to name your teams now, "she advises this group. A third grade group comes up with "The big gray wolf was howling at the moon," to which she replies, "Then what? Something that rhymes with moon." The line "Soon he'd better go find some food" is easily rearranged to fit the rhyme pattern: "He'd better go find some food real soon." Pam acts as scribe for the class ideas, and, for the older classes, asks for a volunteer from each group to record everyone's ideas.

Writing songs together definitely requires a cooperative spirit, and some groups are more successful than others at working together. The "Fire in the Desert" group designates a recorder, saying, "He's the director of us." And a good director he proves to be, guiding his group of fourth graders: "That's the main idea, and this is like the detailing part. Now we'll put more details." One of them goes to get an encyclopedia and they mine it for the names of desert 
inhabitants: "scorpion, spiny-tailed lizard, tortoise" and so on. By the time Pam makes it around to their group, the first draft of their song is nearly finished.

Some groups are not so fortunate in their dynamics. A third grade group that has agreed to combine the ideas of "space" and "art" into a song based on a dream gets frustrated by a disagreement over a proposed chorus insisted on by one rather bossy girl. This particular combination of people cannot work together independently, I conclude, as I visit this group while Pam works with a different one. Finally, their turn comes for her attention, and she mediates their differences of opinion. With her guidance in building the lyrical structure, the finished song is a successful compromise, and is even selected by the class as the one they wish to sing for the final performance (song 3).

I had a weird dream late last night

I dreamed about planets, black holes, stars

When I woke up, I took my brush

I painted my walls in a great big rush

I drew a picture late last night

What a very beautiful sight

It was a dream come true

Black, yellow, red, green and blue...

\section{A little bit of recorded history.}

Little by little, line by line, each song takes shape, Pam teaching the children how to construct a solid foundation for their songs as she attends to rhyme, to rhythm, and to the story line. The wolf "hunted a rabbit with his big 
sharp jaws, he cut it right up with his_-" "Claws," a student provides. "You need a few more syllables," she tells him, and he changes it to "with his big, sharp claws." "Big sharp claws, good," she replies. The camping trip group has established the purpose of their trip and what they are taking:

I'm getting ready to pack my bags

I'm going to the mountain to see great sights

I'll pack my gun, my light, my hat. . .

Pam asks for a rhyme for "sights" and gets in response, "mights," "bites," "fight," "dites" and "nights." "Nights, let's do something with nights," she says— how long are we staying?" They call out: "Three hundred weeks!" "Eighty hundred weeks." "Eighty nights." She asks one student, "How many nights are we going to stay?" to which he replies, "Two weeks." She asks him how many nights that would be, which finally leads to the ending line of the verse: "I'll only stay for fourteen nights." "There's your first verse!" she proclaims triumphantly. The next verse sends a student to the dictionary to look up the spelling of "carabiner" (a rock climbing device), and the third verse sparks a lively discussion on the merits of burned versus melted marshmallows.

This song, like a number of others, follows a story format, as she explains: "Somehow, we're going to make a little story happen. We've got to have a beginning, a middle and an end." She introduces the concept of setting in a natural way: "So we might want to start our song out by telling our audience where things are happening. Where is this taking place?" And off they go, to the ocean or the desert, to outer space, to a place called "Boring School" where a 
mysterious marauder steals all the books to make a ladder with which to cut the power line so school is dismissed early. (The surprising resolution to this rebellious song, however, is that the principal hires the teacher, "Detective M." who solves the crime and gets five million dollars in pay!)

Some of the songs travel back in time, as the poppy and fun "Hippies in the 60's" ("We wear tie-dyed clothes and platform shoes, bell-bottom pants and we sing the blues"), or the dramatic, informative "Dinosaur Rock" which describes eight different species and begins (song 4):

Dinosaurs lived a long time ago

Sixty-five million years or so

Some were big and some were small

Some were short and some were tall

Dinosaur Rock, Dinosaur Rock

Here comes an asteroid, we'll all be destroyed. . .

Many of the songs take place on the ball field or court ("Basketball is so much fun! Basketball, makes you run") and some venture out into nature ("I saw some rocks, then a flower; I was weak then I felt the power, Of the beauty of the water that flows, and the sound of the wind that blows"). And of course, some of them, like this kindergarten composition, are just downright fun (song 5):

I had a wiener dog, his name was Chili

When he went to the store, he looked so silly

Mustard, custard, and ketchup

Mustard, custard, and ketchup 
He went to buy a bun to put himself in

He forgot to buy ketchup, so he ran back in

Mustard, custard, and ketchup

Mustard, custard, and ketchup. . .

Pam, unlike Paul, does not begin putting the songs to music until the lyrics are completed. Then she provides some examples of different types of music and allows the children to decide what style is appropriate. "I'm going to play a few different types of things, and we're going to make a decision about what we want our song to sound like. For example, we could have a country alien song, but would that be appropriate for space?" she asks the second-graders. "No!" they respond. "What would be a more appropriate type of music for a space song?" They suggest rock and roll, but first Pam wants them to hear how their song would sound in different musical styles. Using their finished lyrics, she first plays softly and sings gently in a high voice: "Once there were some aliens fighting. . . ." The kids laugh loudly. "What's so funny?" she asks. "That was too sweet," they cry out-“They're mean!" In this way, she offers them a chance to hear their words set to music in a variety of genres, and lets them choose the one that gives their song the feel they want it to have.

I later ask Pam whether she does all the writing of the music, and she explains how the children contribute melodic elements: "They may sing a line that they just come up with off the top of their head, and l'll hear that, and sing it back to them, kind of stabilize it, you know, because the next time they might sing a different melody altogether." A few songs are based partly or completely 
on familiar song melodies, but most of them have original music created for them, Pam's only notation being the chord progressions. During the musicwriting session, lines are edited as needed to fit the developing tune. Pam comments to the students on the importance of "getting all the words in so you can tell what they say, and getting the phrasing in there." Quite a few of the classes choose a rock feel; a few prefer country, reggae or blues, and some groups decide to write rap songs that use little accompaniment, sometimes only adding percussive sound effects.

Once the musical arrangement is finalized and practiced, Pam brings in a tape recorder and records the finished songs. The children are invariably proud of their creations, made all the more tangible by designing their own tape case covers and the promise of a tape of their very own. Pam reports, "When they realized that they could take a recorded piece of music home, they responded very excitedly to that. Because that's something they've never been exposed to, never gotten a recording of themselves to take home, share with their family, and keep." Their excitement is evident in the final recording of "Big Gray Wolf," complete with the howls of a pack of third-grade wolves (song 6):

The big gray wolf was howling at the moon

He'd better go find some food real soon

He hunted a rabbit with his big, fat jaws

He cut it right up with his big, sharp claws

He took it home to his three furry babies

But he made sure that it didn't have rabies 
They gave the foot to the leader of the pack

To bring good luck so he wouldn't break his back

Late that night the pups snuck out

An owl came down and freaked them out. ...

Pam concludes each of her seven-day residencies with a performance for the entire school and invited guests, showcasing the original songs written. Classes perform one song each, voting on their choice if several group songs were written. In evaluating the project, Pam counts up the participation: over 100 songs written in 42 classes from three different schools, involving nearly one thousand children. Her passion for music and songwriting shines brightly as she reflects: "I really feel like I'm sharing and spreading something very important to me, and I believe that it's important to other people, too. I ask the children, 'Why do we listen to music? Why would you write a song?' And a lot of the kids say, 'Because it makes you feel good.' You know, maybe they haven't really put that into words, but it reaches something in our souls, I think."

\section{Site Three: The Country Music Songwriting Tradition}

\section{A rich musical environment.}

My third research trip brings me my first taste of "Music City," Nashville, Tennessee. The country music jewel at the hub of three intersecting Interstate highways, she beckons to would-be stars and songwriters from 'round the globe. Upon arriving at my hotel room, weary from the 600-mile drive, I pick up a local entertainment weekly to check out the scene. On Tuesday night alone, the paper 
lists no less than a dozen "writer's nights," where novice and veteran songwriters alike gather to test new material, share camaraderie, or dream about being discovered.

No wonder this town can boast of a two-decades-long program of songwriting partnerships between schools and professional songwriters, sponsored by the Country Music Hall of Fame. The museum's education director tells me, "In this town, everybody knows songwriters. . . . They've all seen napkins on a table with two lines on it, and so there is a culture of belief that people can write songs." And, among its other roles, the Country Music Hall of Fame is engaged in passing this unique, creative tradition along to the youth of the area.

In the morning, revived after a night's rest, I follow the briskly-moving traffic into town and make my way to Music Row and the museum. I am nearly as excited as the schoolchildren, arriving for a field trip to the museum, who are directed to take their seats on the lobby floor's "Hall of Stars." They giggle and point excitedly at the well-known names ("Willie Nelson," "Alabama," "Reba Mclntyre," etc.) and at the giant postage-stamp banner of country music's godfather, Hank Williams, Sr., hanging high up on the wall. Some groups come here only to tour the facility; others also meet with their designated songwriter and discover which students' original lyrics have been chosen to be brought to life with a musical arrangement. 


\section{Seeing the pride and glow in their faces.}

For several weeks, I have been in communication with the coordinator of the educational "Words and Music" program, making arrangements to observe examples of both the classroom instruction and songwriter presentations while in Nashville. In this partnership, the museum supplies classroom teachers with instructional materials on lyric writing, then teams classes up with professional songwriters who select several student-created lyrics to set to music. My first observation this morning is a session in which one of the songwriters presents the finished songs to his group of sixth grade co-writers. The coordinator has informed me that forty-eight schools have one or more classes participating this year, most of them in the seven middle Tennessee counties, but a few located in eastern and western Tennessee, Kentucky and Georgia.

The songwriter session is held in a small, round auditorium, equipped with carpeted tiers on which the audience sits, rather than chairs. Across from the semi-circular seating area is a small stage. Here the songwriter is setting up his guitar and a music stand as the children excitedly enter the room after touring the museum. The normally boisterous sixth graders nervously take their seats, wondering whose songs have been selected.

The songwriter introduces his performance with an explanation of how he chose the lyrics he set to music: "Well, I certainly had fun going through all these tunes. I've chosen seven that 'spoke to me'; I thoroughly enjoyed all of them, though. Some are funny and some are serious. And all are just pure wonderful." 
The student lyricists are asked to come to the front of the stage during the songwriter's performance of their songs. As their names are called, the class erupts into giggles, hoots, and enthusiastic applause, and the young writers, both thrilled and embarrassed, join the songwriter on stage for their moment in the spotlight.

From the topics of the songs they've written, it is clear that these particular sixth-graders are from a rural area. Scenes of work and play through the eyes of a couple of country boys start off the show with "Field Workin'," and "Goin' Coon Huntin'." For the next song, an attractive blonde comes to the front to hear the musical rendition of her lyrics, "Backwoods Kind of Girl": "I like to hunt, I like to fish, I eat my frog legs in a dish; That's why l'm a backwoods kind of girl." Following that, it's a universal truck-driving theme: "Pop a clutch again, my tire is gettin' low; I'm runnin' outta gas, but l'll still tear up the grass-Pop a clutch again; pop a clutch again!"

The songwriter performs several more of the collaboratively written compositions, the group squealing with surprise and excitement every time another classmate's name is announced. The crowd's favorite performance has to be the one for which he solicits their help. For this song, he performs an interesting balancing act, playing the guitar while periodically holding up one leg as a cue for the students to shout out the refrain (song 7):

"Brush your teeth!" (Every day, every night)

"Brush your teeth!" (Because if you don't you may wake up to a fright)

"Brush your teeth!" (Your teeth may be the color of an apricot) 
"Brush your teeth!" (If you keep eating that junk)

"Brush your teeth!" (Your mouth will smell like a skunk)

"Brush your teeth!" (Brush your teeth, every day and night. . .)

After the thirty or forty-minute session, which is recorded so that the class will have a tape to take back to school with them, I chat with the songwriter, and ask him how many changes he makes in adapting the students' lyrics to music. He replies, "Actually, I try not to do any," which surprises me. The coordinator explains, "If there's a line or two that can be switched around that makes more sense, they might do that, or if a verse makes a better chorus or bridge, but they really try to keep it true to what the kids have written."

Seeing the children engaged in the process of lyric writing is the other part of my mission in Music City, and I have made arrangements to visit one of the outlying schools and observe this process as it is taught in the classroom. As the songwriter packs up his gear, I thank him and the coordinator for allowing me to sit in on the session, and prepare to drive out to the school where the teacher, Jean, is expecting me that afternoon. She has already spent several class sessions with her fourth and fifth grade gifted students covering the basic material, and is nearly ready for her three participating classes to begin their actual lyric writing. I look forward to seeing Jean and the kids in action.

\section{A toolbox of songwriting skills.}

The school, built in 1979, is situated in a sprawling suburban neighborhood of single-family homes on the outskirts of the city. On this April morning, the beautifully landscaped entrance to the school has vivid purple and 
yellow pansies surrounding a tiny pool and fountain with three goldfish, a silk lotus blossom, and a plastic alligator. On one side of the lovely foyer of the K-6 school (population 560 students), potted plants surround a rocking chair and a wooden bench with a heart carved into the backrest. On the opposite side, a glass case displays masks creatively adorned with feathers, pipe cleaners and colorful decorations, one proudly bearing a red ribbon marked "Principal's Award."

I am directed to Jean's classroom near the main office. As I wait for one group of students to leave and the next to arrive, I read the proclamation posted on the wall beside her room. Beautifully scripted in calligraphy and beginning with an ornate "W" ("We, the teachers. . "), the poster bears the signatures of faculty members who promise, among other things, to "accept the diverse ideas of others" and "be unafraid to try and explore imaginative techniques." The door opens, and I step inside to watch this declaration come to life.

As the class enters the small room, Jean does a bit of furniture juggling in order to free up a desk and chair for me to use as my observer's post. The nine fourth graders in this gifted class retrieve their writing folders from a central file box and take a seat at one of the two round tables or the long, rectangular one. After a reasonable period of chattily settling into place, Jean announces that "the rule is in effect" (which I assume means that hands must be raised in order to talk) and the class officially begins.

The curriculum materials on loan from the Country Music Hall of Fame come in a colorful red and white file box and consist of informational handouts, 
examples of song lyrics, and an accompanying audiocassette. The teacher's kit focuses on the songwriting concepts of theme, song structure, rhyme, meter, instrumentation, and originality. The use of these materials and the pacing of the unit are individualized by each of the participating fourth through twelfth grade teachers, but the lessons are typically spread out over a period of a few weeks. The only stipulation is that the package of completed student lyrics be forwarded to the songwriters at least one week prior to the scheduled museum visit to allow time for reading the submissions, making their selections, and writing the musical arrangements.

Jean has already covered most of the instructional material, and spends the first session I observe reviewing and reinforcing concepts. She begins by reminding the students that they need to copy the following information off the blackboard (figure 6):

element-part hook-line-states the theme of the story in as few words as possible verses-tell the events of the song and each one has different words chorus - tells the theme and is repeated after each verse bridge- often only a few lines with a different melody and it emphasizes ideas in the verses and chorus rhyme-having ending sounds the same exact rhyme-rhyming with exactly the same sounds approximate rhyme-words that almost rhyme, close ending sounds forced rhyme-rhyming for the sake of rhyming rhythm/meter-pattern of beats or flow of words in a song

Figure 6. Definitions of song elements from Jean's blackboard. 
Jean picks up her class discussion where she left off in the previous class, on the topic of rhyme. She instructs the students to get out one of the lyric sheets of the song examples in their folders and find rhyming words. They first notice the obvious ones: "sky" and "eye," "trees" and "breeze," and "away" and "yesterday," all of which are identified as exact rhymes. A student offers, as an example of approximate rhyme, the words "orange" and "forage." Jean explains that vowel sounds are more noticeable than consonants in singing, making it acceptable to use approximate rhymes such as "road" and "home." Forced rhyme, she adds, is "rhyme just for the sake of rhyming" and is to be avoided, because "it might not have anything to do with what your song's about."

Jean taught a poetry unit to the students earlier in the year, and she refers to it as she asks them to analyze the rhyme scheme of the song: "If you remember when we did the couplets and the quatrains. . . .what kind of rhyming pattern is he doing? Is he rhyming every two lines, or is he rhyming every other line? Do you see a pattern?" Upon analysis, the group decides that the rhyme scheme changes between the verses, chorus and bridge. "He does a lot of different kinds of rhyme," she summarizes, and then relates it to their own writing: "And so, in your song, you don't have to do it like a couplet, where every two lines rhyme-that might even be too much rhyme."

Rhythm and meter are the concepts to be covered next. Jean reviews the definition given in the handouts, "Meter is the pattern of beats or flow of words in a song." She then directs them through several activities to experience the feeling of rhythm and meter: clapping "Mary Had a Little Lamb," first on every 
syllable, then on the beat only; counting and clapping the rhythm of songs on the tape; and counting out $4 / 4$ and $3 / 4$ time, which leads into a discussion on note values and time signatures. Again, she makes the connection with their study of poetry, reminding them how they counted syllables and determined meter with some of their poems.

Jean refers back to the teacher's guide and reads: "Writing lyrics is very much like writing poetry. A talented songwriter uses basically the same set of rules as are used in writing specific types of poetry." "What do you think is the same about songwriting and poetry writing?" she asks the group. "Rhyme" is their first response, followed by "verses" and "Sometimes we would come back to the main thought again," which Jean relates to the chorus in a song, noting that poems don't usually have choruses. Other similarities noted are lines, titles, themes, rhythm and, sometimes, the use of repetition or sequence. One student states that in writing poems or songs, "We might use better words, because in a book, they explain it a lot." Another student comments, "There are different types of poems, like couplets and stuff like that, and with songs you have waltzes and other styles."

When asked what the differences between poetry and songs are, students pointed out, "Songs are to music; poems don't have any," and "Some songs have choruses and bridges but poems don't." Jean emphasizes the difference in form between poetry and songs: "You did do some poems where you repeated things, but having a specific verse that tells the story, and a chorus that kind of tells you the theme, you're going to do a lot more of that." The group discusses 
other characteristics as well, and Jean summarizes their discussion on the blackboard (figure 7).

\begin{tabular}{ll}
$\frac{\text { same }}{\text { rhyme-sometimes }}$ & $\begin{array}{l}\text { different } \\
\text { songs longer } \\
\text { bridge } \\
\text { rhythm }\end{array}$ \\
$\begin{array}{l}\text { chorus/verses } \\
\text { hook-line } \\
\text { theme }\end{array}$ & music-singing, instruments \\
sequence-story & \\
\hline
\end{tabular}

Figure 7. Comparison chart of poetry and songs on Jean's blackboard.

For the most part, Jean's class is well-behaved and attentive throughout the lesson, but, as always in a classroom, there are some who are not on-task. Two boys at the middle table conduct a pantomimed conversation, then pretend to eat their pens. They do not appear to be paying attention, but as they are not disruptive to the class, Jean does not seem to notice. The others patiently participate in the exercises, but I suspect they would like to be finished with the background theory and get down to the business of actual songwriting, which they know lies ahead.

Jean has one more topic to cover before turning the students loose to be creative: "What l'd like you to do for your first song, is to think of a story that you can use for your song. So before we start actually writing our songs, I want to talk about the parts of a story." She again quotes from the curriculum guide: " $A$ story song should have a good beginning, a middle that builds the story, and most importantly, a good ending. Story songs stick to an interesting theme, and 
the action follows a sequence, or order in which the events of the story take place." She asks what is usually found in the beginning of a story. "The names of characters, and their ages and personalities." "The setting, like West Virginia, and when it happens," says another. "Usually you introduce the beginning of the plot, like if you're thinking about some kind of kidnap," suggests a third.

Jean accepts all these answers, and moves on to discussing the middle section of the story. "This is where most of the events occur," she tells them. "In order for it to be an interesting story, what usually happens in the plot?" "A problem," one student replies. Jean asks them for examples of possible problem situations. "You lost something." "You won a million dollars but you didn't want to be rich." (Disbelieving students laugh at this unlikely situation.) "You hear a big, huge thud and you go see, and your cat has a broken leg." Another describes a problem in a relationship between two friends.

When asked what belongs in the ending of a story, a student offers, "You need a solution, and you need a closing, 'cause if it doesn't sound like it's the end, then it won't sound right." Jean agrees, telling them, "You need to wrap up all the loose ends by the end of the song or the story" and adds a chart explaining story structure to the other ideas on the board (figure 8).

\begin{tabular}{|c|c|c|}
\hline $\begin{array}{l}\text { Beginning } \\
\text { characters } \\
\text { setting-where } \\
\text { when }\end{array}$ & $\frac{\text { Middle }}{\text { problem }}$ & $\begin{array}{l}\text { Ending } \\
\text { solution-resolution } \\
\text { closing }\end{array}$ \\
\hline
\end{tabular}

Figure 8. Story structure on Jean's blackboard. 
By the time the class has finished discussing story format, the class period is over, so the children do not get to begin writing their songs in this session. Jean sends them off with the assignment, "Think of some story that you could put into a song. This could be a true story, something that really happened to you, or it could be a made-up story that you think would give a good message to other people." I notice that some of the children are softly singing to themselves as they gather their things and leave for their next class.

The other two class sessions I observe that day, a group of thirteen fifthgraders and another fourth-grade group with eight students, cover roughly the same material as the first session. I am impressed with Jean's ability to know exactly what material she has covered in each class, which differs slightly, and at what point in the process to begin that day-a trademark of a well-organized, experienced teacher. Although the first day's sessions primarily involve discussion, I notice that each class includes sufficient active participation, such as clapping out the rhythm of the song examples, to hold most of the students' attention throughout the forty-five minute to hour-long class periods.

I return the next day to observe the three classes again. Jean resumes her instruction on story songs with an example of lyrics from the teacher's kit, and asks the students to identify the characters, the setting and the problem in the song. The students justify their answers by reading the specific lines in the lyrics that support them. One more quick review of possible rhyme schemes, and finally Jean feels that they are ready to begin writing. 
"I'm going to give you two minutes, and I want you to think of about five different stories that you could write a song about. You don't need to write out details, just write something brief, like the title, or just the topic of your song." Jean also reminds them of the common themes they discussed earlier in the unit (humor, heartbreak, home, transportation, love, religion and work) and tells them she wants the songs to "have a message that you're trying to say with your song." One student suggests that "school" be added to their list of possible themes.

As the students prepare to write-getting paper, sharpening pencilsJean reviews some basics of brainstorming with them: "Write down anything that comes to mind-they don't have to be perfect ideas. And remember, the more ideas you come up with, the more good ideas you might have. "She and I circulate around the room as students scribble down ideas which run the gamut from true life adventures ("I fell in the lake" and "Stuck on the Metro") to everyday living ("bugs," "football" and "bad hair day"), from feelings ("school dance disappointment") to fantasy ("pokka dot worms") and, of course, the realities of school ("cafeteria food," "Friday morning blues," and the catchy "School drools").

Most of the students are successful in thinking up several ideas for songs. Jean then instructs them: "What l'd like you to do now is look through the topics that you wrote down, and put a little check next to anything that you think really has a theme, ones that you think you could come up with a good story" and from those, to select an idea for their first song and circle it. 
The next step is for students to get a fresh piece of paper, write their song idea at the top and divide the paper into three sections for the beginning, middle and end, and jot down ideas for the characters, setting, problem and resolution. Jean clarifies for them, saying, "These are not your songs—-these are just notes about what you're going to write." She asks for volunteers to tell the class their problem situations as examples. One girl shares: "My problem's going to be trying to make it to the hospital in time when my baby brother was born." Jean agrees that would be a good topic for a song.

Again we move around the room while the students write. A few of them who need more guidance consult with Jean as she comes to their tables. I notice at this point that there is suddenly a divergence among responses. Some of the students are still making idea lists, some are figuring out a problem statement, many of them are working on the beginning/middle/end chart as directed (figure 9), and a few of them have skipped the plot outline altogether and have jumped right into the lyric writing, some with verses and the chorus specified.

\section{My Favorite Pet-TRUE}

B- I went to my friend's house with my turtle named Betsi in a bucket. We went down to the lake and I tripped over a log and dropped the bucket and the turtle was gone

M- My friend and I looked and looked out but we couldn't find Betsi! We went home without my pooooor little Betsi.

Chorus Betsi, Betsi, she is my pet!

End-That night I went in my bed and cried and cried but crying wouldn't bring her back.

Figure 9. Example of student's chart showing beginning, middle and end. 
Jean, too, recognizes the individual nature of the writing process, and allows them more liberty to proceed on their own: "People are probably at different places, but before you really start writing your song, please organize yourself by making notes." She also loosens the restriction on talking to facilitate collaboration: "If you need to talk quietly to someone, you can, but try to keep the volume down." The children clearly appreciate the opportunity to try their lines out loud, practicing rhyming words, and running ideas past their neighbors. "Nice line," I hear one boy say, but the response he gets is, "It's got too many beats. Seven beats-I need to make it 3/4." Other voices: "Will you listen to my song?" "I've heard it and heard it already." "I changed the ending—see? It's different."

As Jean and I go from table to table, she fields questions and coaches slow starters, and I document the process with my hand-held tape recorder and note pad. One boy reads the beginning of his song aloud for me (song 8):

When I first went to school

In the fall of '94

The very first second I went in there

I knew it was a bore

I couldn't think of what to do

As I sat down in my desk

I thought I would start to rest

But then we had to take a test 
Little does he realize as he writes this rough draft, that his finished song will be one of the ones chosen by the songwriter from the entire collection sent in from Jean's classes and presented to the appreciating audience at their session at the Country Music Hall of Fame (song 9; figure 10).

\section{School drools Ohoh Yeah!}

Chorus. I never knew anything could be that bad

I seriously think it's gonna drive memad

As I sit down in my room

I know my life is doomed

Verse I though this would be a good de' cool day.

But all I get is another day of work without pay

$$
\begin{aligned}
& \text { I insulted the teacher } \\
& \text { Verse I kicked at the chef } \\
& \text { That's about the time I staited to make some F's } \\
& \text { Chorus }
\end{aligned}
$$

Figure 10. Excerpt of song, "School Drools," as submitted to songwriter.

After a period of writing, Jean interjects into their thoughts and conversations: "Could everyone stop working, just for a second—let's make sure we all know what we're doing." She refers to the chart of song elements written on the board. "I want you to try to have all these things in your song. Everybody has a theme; we've established that. It would be good if your theme could have a 'hook-line,' and remember that a hook-line keeps coming back in the song, so 
that's something people are going to remember. Set this up with verses and a chorus, and if you want to save time, the next time you come to the chorus, you can just write 'chorus.' If you want to have a bridge, that's up to you; however, a lot of the times the way the bridge is distinguished from the rest of the song is the tune, and since you're not writing the tune, you'll need to alert the songwriter that you'd like it to be a bridge. Think about the meter; you probably want to have pretty even amounts of syllables in your lines, so that it sounds good." A student asks, "Do you have to have rhymes?" Another student queries: "Where do you put your punctuation mark?" Jean answers these and a few more questions, then the students return to writing and discussing their songs in progress.

As I walk around the room from table to table, I find their conversations especially interesting. In a true spirit of collaboration, they help each other work out phrasing and search for rhymes. "Not a lot of things rhyme with 'ask," one girl says to another. "Mask?" the second girl suggests. "Masking tape. . . masks. .. not exact, it would be an approximate rhyme, hm. . ." When students complete a draft of their song, Jean instructs them to trade papers, read each other's work and "critique each other's songs—put some comments about things you think are good and things that you think could be improved." The critiques include comments such as "I really like your chorus" and "Sometimes your rhymes don't rhyme very well."

The second day's writing sessions conclude with students at various stages in the process, with everyone having written something. A few appear to be frustrated by a lack of ideas or difficulty following the format, but for the most 
part, the students seem to be engaged in the process, excited about their creations, and supportive of each other's efforts. Their spirit of cooperation returns when they arrive in class the next day. I observe a group of four girls eagerly sharing work with each other and discussing specific parts of their songs in very adult-like conversations. One points out: "This is forced rhyme." "So?" the other girl responds. "Do you have a bridge in your song?" another girl asks. The fourth girl comments, "Well, I think that will work, but don't you think maybe that should be your chorus, right here?" It is evident that these students are taking the songwriting assignment seriously. By the end of my third and final day of observations in Jean's classes, most of the students are well on their way to finishing their first drafts, and seem quite proud of them.

I return to Nashville three weeks later to attend Jean's trip to the museum with her classes, at which time they meet the songwriter who received their completed lyrics and adapted some of them into finished songs. He has chosen seven out of approximately thirty that he received. With a witty sense of humor and a sincere show of support for all the young writers' efforts, this songwriter quickly establishes a rapport with the group, as did the other songwriters I observed at the museum.

"I certainly had fun going through all these tunes. There were some wonderful, wonderful tunes, and I wish I had time to do them all," the songwriter begins. "There were a lot of 'I woke up this morning' songs," he tells them, several of which he has chosen. One is a spoof on the morning news which he performs in a spoken word rendition with a broadcaster's voice; another one, the 
"Summer Blues," he sings in a laid-back jazzy-blues style. One of the chosen songs is silly; one is serious. The next one he introduces by saying, "What drew me to this song is because I saw a lot of myself in it. We all have mornings like this one!" (song 10; figure 11).

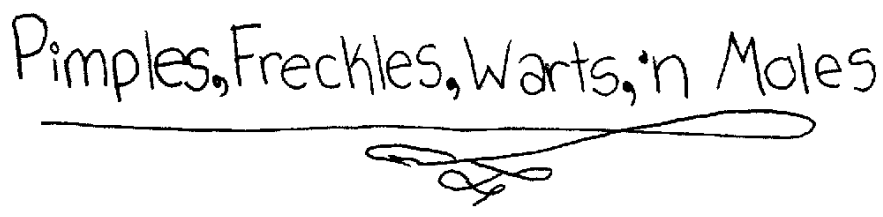

Verse My toothorush was in the toilet,

My brush was in the sink.

Inad tooth paste on my nose, The culprit is a fink!

I put my shirt on backwards,

My shoes were way toosmall.

My dog chewed up my nome work,

His foodbowl made me fall!

〜 chorus

Pimples, freckles, warts, and moles, all over my face, I look kike a troll!

My hair is all knoted and tangled and grass,

I look disgusting if you see me up close!

Figure 11. Excerpt from lyrics for "Pimples, Freckles, Warts, 'n Moles."

"You're a little hard on yourself there," the songwriter light-heartedly tells the self-conscious writer who blushes when her name is announced, and sits very still throughout the performance of the song. I later ask the coordinator of the program whether the students are often embarrassed, and she laughs and 
replies, "Always! But most of the time they are happy with the way their songs come out, and with the whole experience. And even if a child's song is not selected, they're really excited for their classmates."

The songwriter for Jean's group concludes his presentation with a chance for the children to ask him questions. One of them asks him how often he writes songs. He explains that he tends to write in "creative cycles" which vary. He encourages the students to continue developing their own self-expression: "You'll learn after a while, if you really start writing a lot—poetry, anything—-that you'll start to feel when you need to express yourself. Like when you're talking to a friend and you feel like there's something you want to say-that's what it feels like." And several of the fourth and fifth graders nod their heads, knowingly.

\section{"The Children Want to Be Heard."}

The grand finale of my second visit to Nashville and of the entire year's "Words and Music" program sponsored by the Country Music Hall of Fame is a public performance of songs performed jointly by the songwriters and students. The twenty songs selected for the concert represent the hundreds written throughout the school year, and are chosen by a committee to show a range of song topics, musical styles, ages of participants, and geographic representation.

The performers gather in the small, circular auditorium the day before the event to practice their songs and do a run-through of the show. Some of the songwriters have met with their young lyricists on their own; others have not seen each other since their field trips to the museum, some of them months earlier. As the families and songwriters arrive, co-writers pair up and break away from the 
group. One songwriter and his student retreat to a red cushioned seating area in an alcove. "Look what l've done," the songwriter says as he shows the native Spanish-speaking student a computer print-out matching the Spanish words and English translation of his song. Another songwriter arrives and gives his student a CD, saying, "Here's a copy of my new album that comes out tomorrow." One team practices in a corner of the lobby. "If you make a mistake," the songwriter tells his little singer, "We'll find a place to fall back into it. You have a lovely voice, a naturally sweet voice."

The education director calls the rehearsal to order and goes over a few points relating to the performance. He asks if anyone is nervous, which meets with a combination of groans and chuckles. He reassures them that nervousness is okay: "Being a little nervous is the fire inside of you that you're going to use to give a hot performance." He explains the running order of the show, trains them on microphone technique, and encourages them to wear whatever will help them to express themselves creatively. "It's your song; it's your night-we're celebrating you."

The big night arrives and the "Hall of Stars" is filled with folding chairs, proud parents, and members of the Nashville music community. As each songwriter is introduced, the list of songwriting credits grows to include every country music act imaginable, and many artists of other genres. I am quite awed by the level of professional success of the participating songwriters who volunteer their time to work with the children. In an earlier discussion with the education director, he explains to me one benefit for the songwriters: "Here they 
are on Music Row, with a writing appointment at nine o'clock, a demo at two, and they're worried their song's gonna get on the radio. All of a sudden, here's a kid, writing about wanting a horse. And they say, 'Oh, yeah-that's why I started writing songs.' They reconnect with what it was that made them decide to do this in the first place."

During the performance, the connections between the songwriters and the children are obvious and delightful. One pair, whose song is about winter, appear in heavy jackets and wool hats; another team don sunglasses for "Sweet, Sweet, Jamaica Land." A songwriter introduces a pair of ten-year-olds wearing ten-gallon hats, fancy belt buckles, and cowboy boots, saying, "I worked for a long time on a farm, and these boys truly captured those images of life in the country." One songwriter calls himself "an old hippie at heart" and says that his lyricist wrote "a very flower child kind of lyric" full of moonbeams and merry-gorounds. A team of three songwriters and three students wear backwards ball caps and rap to the beat in "B-B-B-Bad Day," a hilarious take on the daily disasters of school life, ending with: "If you think it can't get worse, well think again, you're wrong - my homework was to try and write a country song! B-b-bbad day, b-b-b-bad day, b-b-b-bad day, bad day!"

But the Spanish-speaking student and his songwriter were the team whose song really spoke to me. Their song was written and performed in Spanish, with excerpts translated on the program:

Que no se dan cuenta son muchos niños los que mueren en esta gran ciudad 
No somos los niños del mañana

Somos los niños de hoy

Frenemos estos problemas para vivir mejor

("Don't you understand that too many

children have died in this grand city

We are not the children of tomorrow

We are the children of today

We will stop these problems in order to live better")

Que se acabe la violencia

Que se acabe las armas

Que se acabe todo esto ya

("Stop the violence

Stop the guns

Stop this all now")

When this duo takes the stage, the songwriter introduces his fifth grade writing partner with these words: "What he's saying here is very important. The title of his song, 'Los Niños Queremos Que Nos Escuchen,' means 'The Children Want to Be Heard.' And I think that's a lot of what our program is about, allowing those children to be heard. So let's do it." 


\section{Site Four: An Integrated Perspective in a Fragmented World}

\section{On the edge of a multicultural metropolis.}

My fourth and final adventure on the trail of songwriting-in-education takes me to the metropolitan D.C. area, one I know fairly well and usually try to avoid. But this time I am filled with eager anticipation for I am en route to see an original opera, written, performed and produced by fourth and fifth graders.

Only five days earlier I had learned, through the magic of public radio, about this educational outreach program sponsored by the Metropolitan Opera Guild of New York, and made contact with the participating teacher via the wonders of the Internet. Arriving during rush hour, I am indeed fortunate that the school is located on the western edge of the vast metropolis which is our nation's capital, not far off the Beltway in a middle-class residential neighborhood.

Having been instructed to arrive early in order to get a good seat in the audience, I find a parking place with no problem. When I approach the front door of the K-5 school, a student greeter whispers to her companion, "She must be a V.I.P." and runs ahead of me to the reception table in the foyer. I announce that I have driven 200 miles from West Virginia to attend the performance, but apparently I do not qualify for V.I.P. status without the appropriate invitation. "Gosh," one little girl says, "You must really have wanted to see the show!"

The performance is held in the gymnatorium, and people fill the exhibitlined hallway waiting for the doors to open. The families represent quite a mix of cultures: the couple in front of me are speaking Spanish, the next lady has a Caribbean accent, and the man in front of her is African-American, and when I 
take a seat, the family beside me is Asian. Clearly this is a multicultural community. (I later learn from the music teacher that the school population of 600 students is $50 \%$ international, with many of the students speaking "not one word of English" when they arrive! Families in this area frequently come from other countries for the parents to work as military attachés, low-level diplomats, or employees of the National Institutes of Health, she explains.)

In the multi-purpose room, families excitedly compete for the best available seats while the "V.I.P" section awaits its honored guests. Beige curtains at the edge of the built-in stage only partially conceal glittering mirrors on a blue background, and in front, silver-painted scaffolding draped with lengths of sparkling dryer hose create a futuristic, interstellar atmosphere. Shortly, a fifthgrade girl in a black satin off-the-shoulder dress steps up to introduce the company and the production, and I settle back to be transported to the Red Planet.

\section{Cooperating to make something "really big" happen.}

As an experienced elementary school teacher and the director of many children's plays and concerts, I know the quality of work that is possible with young performers, and many school productions I have attended fall short of my standards. This is not the case here, however, for I am impressed with the level of young professionalism in this original opera. From the opening scene, in which the actors in baggy white jumpsuits exercise on every level of the spaceage scaffolding, through the various scenery, musical and mood changes that transpire as the story evolves, the commitment of the cast and crew glows with 
pride and polish. Their voices ring out, bright and clear, as they sing about being the pioneers who are "terraforming" the planet Mars, living underneath a dome while building the structures that will allow their families to join them later (song 11):

We're on the planet Mars

From here Earth is a star

There's overpopulation on every single nation

Because of complications, we'll build a civilization

On Mars, the planet Mars

On the planet Mars

The plot involves one of the young workers who is ruthlessly teased because she doesn't have any family, and the conflict that arises from this situation. As in adult operas, most of the exposition and dialogue takes place in the songs, which are well-crafted and performed with conviction. One adult on keyboard and a small crew of student musicians on percussion and sound effects provide an accompaniment that is tastefully simple, yet musically interesting.

The evening I attend is the second and final one of the two performances that culminate nearly a year of planning, writing, and production work for these students. The emotional climax of the evening comes at the curtain call, as the poised young production manager returns to introduce each of the hard-working production teams: writers, composers, documentation team, costume crew, make-up crew, public relations, set design, carpenters, electricians, performers, and stage managers. With only minimal glancing at her cue cards, she 
gracefully credits the adults involved-a student teacher, two classroom teachers, the volunteer accompanist, and their obviously dedicated music teacher, whom she thanks for "guiding us in the right direction throughout the opera process."

As the enthusiastic crowd gradually thins out and volunteers begin the first steps of deconstruction, I introduce myself to Debbie, the proud but exhausted music teacher, and make arrangements to meet her in the morning. I am curious about the process the children used in writing the opera, and look forward to the next day. Before leaving, I take time to browse the artistically designed and highly informative production display that lines the entrance hallway, and delight in the words of the children as they describe the different stages of their project. "There are a lot of steps we took to finish the opera, and all of the steps were hard. . ."

\section{The overwhelming responsibility of writing an opera.}

I arrive at the office the next morning before Debbie. Teachers and parent volunteers are bustling about, preparing for Field Day, and excitement is in the air. While waiting for the director, I chat with a couple of mothers about the opera. One of the mothers tells me that her son's participation in the program has made him more responsible and mature. The second parent concurs with her, saying, "They lose a little of the curriculum but they gain a whole lot more."

Debbie arrives, collects a group of students and assigns them various tasks of dismantling the display, returning materials, putting equipment away and so on. It is obvious the children respect her and are willing to work hard for her, 
as they attend to the wrap-up tasks with no complaints. Once the necessary jobs are underway, she sends for the writers and composers, and we find an empty classroom where we can talk.

One fascinating component of the "Creating Original Opera" program is the division of labor. After an initial period of whole group work with all the students in the two participating classes, students apply for their choice of jobs as writer, carpenter, and so on, filling out an application and completing an interview. Student writings posted on the school's opera website show how seriously they take this process: "I felt nervous getting interviewed for my job. I was scared that I wouldn't know what to say. After my job interview, my brain cells couldn't think correctly!" "This is how I feel about getting my first job. Right before I knew, I felt like my whole body was exploding with confetti!" "I feel very happy about getting my first job in the opera. I just found out that I was going to be a PR! My heart was pounding of excitement." The applications also require that students show some aptitude or competency for the assignment-applicants for the job of writer must write a poem and a two-minute skit; future composers are required to submit an original melody.

I learn from Debbie and the students that before the classes break up into the job divisions, they lay the groundwork for the opera as a whole group. The first task at hand is to develop the theme and thesis of the opera, beginning with the questions, "What do I know about?" and "What do I care about?" The spring newsletter published by the Documentation Team explains this process: 
Our company started out this year by thinking of a theme and thesis. The theme was developed by thinking of what we want to know about and care about. Surprisingly, most of us wrote about family in one way or another, so our theme is family. Then we had to develop a thesis statement, which had to relate to our theme, but leave us open to many possibilities for story ideas. Our thesis is, 'My family is a part of me, wherever I am, whatever I do.'

Debbie explains that the next step in the process is to create characters. "We have these huge chart papers up around the room; we list every positive and every negative trait that we can think of, and traits that can be positive or negative. And then for homework, the kids have to build one interesting character, using the ' $2+3$ Plan': two positive and three negative traits, or three positive and two negative." Character relationships are explored and possible conflicts between characters identified before the story line is ever developed. Students vote for the best eight characters who would be "interesting to meet or read about," the newsletter says. At the same time, the classes are brainstorming a list of possible and unusual settings. The preliminary list displayed in the hallway exhibit includes "back alley," "future in laboratory," "any battlefield," and "a new space colony," which is circled as the final choice. Elaborating on the selection, the list continues, "Mars-introduction," "physical features," "weather," "life on Mars," "transportation," and "fast facts."

At this point in the process, a narrative story line is begun while students apply for and take on their specific responsibilities for the duration of the production. An exhibit panel on the writers' role in the process lists the writing assignments above and adds "scenario, insert musical moments, narrative, lyrics with composers." A quote on the display gives a writer's perspective on his role: 
Each writer picked one or two characters to write for. Then we began writing dialogue and ideas for our songs. After many drafts, we finally started meeting with the composers to create lyrics for our songs. What I like most about being a writer is that you can write lyrics. It's a really fun activity, even though it is quite challenging.

A similar section on the role of the composer explains, "The composers have to create the music for the opera and then work with the writers to coordinate the lyrics with the music." The list of concepts and activities addressed by the composers is impressive (figure 12):

- Brainstorm and define musical terms: rhythm, timbre, refrain, contrast, melody, form, solo, quartet, dynamics, percussion, duration, repetition, pitch, style, duet, ensemble, phrase, rest, tempo, mood, harmony, range, trio, variations

- Initial melody writing: random, pitch set, use letter names to spell words, rhythm skeletons, assign parameters, use magazine graph to define the melody, visual images, physicalization, shuffling/limping

- Integrate musical ideas: motif, phrase-contrasting/repetitive, sequence, transposing, retrograde, inversion, round, variations, counterpoint, diminution, augmentation

- Develop musical movements: understand characters, what ensembles will perform each musical moment, establish mood, disclose character and plot information, advance action, reveal character's inner thoughts

- Lyrics: integrate composition and writing process

Figure 12. Exhibit display information on the job of composer.

The composers explain to me some of the exercises listed for "initial melody writing" which gave them practice in building melodies. "We had little assignments. We'd draw buildings on the staff, like igloos and apartments, and then write down the notes that would be the lines for the buildings." "Our teacher 
cut out bar graphs from the Wall Street Journal about how far the market went up and down. Almost every graph has five lines, just like a staff, so we would label them E-G-B-D-F and go up and down just where the notes would go." "Sometimes we'd have to take off some of the notes of the xylophone and just sit down and compose." Their teacher reminds them that they used a "rhythm skeleton" for this activity, which gave them a rhythmic pattern to follow while improvising. Other exercises were to write a melody given a pitch set of specific notes, and to make up words composed only of letters found in the musical scale, and then convert them to notes on a staff. As they became more skilled in the process of melody-writing, they would save the melodies that sounded best to consider when they began to think about the "musical moments" for the opera.

\section{Telling a story by singing.}

Meanwhile, the writers are developing their characters and completing a rough script, which is mostly dialogue at this point. The next step is to determine appropriate places for the songs . A writer explains: "We read through the script, and then we thought of places where it might be good to have a song instead of just having a person talking to themselves or with other people. Like when there's something really emotional going on, like if someone's feeling excited, happy, or something sad." A second writer shares an example: "The 'I'm Alone' song was kind of like a really sad time, so we thought that might be a good place to put a song" (song 12). 
I'm alone, (She's alone), all alone

I'm alone, (She's alone), on my own

Why do they always tease me, yet no one ever sees me

Inside I'm (she's) just an orphan

On the planet Mars

One of the members of the composing team explains how he came up with this poignant melody: "I thought it should be slow, because slow music sounds lonely. So I was thinking it in my mind, and then I tried to play it on the piano and it sounded good, so I wrote it out." In response to my inquiry, I am told that most of the six composers have some musical background, such as piano lessons, but at least one of them learned music notation in the process. A booklet given to composers states:

Composing music and putting it on paper are two different things. It is not necessary to know how to notate music in order to be a composer, but it is helpful. A time will come that you will need to write things down or you will simply forget them. Having a tape recorder running whenever you are working is also a useful way to save ideas.

Another student shares his composition process: "I did the main part of the teasing song. When we had to compose it, I thought of what teasing sounded like, and I got 'na-na-na-na-na-na,' so then I just dropped that into the song" (song 13):

You don't have family

You don't have family

Well, you're alone in space

You're just a big disgrace (So what?) 
I don't want family (na-na-na-na-na-na)

I don't want family (na-na-na-na-na-na)

A sib like you, no IQ, nightmares, no thank you!

Remembering how some of the songs had several well-developed musical sections, I ask Debbie about the overall song structure. "The melodies are not complex," she replies. "It's just their little pieces all strung together. "She adds that after the children write the melodies, their accompanist does the harmonic structure for the arrangement.

In this collaborative writing approach, I learn that after the rough script is developed, the writers identify the general musical moments, giving a description of what would be happening at that time and possible song titles. The composers take this framework, develop the melodies which are then played for the writers' approval. In the finally step of the songwriting process, these two groups merge and write the lyrics together.

It appears from their discussion that this step provided them with some of their most challenging assignments. A writer tells how they constructed "The Building Song": "We had homework to list, maybe, ten ideas for the song. We thought of things that various characters would say in this song, so when we actually got to the point of writing the lyrics, we had a whole list of ideas." Another student elaborates: "What certain characters would say depends on their character traits and personality. If you said something that would fit in with your character, we would keep it, but if it didn't, we would either change the character or we just wouldn't use it." They give an example: "Terra 3-he's a 
really serious person, so during the Building Song, a babyish character, like Soyuz 6, probably wouldn't want to work, so 3 would be saying, 'Get to work!'” This thoughtful consideration of each written line helps to create the cohesive whole of the final song (song 14):

Climbing, sawing, hammering—what's happening?

Boom, bang, boom, bang, boom, bang, boom—DUCK!

Bring it here, heads up, construction zone-keep it clear!

(whistle blows)

Preparing for earth's future, building here on Mars

We're colonizing this world, building here on Mars

Kassae Vallis our new home, this will be our safety zone

Living underneath the dome, building here on Mars

The lyric writers also had to consider character traits in making word choices. "Two of the characters are really intelligent, so we had to think of 'super-brain' words, and that was sometimes really hard." This led to further complications: "All of these smart words are really long, and wouldn't fit into the proper amount of syllables." The students grapple with the songwriter's dilemma of phrasing. "Sometimes we had perfect lines, but they had too many or too little syllables." "We needed to fit the words of the song to the pitch, like how high you can say a word and how low you can say a word." They give an example from "The Teasing Song." "First we had the line, 'You don't have a family." (One sings the line with the high note on the word "a.") "But that didn't work, there 
would be too many syllables and the emphasis would be wrong if we used 'a,'so we made it, 'You don't have fam-i-ly'."

They talk about the difficulties of finding appropriate rhyming words. “Rhyming was also sometimes really hard. Sometimes we couldn't find the stuff in the rhyming dictionary, which was kind of annoying." "We would think of so many ideas, and we thought those were very good, you know-it would rhyme, it would work, but then we realized later that it wouldn't really fit it." Due to the chosen setting on Mars in the year 2030, the students explain that they also had to come up with futuristic words like "terraform," "hydration" and "biopods."

Working through these difficulties provide experiences that are both frustrating and rewarding for the students. One of the writers admits, "Another writer and I had huge fights over 'this isn't good enough,' you know, and then we became best friends at the end!" And the following statement really describes the biggest lesson of all: 'You kind of learn that if you don't cooperate, and if you don't think with everybody, then it's just going to be a whole bunch of arguing. It's going to be nothing like an opera. And we learned that you have to cooperate to make something really big happen. And we did."

\section{Weaving the arts into the cloth of the curriculum.}

Debbie tells me that two hours of the regular school day are committed to the project in the fall semester, and three in the spring. This is supplemented by teacher planning sessions and "breakfast meetings" to bring the writers and composers together for lyric-writing, closer to production. Debbie describes how the participating teachers divide up the groups, each supervising three teams: 
"The performers are mine, the composers are mine, and the carpenters are mine. They all work in my room, at the same time, so the carpenters are building a flat, banging hammers and nails, and in the same room, you've got the composers with their headsets on, finishing up melodies on their keyboards, and then you've got the performers doing vocal exercises. So it's crazy!" But the sparkle in her eyes as she describes this scene in her classroom lets me know that the creative chaos just adds to the sense of excitement and urgency.

One aspect of the "Creating Original Opera" program that Debbie praises is the way that all the activities are designed with "real-world intent." "In education," she says, "We talk about making things real and we don't. Where are the kids going to get a better writing experience? And not just writing the script. Writing programs, writing invitations, writing conversations to call people who haven't 'RSVPed', like the President or the Vice-President." "Did someone try and call the President?" I ask, amazed. "Well, they called us!" she exclaims. "The kids sent an invitation to the White House, and someone calls to respond, so the Production Manager goes down and takes the phone call!" We both laugh, imagining the thrill of the moment.

The principal stops by, a petite, high-energy woman, about whom Debbie brags as being "totally supportive." I take this opportunity to ask how the school manages to fit in a huge project like this one, as well as teach everything they're supposed to teach. She explains how the teachers weave in elements of the opera curriculum into their regular program: "For instance, our science units have to do with structures in the fifth grade curriculum, which fits in beautifully 
with set design, only instead of building with straws, they're building with real materials. And electricity in the fourth grade—open and closed circuits—all those pieces, it's fourth grade curriculum. We just used that with a real-life intent, which is the electrical work for the opera. And the poetry pieces fit in directly with the poetry outcomes," the principal says. Debbie adds, "The whole writing piece that goes with it. Not just note-writing, but writing for intent. . the whole rhyming piece, the whole intent in terms of expressing emotion. . .." The principal, ready to resume making her rounds, begins her exit while we are discussing this. "A particularly wonderful music teacher, who knows how to integrate the classroom curriculum with what they're doing. ..." Still talking, her voice fades out as she leaves the classroom.

Debbie describes the training process provided for the teachers by the Metropolitan Opera Guild, in which they spend eight days at one of five regional training sites, "doing exactly what the kids do. You are writing, doing make-up, building lights and flats, lyric writing. . . You're learning how to do everything that the kids do in a year." The groups are divided into two sections, each of which write about half of an opera act. The next to the last day, the groups trade operas and have only that night and the following morning to memorize lines, build sets, etc., and prepare to perform the act on the final afternoon. "And the beauty of that, "Debbie explains, "is that you feel the same stress, the same angst that the kids feel. It's a reminder of what's going to happen to your own kids."

Debbie kindly provides me with examples of her student handouts, the job 
description books given composers (provided for each job assignment), the opera logo (figure 13) and a copy of the script before I take my leave. I ask her if she will be creating a new opera with the students next year, and she says with a smile, “We don't talk about that today. . . . The day after, we don't talk about that!" I can certainly understand why.

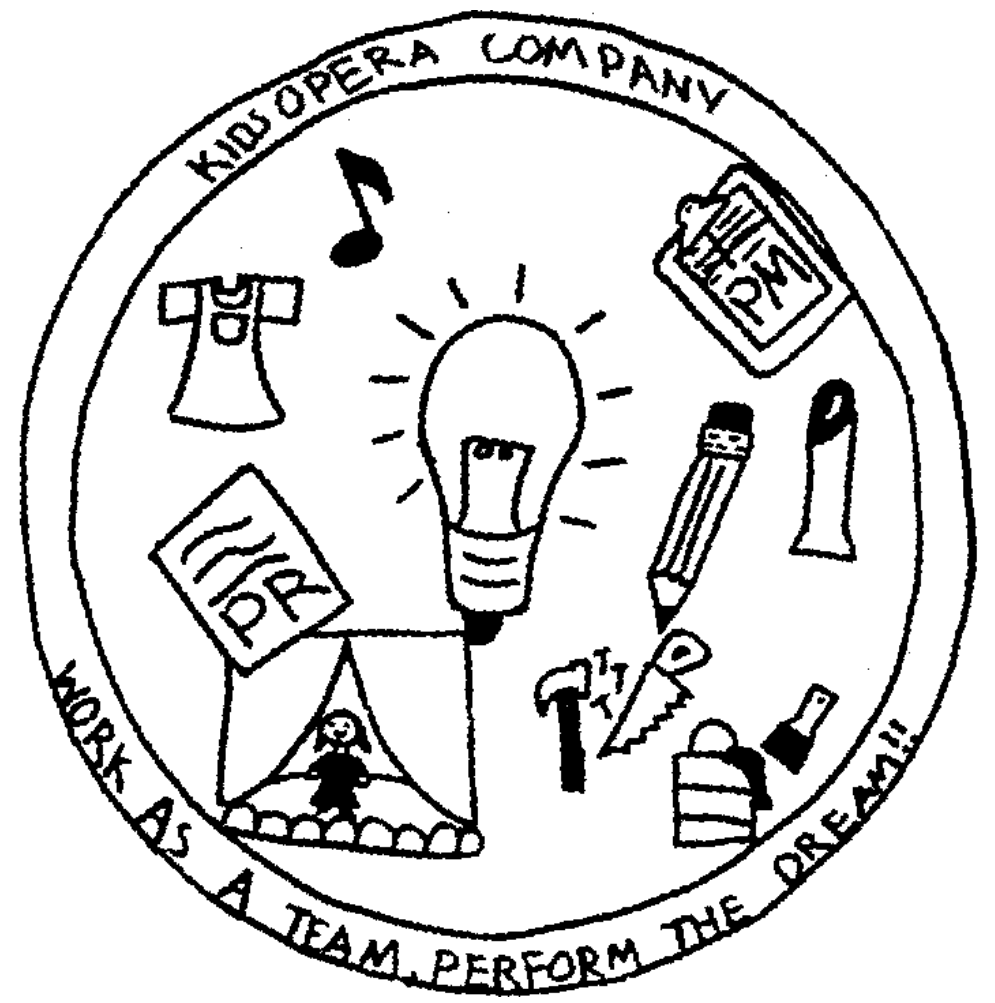

Figure 13. Logo designed by students for the youth opera company. 


\section{Chapter Five}

\section{Conclusion: Reflections on the Portraits}

As I completed the individual portraits depicted in chapter four, I discovered a number of commonalties and differences among the four approaches to teaching songwriting. The most obvious difference was the amount of time spent in the songwriting process and the level of student participation. These ranged from the fast-paced creative spontaneity of Paul's sessions at Site One, through the more sequential and methodical approaches at Sites Two and Three, to the in-depth, year-long project at Site Four. (See Appendix B for a summary of the songwriting pedagogy at each site.)

Correspondingly, each school's songwriting instruction varied in emphasis. At Site One, the rural school in Virginia, the residency involved the least amount of student contact time, but reflected the highest degree of professional songwriting experience and teaching. Paul's musical background combined with his innate ability to quickly stimulate and respond to the creative flow in the classroom allowed him to meet his objective of helping students to write songs in a very short period of time. "My first and foremost goal is to get them excited about songwriting," he shared with me. The excitement in his sessions was evident as students' voices tumbled over one another, calling out ideas, once they overcame their initial shyness and conditioning to be quiet in class. The regular music teacher at the school commented, "There were a few classes who, once they got the creative juices going, couldn't stop talking." "I liked how he 
drew out the students," reflected a first grade teacher who described her class as "all jazzed up" and reported that they "seemed inspired" to write follow-up stories on the same topic as their wishing song. When I asked Paul what would be required for a non-music teacher to teach songwriting, he responded that he thought someone who was "excited and really quick on their feet" could do it. A sense of lyric writing would be the only thing necessary, he added, suggesting that already existing songs could be used for the melodies.

The songwriting process in the West Virginia mountain schools of Site Two resembled that of Site One, but with a series of sessions spent in each classroom and the incorporation of the visual element and writing groups, which provided more opportunities for individual creative expression. Pam, also an experienced songwriter and musician, had the added benefit of classroom teaching experience. This was apparent in her approach, which was more sequentially designed and taught. Pam was able to break her process down into specific steps and teach them in each daily session, older students writing on their own in groups, while Pam circulated and assisted each group in turn. Her skill in classroom management was apparent as she responded to the changing attention levels of students by varying the activities to maintain their focus. Pam felt that understanding effective teaching practices was important, "knowing when they've reached their limit, knowing when to change an activity," but felt that a non-songwriter could be very successful if there was a system to go by. "I showed the kids, step by step, how to come up with ideas, describing words, and then rhyming words, and how to create a song using those words. I think 
knowing they had a word bank to work from helped build confidence in them," Pam explained. She suggested that listening to and analyzing children's songs would also be helpful for teachers interested in songwriting with their students.

The school-songwriter partnerships arranged by the Country Music Hall of Fame at Site Three directly involved students in only the lyric-writing aspect of songwriting. Jean, the classroom teacher I observed, successfully integrated the songwriting lessons from the curriculum kit into a creative writing unit, addressing student goals for creative expression and critical thinking. She commented, "It really works nicely extending from the poetry unit into lyric-writing." Her content knowledge base provided a strong framework for the addition of the lyric-writing element, even though she reported that she herself was not a songwriter. The limitation of this approach was the requirement of collaborating with professional songwriters or musicians in order for the songs to be completed, and consequently, only a limited number of the students' lyrics submitted could be selected. I had expected to see more disappointment from the students whose songs were not chosen for finished arrangements, but this did not seem to be much of a problem. Jean noted that the songwriter "took some of the other songs, and read some of the lines and talked about rhyming and the process, so a lot of people got mentioned at some point during the session."

A strength I noticed at this site was the attitude of professionalism towards the students and their compositions. Even students whose work was not selected for finished arrangements were treated like they were "real" songwriters. The education director at the museum explained to me: "The students" work is 
respected all the way. These lyrics are passed on to another adult who doesn't know them, and who's so intrigued by what they've written that they'll pick up an instrument and add music to it-the ultimate certification. It has value all the way along; it is very respectful of students' efforts."

The songwriting process in Site Four's opera program was the one most completely integrated into the curriculum, as Debbie and her cooperating teachers trained the students in the complete process, from crafting the initial theme on through music writing, lyric writing, and performance. In order for a school to participate in this program sponsored by the New York Metropolitan Opera Guild, there must be a partnership between a music teacher and a classroom teacher, and the school has to agree to provide time within the regular school day for the opera program. This wholistic approach provided, by far, the most in-depth songwriting instruction of the four observed, but came with the price tag of extensive commitment, involvement, and teacher training. The principal described the qualifications of teachers who could successfully integrate this into their teaching: "You have to have a really perceptive, well-trained individual, competent at teaching the regular curriculum, in order to compact it and also do the opera program."

The program given to the audience the night of the performance provides some insight into the experience: "Two key words in the approach to the program are 'process' and 'original.' By taking the students through the process of creating something themselves, their mental and physical capabilities are fully challenged. And by forming their own opera company and taking on the adult 
roles of their professional counterparts, learning becomes more meaningful and purposeful. ... But perhaps the real bonus is that the production serves as a stage where a myriad of real-world skills, not usually addressed in the lower grades, will be learned. Project management, leadership, and teamwork play a major role in the overall success of the program."

\section{Collaboration, Cooperation and Engagement}

Despite the differences between the four approaches to the songwriting process and the contrasts in levels of student involvement, certain attributes stood out as being present, in some form, at all sites. Collaboration seemed to be the undercurrent running throughout this entire study, and it appeared in all different forms. Collaboration between students and songwriters, between teachers and songwriters, between teachers and students, and between groups of students. In the three sites that involved collaboration between professional songwriters and children, a great deal of respect and support was shown the students for their ideas and writing efforts. The music teacher at Site One described how Paul "made the kids feel that what they were coming up with was accepted," even if he didn't incorporate their ideas into the final song. "He always had a positive comment. Sometimes he would even say, 'Maybe that needs to be a different song. If we have time to write another song, let's put that in there." Paul, in turn, acknowledged the important contributions of the music teacher who "took a lot of responsibility and a lot of initiative" in organizing the residency and made things run smoothly by arranging the complicated 
scheduling, providing space as needed, typing out lyrics, and notating songs to be recorded.

The teachers at Sites One and Two who had songwriters visit their classrooms were impressed at the rapport the songwriters established with the students, and had positive things to say about their classroom management as well as songwriting skills. A third grade teacher, reflecting on Pam's sessions with her class, said, "I thought she did a very nice job. I was impressed. I could tell that she has experience working with children. She found something that interested them, and she kept them busy." The music teacher at Site One described the response Paul got from the students: "They all just loved Paul. They'd see him in the hall or at lunch, and they'd be hugging him—he became their hero. And I think kids respond like that with someone who's giving them a positive experience, a learning experience."

Students, too, recognized the value of working with the professional songwriters. The students at Site Three discussed their experience of collaboration: "It felt good to see that a professional songwriter thought that your song was good." The author of "School Drools" objected, however, to a clever verse the songwriter added to the end of his song:

Now all of this is just a work of fiction

'Cause you know that I love school

Because my parents, teachers and classmates

All combine to make it cool

I'll make them all proud, just you wait and see. 
Could someone please come up here

And wipe this school drool off of me?

The student's reaction to the adaptation was, "I liked it, but he changed some parts of it. And oh, I did not like that last part. It was totally going against my song." When I related this comment to the education director at the museum, he responded, "Well, professional songwriters here in Nashville say stuff like that to each other all the time-that's what the co-writing peer relationships are like."

Students also discovered the importance of working together cooperatively. When asked what they learned from songwriting, a fourth grader at Site Two responded, "I learned that you need to stick together." "You got to collaborate," a second one confirms. "Yeah, collaborate, stick together." The opera writers at Site Four reported, "We learned that you have to cooperate to make something really big happen."

At all four sites, cooperation was an integral part of the songwriting process, although it was less noticeable at Site Three where students wrote individual songs. Whole group interaction and cooperation was essential in Paul's sessions and in Pam's work with the lower grades at Site Two. Clusters of around four to eight students in Grades 3, 4, and 5 negotiated the dynamics of small group work as they collaborated on songs at this site. "One of my objectives was to get them to work cooperatively," Pam explained, "And they certainly did that. I had no discipline problems at all in the first school residency, which I thought was kind of amazing." Cooperation was also a prerequisite at 
Site Four, both in the initial development of the opera with the whole group, and later as the classes divided up into job assignments for their specialized tasks.

A fourth grade teacher at Site Two noted that the groups in her class worked together very successfully, and added, "They had a lot of experience with cooperative learning, and that really makes a big difference in how they handle things like that." She added, "Sometimes you see disagreements in cooperative learning. It's very common to argue about something. But I didn't see this at all." Naturally, the groups with less supervision had more opportunities for problems to arise; however, in all my observations, I only encountered one group whose interpersonal conflicts obstructed progress toward their goal (described on page 70), necessitating teacher intervention.

A third grade teacher, also at Site Two, said that working together in groups helped the students to be creatively productive: "Some people just cannot think, you know, but when you put them with a group, they don't feel so threatened." The Site Three classroom teacher noticed that when the students were allowed to interact while writing their own songs, "They did a lot of bouncing ideas off each other. They were kind of helping each other as they went along."

Throughout my observations, the students were excited, enthusiastic and actively engaged during nearly all of the sessions that I attended. When I asked a group of third graders at Site Two how it felt to write their songs, they responded "crazy," "happy" and "excited." A third grade teacher at that site observed her students' attitudes: 'They're very involved and interested in what they're doing. It seems like a lot of people are interested in music when they're not interested in 
other things, and it may be a good way to get them to write more." This statement was echoed by a fifth grader at Site Three who said, "I liked it because I'm really into music, and that's my first time writing my own song."

It was impossible not to notice the engagement of the students at work, especially in the groups writing independently at Site Two. One of the mystery writers volunteered to act as recorder for her group with the statement, "I can write really fast." The other members of the group excitedly tossed out ideas for clues such as finding muddy footprints and a sledgehammer by some broken pipes, and the suggestions quickly filled up the page. "We're gonna have to write on the back of that," commented a student. "That's what paper's for, to have a back where you can write!" giggled the first one. "This is going to be a good song."

At Sites One and Two, some classes would get so involved that they called out ideas more quickly than the songwriters could write them down. Kindergarteners writing about animals in the zoo shouted out descriptions of the lion: "He rolls." "He jumps!" "He leaps!" "He ROARS!" Pam sifted through the competing voices for ideas: "Roars and leaps," she wrote, and then quieted them down, “Okay, we don't want to yell out. Then we'll get too loud and I can't hear anyone." She selected a child whose hand was raised, and acknowledged him: "But I like the way you have your hand up." Pam confessed to me later, "Some of the times I was writing with the kids, they got a little noisy, and it was hard to hear their ideas-they weren't taking turns. So that was a little bit of a problem in some classes." 
Most of the classes were well-focused and highly engaged in the songwriting activities, but there were a few instances of inattentiveness. In one session at Site Three, while Jean was teaching about the song elements prior to the students writing their own lyrics, a few played with various objects at their seats, appearing to lose interest. Another group, a second grade class at Site Two, had an unusually high number of off-task behaviors (including several girls braiding and decorating each other's hair with butterfly barrettes) but this did not seem to disrupt the songwriting process for the class as a whole.

In every group, students exhibited amazement and pride upon completion of their songs, and at the end of a second grade session, when Pam offered to give the students copies of the words to their newly-written song, one boy exclaimed, "Yay! We can practice at home!"

\section{Voices of the Children}

In my opinion, the greatest value of the songwriting experience for children is in providing them with opportunities and techniques to express themselves and be heard. Other creative writing activities may share this aim; however, I believe that songwriting is especially suited for this purpose. Most students place writing assignments in the category of "schoolwork," but the novelty of songwriting sets it apart and makes it more appealing. In the words of the education director at the Country Music Hall of Fame, "Songwriting is supposed to grab something you feel strongly about, and direct it into that form."

For some students, it provides an outlet for their innate creativity. The "Words and Music" coordinator at Site Three projected the feelings of 
imaginative youngsters who might think, "I wonder if I'm weird, or there's something wrong with me-l've got all these words and all this music in my head," and the validation the songwriting experience would give such children. For others, songwriting can be a vehicle for developing self-respect, as described by a fourth grader at Site One: "It will help you because some people don't think you can do it, and then if you write a song, they'll believe you and think that you're doing something better with your life."

Children's lives are too often filled with disappointments and hardships of many different kinds, and opportunities for them to express their deepest feelings are few. The coordinator, who has read and heard thousands of children's songs in her eleven years working with the program, commented, "A lot of the kids will write about a divorce, or a parent dying, or some traumatic thing that's happened to them, that maybe they haven't said out loud to anybody, but they'll sit there and write it and turn it in as a song." A fourth grader at Site Three shared the release she felt after writing her song about a school dance disappointment: "It felt good to let my feelings go. I haven't let them go, and it seems like they stayed inside my body all my life. It made me feel better."

One of the songwriters who adapted student lyrics at the Country Music Hall of Fame reaffirmed this in reflecting with the students on their choices of topics: "A lot of you have some very serious lyrics. I think that there's a lot of things going on in the world nowadays that make children have serious thoughts, way ahead of their time. When I was a little girl in the fourth grade, I was thinking 
about dandelions and puppies, and you guys have more serious things on your mind; that's reflected in your songs."

The education director described the power of the song: "With the song, for some reason, kids will leap right into the notion, 'I can write what I really want to say.' It can empower you to tell your own story." He gave the example of a song called, "Daddy, Don't Leave Me," written by a fourth grade girl. He learned from the teacher that the girl's father actually left three years earlier, and, through the song, the girl talked about her feelings for the first time. "After that, I thought, 'This is powerful stuff.' She was speaking for an awful lot of kids who, up to now, haven't found any other way to say something that's very important to them."

Not all of the songs I encountered, however, were serious, by any means. The topics chosen by the students at the schools I visited ran the full gamut of possibilities, including songs about activities they enjoyed (for example, favorite foods, camping, music, sports and holidays); imaginative themes (space aliens, cowboy adventures, fantasy characters, and funny stories); family, pets and friends (including many variations on friendship and unfulfilled love); outdoor themes (such as farming, hunting and fishing, nature and animals); school (mostly about unpleasant experiences such as missing the bus, homework, and the ever-unpopular school lunch); serious topics (moving, loss of a loved one, and a full range of emotional issues), and songs based on classroom units of study (dinosaurs, historical events, cultures, a trip to the zoo, etc.).

Paul commented on songs that correlate with the school curriculum: "I went into one class and they had been studying Jamestown, so we wrote a song 
about Jamestown and why the people came. It both reinforced the history, and let them use their creative imaginations to see why things happened. Those people were leaving and seeking something different, and the 'whys' become really important in a song. In one of the other classes, they'd been studying the plight of women in Afghanistan, and we wrote a song about that. But I always go in with a little trepidation for the idea of taking what they're studying and writing a song about it, because it puts a little bit of a burden on the songwriter."

The songs about emotional themes and unrequited love were more often found in the upper grades; the younger students usually selected more lighthearted topics. (For a more detailed outline of song topics at the first three sites, see Appendix C, "Song Topics Grouped by Theme.") The education director shared his perspective on working with different age groups: "Really young kids can write a song if you will do it for them. For example, you ask them, 'What do you like?' 'I like dogs.' 'What about dogs?'-you know. But it really starts to work at the fourth grade level, when kids know how to spell, how to write things down independently, do something on their own. At that moment, they are ready for independent activity. One of the real values of teaching songwriting is that it gives the students the opportunity to use all those language and writing skills to say something that is uniquely theirs. It is difficult to create those kinds of experiences in schools."

\section{Authentic Learning Experiences}

At each site, songwriting was the vehicle through which students actively participated in a wide range of learning experiences. Some of the educational 
goals were specifically targeted; others were incidental to the primary objectives, naturally occurring within the process of planning, writing, practicing, and performing original music.

As all four of the sites involved the students in the lyrical aspects of songwriting (and this was the main involvement in three of the four), creative writing was the area mostly closely tied in with the regular curriculum. There were many connections made between songwriting and the writing of both stories and poetry. Elements common to both song and poetry writing included various types of rhyme, rhythm and meter. Paul explained, "Kids can really get into poetry in songwriting. You can give them information about writing poetry in songs without getting too pedantic. Sometimes so much gets stuck in the technical details. As long as we don't get caught up in all these rules, we develop a natural ear for music and language. My general belief is, the way you learn to write is to write."

References were made at all sites to the story elements of character, setting, and theme. At Site Three, Jean specifically instructed her students to use a plot structure to organize their songs: "Make sure you include who the characters are and what the setting is. And when you get a little further along in your song, make sure the problem is well explained, and when you get to the end of your song, make sure you've resolved your problem." Jean also involved her students in critique and revision, and emphasized the importance of being concise: "The average length of a popular song is three minutes. You don't 
have very much time to say what you want to say, so you need to really think about your words and choose them wisely."

Language arts concepts and mechanics naturally emerged as the songs were being created. Pam, experienced at teaching first grade, would point out reading skills such as short vowel sounds, compound words, and phonics blends, as her younger students suggested words for their songs: 'Oh, 'stick' and 'brick,' those are good blends. When you put two letters at the beginning of a word, that's called a blend." She sounds them out: "St-ick, stick. Br-ick, brick." Fourth graders at Site Two practiced their spelling skills in this discussion during the writing of "House on Haunted Hill": "Skeletons hanging from the ceiling. . . how do you spell skeleton?" "S-K-E-L-E-." A third student interrupts, "It doesn't matter, as long as you can read it." But another one pipes up: "Hey, we had that as a spelling word!" "Oh, yeah!" And suddenly they all remember how to spell it.

Paul, at Site One, emphasized the creative writing devices of figurative language, imagery, and the uses of comparison, contrast, and repetition. Always stimulating the students to "think outside the box," as the music teacher described it, Paul would ask questions like, "What else hates snow and rain?" and, "What else glitters?" Inspiring students to think of unusual combinations for the "weird food" song, he tells the writers, "One of the great things you can have in a song is contrast." In his studio, he expressed some of his views on the creative use of words: "I feel like they're learning the rhythm of language, both metrical and poetic, in the way rhyme creates rhythm, in the way sound creates 
rhythm. I work a lot with metaphor, the way things relate to each other in a figurative way of speaking."

When I asked Pam, the songwriting instructor at Site Two, what types of student learning she had observed during the songwriting sessions, she answered thoughtfully, "The creative process. . . use of imagination. . . using rhyming words-an English skill, and grammar skills, and even a rhythm skill, because they had to make the words fit into a certain rhythm. And they also had to sing on key, and put the phrases within the music. Actually, there were a lot of skills I saw they were learning as we did it."

A third grade teacher that I interviewed at this site shared her observations with me: "This class likes music and they don't even realize they're writing. To me, they're doing skills that sometimes might be dreaded, whereas right now, they don't even realize what they're doing. They're having fun. And I think, if you can present anything they need to work on in a fun, interesting way, that's over half the battle."

Along with hands-on learning experiences in the writing process, students had the opportunity to gain practical knowledge in many musical concepts and skills-song structure, the relationship between melody and lyric, the feel of rhyme, the sense of rhythm and meter, the differences in musical styles, as well as practice in singing. The importance of word selection, rhyme, and phrasing in lyric-writing was incorporated into the process at all sites. Paul emphasized the importance of vowel sounds in rhyming for songs: "It doesn't have to be a perfect rhyme, because in singing, you hold out the vowels. So all we need is 
something that's got an 'aw' in it." Paul also introduced the concepts of mood, transposition, and the ritard. Pam asked her students to identify a variety of musical instruments and genres of music in the recordings she played for them, and taught the concepts of rests in music, and major and minor keys. "I want to play you a chord that is major," (she plays A major on her guitar) ". . and the same chord as a minor." (She plays A minor.) "One sounds a lot happier than the other. Which one's happier? Which one is sadder sounding?" Discussion in Jean's classes focused on the musical concepts of reprise, accent, the tie, pickup notes, and time signatures. The curriculum kit provided by the museum offered advice on the characteristics of a good song: "A good song appeals to many people and uses words that catch the listener's attention, making the song easily remembered." The composers at Site Four learned to be accompanists for the performance, as well as developing skills in music composition.

The songwriting process, like many of the creative arts, is an ideal vehicle for the development of both creative and critical thinking skills, which are among the most difficult (and most neglected) outcomes in the elementary curriculum. Activities to promote creative thinking such as brainstorming topics and details and the use of clustering or webbing of ideas were common to all four groups. At Site One, Paul interjected questions requiring the use of the critical thinking skills of reasoning and understanding cause and effect in drawing ideas for song lines from the children. The music teacher at Site One reflected: "They've had to force themselves to think a little further-'I want a word that means this, but I want it to sound like this'-you know, they have to brainstorm it. I think it really 
stretches mind power, to do that." A third grade teacher at Site Two described students' thought processes as "coming up with different ideas, trying to keep to the main idea, putting things together to make sense, to sequence things." A fourth grade teacher at the same site described the songwriting process as "disciplining their minds, making them organize materials. It's very creative." At Site Three, the strategy of analyzing song examples and applying that knowledge to creating original songs is a perfect example of utilizing the higher-level thinking skills of analysis and synthesis. The songwriting teachers at every site stressed the use of the imagination and provided positive reinforcement for creative and divergent thinking. In Paul's words, "Imagination is one of the keys to writing songs." "It's just like a movie projector you're thinking in your head," explained a perceptive first grader.

Although the primary emphasis at each site was the process of songwriting, each program included a performance aspect, which ranged from singing the finished song into a tape recorder, clustered around one microphone, to the fully-mounted opera production at Site Four. The students were invariably excited about and proud of their creations, and the opportunity to perform their songs in some manner was an enjoyable culminating experience for them. Several of the songwriters encouraged the students to continue their creative expression on into the performance mode, ad libbing animal sounds or words appropriate to the song. For example, at Site One, Paul suggested that students add cat and dog sounds in one song, and "Good-byes" and "Happy Birthdays" in others. Suggestions were shared with the children at several sites to help them 
with performance skills such as voice and diction, memorization, microphone technique, recording procedures, planning costumes, overcoming nervousness, and stage presence.

As we discussed the role of songwriting in the curriculum, Paul described the process as "a natural and fun lead-in to both music and creative writing." The music teacher who facilitated Paul's residency shared her view: "In music, I think songwriting needs to be more of an essential part. There are a few specific outcomes for music that involve the creative process, but l've seen how much good it's done the kids, so I feel like we're going to need to continue something with this creative process from year to year, not just in one year." (See Appendix D for the National Standards for Arts Education relating to the songwriting process.) The education director at Site Three described how the "Words and Music" program connects to the regular school curriculum:

We're trying to pick the part of the songwriting process that can be built on skills they are already learning in the curriculum: language skills and how to choose an adjective; skills of description; how to tell a story with a beginning, middle and end; how to say something in an unusual way; how to edit and revise-all language skills, all being taught in the curriculum. Now you bring songwriting inyou're teaching those skills plus meter, phrasing, line length. The teachers see what we're doing as an amplification or an embellishment to what they set out to do with the curriculum in the first place.

\section{Reflections on Research}

I began this dissertation with a discussion of the multitude of ways in which the arts in general can enrich and enhance an educational program, and introduced the idea of incorporating the creative process of songwriting into the 
elementary curriculum. Through individual portraits depicting four different approaches to the songwriting process with elementary students, and by reflecting on those portraits and some of the learning experiences of the children at the four research sites, I have provided support for this premise. It is my belief that there is sufficient justification, outlined specifically in national and state standards, supported by research literature, and brought to life by the experiences and voices of those pioneering in the field, to incorporate songwriting into the regular elementary curriculum.

This study, however, is only a beginning. As one of the first published research studies focusing on songwriting in education, I hope that it will serve to inspire other educators and researchers to pursue this exciting work in the field. Some suggestions for further study are listed below.

Songwriting based on improvisation with musical instruments: My study focused on songwriting strategies based primarily on lyric writing (with the exception of the opera music written at Site Four). One topic for a complementary study would be to focus on the process of songwriting with improvisation on musical instruments as the focus, such as is taught through the Orff approach to elementary music (Landis and Carter, 1972).

Songwriting integrated into specific content area instruction: My initial research idea was for case studies of teachers using songwriting to supplement the teaching of subjects in the curriculum. Although I identified several teachers who themselves wrote songs to teach particular topics, I was unsuccessful at that time in locating teachers who involved students in the creative process of 
songwriting to reinforce learning. Consequently, I feel that this would be an excellent topic for a follow-up study.

The uses of electronic media as vehicles for student songwriting: As our popular music is evolving in this electronic age, many young people are experimenting with synthesizing, sampling and sequencing music using electronic equipment and computers as tools for songwriting. Another possible study would focus on these processes in an academic setting.

Strategies for teaching the melody-writing aspect of songwriting:

Traditional music instruction usually focuses on music reading and notation with an emphasis on the complex processes of instrument playing and composition, seldom addressing the simpler genres of song and the aural construction of melodies. Another appropriate study could be to research strategies for teaching students the creative process of songwriting initiating with the aspect of melody (as opposed to originating with lyrics).

Action research studies on songwriting in the classroom: This particular study was conducted from the perspective of participant-observer portraitist, one who observes the process under investigation and is only peripherally involved in the instructional process. Studies conducted by teachers engaged in songwriting with their students in their own classrooms would be very informative by providing another vantage point and contribute significantly to a greater understanding of the role and benefits of songwriting in education. 
In closing, I must return to the words of the education director of the Country Music Hall of Fame who has provided me with so many good quotes already, but I have saved my favorite for last:

I don't care if you're a truck driver or a nurse, but everybody has a story and a need to tell it.

It's not about being a professional songwriterit's about living the full human life. 


\section{References}

Alvin, J. (1966). Music therapy. London: John Baker

Armistead, M. (1996, June). Constructivism and arts based programs. Paper presented at the National Association of Early Childhood Educators' Conference, Minneapolis, MN.

Arnold, R. \& Burke, B. (1983). A popular education handbook. An educational experience taken from Central America and adapted to the Canadian context. Ottawa, Ontario: CUSO Development Education; Toronto, Ontario: Ontario Institute for Studies in Education.

Berghoff, B. Multiple sign systems and reading. The Reading Teacher, 51 (6), 520-523.

Bloom, B. (Ed.). (1956). Taxonomy of educational objectives, handbook I: Cognitive domain. New York: David McKay.

Bogdan, R. C. \& Biklen, S. K. (1992). Qualitative research for education: An introduction to theory and methods. Boston: Allyn \& Bacon.

Bogdan, R. \& Taylor, S. J. (1975). Introduction to qualitative research methods: A phenomenological approach to the social sciences. New York: John Wiley \& Sons.

Bresler, L. \& Stake, R. E. (1992). Qualitative research methodology in music education. In Music Educators National Conference (Ed.), Handbook of research on music teaching and learning (pp. 75-90). New York: Schirmer.

Brunk, B. K. (199u). Songwriting for music therapists. Grapevine, TX: Prelude Music Therapy.

Bryan, D. L. (1980). Music to your ears. Instructor, 90 (4), 131-132.

Campbell, L., Campbell, B. \& Dickinson, D. (1996). Teaching and learning through multiple intelligences. Needham Heights, MA: Allyn \& Bacon.

Carpenter, D. (1999). The impact of songwriting, dramatization, and performance on third grader's ability to learn and retain social studies concepts. Unpublished master's thesis, San Diego State University.

Checkley, K. (1997). The first seven. . . and the eighth: A conversation with Howard Gardner. Educational Leadership, 55, 8-13. 
Ching, M. (1995). Is there a place for song writing in our curriculum? One experience. Unpublished manuscript, Opera Memphis.

Cockburn, V. (1992). The uses of folk music and songwriting in the classroom. In M. Goldberg \& A. Phillips (Eds.), Arts as Education. Cambridge, MA: Harvard Educational Review.

Consortium of National Arts Education Associations. (1994). National Standards for Arts Education [On-line]. Available: http://artsedge.kennedy-center. org/professional_resources/standards/nat_standards_main.html

Cordobés, T. K. (1997). Group songwriting as a method for developing group cohesion for HIV-seropositive adult patients with depression. Journal of Music Therapy, 34 (1), 46-47.

Craig, G. J. (1979). Child development. Englewood Cliffs, NJ: Prentice-Hall.

Davis, K. L. (1998). "To never surrender": Music therapy in the fight against multiple sclerosis. Canadian Journal of Music Therapy, 6 (1), 20-34.

Delk, N. L. (1993). The clinical interview with inpatient psychiatric adolescents in songform: The use of clinical songwriting to identify the internal state. Unpublished master's thesis, Hahnemann University, Philadelphia.

DeVries, R. \& Kohlberg, L. (1987). Programs of early education: The constructivist view. New York: Longman.

Dewey, J. (1934). Art as experience. New York: Capricorn Books.

Edgerton, C. D. (1990). Creative group songwriting. Music Therapy Perspectives, 8, 15-19.

Eisner, E. (1979). The educational imagination: On the design and evaluation of school programs. New York: Macmillan.

Eisner, E. (1988). The primacy of experience and the politics of method. Educational Researcher, 17, 15-20.

Eisner, E. (1990). Implications of artistic intelligences for education. In W. Moody (Ed.), Artistic intelligences: Implications for education (pp. 31-42). New York: Teachers College Press.

Eisner, E. \& Peshkin, A. (Eds.). (1990). Qualitative inquiry in education: The continuing debate. New York: Teachers College Press. 
Elsila, M. (1998). Music behind bars: Learning to teach radically in prison. Radical Teacher, 52, 4-8.

Ficken, T. (1976). The use of songwriting in a psychiatric setting. Journal of Music Therapy, 13 (4), 163-172.

Forseth, S. D. (1976). The effects of art activities on attitudes and achievement in fourth grade children pertinent to the learning of mathematics and art (Doctoral dissertation, University of Minnesota, 1976). Dissertation Abstracts International, 37-12A, 7590.

Fowler, C. (1990). One nation, undercultured and underqualified. In W. Moody (Ed.), Artistic intelligences: Implications for education (pp. 159-169). New York: Teachers College Press.

Freed, B. S. (1987). Songwriting with the chemically dependent. Music Therapy Perspectives, 4, 13-18.

Freire, P. (1994). Pedagogy of the oppressed. New York: Continuum.

Gallas, K. (1992). Arts as epistemology: Enabling children to know what the know. In M. R. Goldberg \& A. Phillips, Arts as education (pp. 19-31). Cambridge, MA: Harvard Educational Review.

Gallas, K. (1994). The languages of learning: How children talk, write, dance, draw and sing their understanding of the world. New York: Teachers College Press.

Gantz, D. (1998). Songwriting: A guide for teachers. Unpublished master's thesis, University of Florida, Gainesville.

Gardner, H. (1983). Artistic intelligences. Art Education, 36 (2), 47-49.

Gardner, H. (1991). The unschooled mind: How children think and how schools should teach. New York: Basic Books.

Gardner, H. (1993). Multiple intelligences: The theory in practice. New York: Basic Books.

Gaston, E. T. (1968). Music in therapy. New York: Macmillan.

Glaser, B. G. \& Strauss, A. L. (1967). The discovery of grounded theory: Strategies for qualitative research. Chicago: Aldine Publishing Company.

Glesne, C. \& Peshkin, A. (1992). Becoming qualitative researchers: An introduction. New York: Longman. 
Goldberg, M. (1997). Arts and learning. White Plains, NY: Longman.

Goldstein, S. L. (1989). The use of music therapy songwriting in the assessment of hopelessness in depressed adolescents. Unpublished master's thesis, Hahnemann University, Philadelphia.

Greene, M. (1978). Landscapes of learning. New York: Teachers College Press.

Greene, M. (1990). Arts education in the humanities: Toward a breaking of the boundaries. In W. Moody (Ed.), Artistic intelligences: Implications for education (pp. 147-158). New York: Teachers College Press.

Greene, M. (1992). Texts and margins. In M. R. Goldberg \& A. Phillips (Eds.), Arts as education (pp. 1-17). Cambridge, MA: Harvard Educational Review.

Greenstreet, S. T. (1990). The use of songwriting as an assessment of anxiety in adults. Unpublished master's thesis, Hahnemann University, Philadelphia.

Guilford, J. P. (1962). Factors that aid and hinder creativity. Teachers College Record, 65, 380-392.

Guilford, J. P. (1968). Intelligence, creativity and their educational implications. San Diego, CA: Robert R. Knapp.

Haladyna, T. \& Thomas, G. (1979). The attitudes of elementary school children toward school and subject matters. Journal of Experimental Education, 48 (1), 18-23.

Hallman, R. (1967). The necessary and sufficient conditions of creativity. In J. C. Gowan, G. D. Demos \& E. P. Torrance (Eds.), Creativity: Its educational implications (pp. 16-31). New York: John Wiley \& Sons.

Hamer, C. L. (1985). The use of songwriting as a treatment modality with depressed adolescents. Unpublished master's thesis, Hahnemann University, Philadelphia.

Hanna, J. L. (1992). Connections: Arts, academics, and productive citizens. Phi Delta Kappan, 73 (8), 601-607.

Hanshumaker, J. (1980). The effects of arts education on intellectual and social development: A review of selected research. Council for Research in Music Education, 61, 10-28. 
Harper, B. J. (1985). Say it, review it, enhance it with a song. Elementary School Guidance and Counseling, 19, 218-221.

Hennessey, B. \& Amabile, T. (1987). Creativity and learning. Washington, DC: National Education Association.

Howard, V. (1992). Learning by all means: Lessons from the arts; $A$ study in the philosophy of education. New York: Peter Lang.

Hubbard, R. S. (1996). Workshop of the possible: Nurturing children's creative development. York, ME: Stenhouse.

Hycner, R. (1985). Some guidelines for the phenomenological analysis of interview data. Human Studies, 8, 279-303.

lannone, R. \& Obenauf, P. (1999). Toward spirituality in curriculum and teaching. Education, 119 (4), 737-743.

Johnson, E. R. (1978). The effect of a combined values clarification and songwriting experience on self concept of socially disadvantaged adolescents in a family-oriented, group living setting. Unpublished master's thesis, University of Kansas, Lawrence.

Krathwohl, D., Bloom, B., \& Masia, B. (1964). Taxonomy of educational objectives handbook II: Affective domain. New York: David McKay.

Kridel, C. (1990). Implications for general education. In W. Moody (Ed.), Artistic intelligences: Implications for education (pp. 85-91). New York: Teachers College Press.

Landis, B. \& Carder, P. (1972). The eclectic curriculum in American music education: Contributions of Dalcroze, Kodaly, and Orff. Reston, VA: Music Educators National Conference.

Langfit, D. (1994). Integrating music, reading, and writing at the primary level. The Reading Teacher, 47 (5), 430-431.

Lawrence-Lightfoot, S. (1983). The good high school: Portraits of character and culture. New York: Basic Books.

Lawrence-Lightfoot, S. \& Davis, J. H. (1997). The art and science of portraiture. San Francisco: Jossey-Bass Inc.

Lee, R. T. (1985). The expanding role of the arts in education. Music Educators Journal, $72(2), 28-33$. 
Lindberg, K. A. (1995). Songs of healing: Songwriting with an abused adolescent. Music Therapy, 13 (1), 93-108.

Martin, M. (1983). Success! Teaching spelling with music. Academic Therapy, $18(4), 505-507$.

McLaughlin, J. (1990). Building a case for arts education: An annotated bibliography of major research. Lexington, KY: The Kentucky Alliance for Arts Education \& The Kentucky Arts Council.

Miles, R. (1993). I've got a song to sing. Elementary School Guidance \& Counseling, 28 (1), 71-75.

Monagan, M. (1989). Special music by special kids. Educational Leadership, 46 (6), 20.

Moody, W. (Ed.). (1990). Artistic intelligences: Implications for education. New York: Teachers College Press.

Morris, W. (Ed.). (1969). The American Heritage dictionary of the English language. Boston: American Heritage Publishing Co.

National Commission on Music Education. (1991). Growing up complete: The imperative for music education. Reston, VA: Music Educators National Conference.

Newcomb, N. S. \& Thompson, C. L. (1994). Music: A powerful resource for the elementary school counselor. Elementary School Guidance \& Counseling, 29 (2), 150-156.

Page, N. (1995). Music as a way of knowing. York, ME: Stenhouse Publishers.

Parnes, S. (1967). Creative behavior guidebook. New York: Charles Scribner's Sons.

Plach, T. (1980). The creative use of music in group therapy. Springfield, IL: Charles C. Thomas.

Rubin, H. J. \& Rubin, I. S. (1995). Qualitative interviewing: The art of hearing data. Thousand Oaks, CA: Sage Publications.

Saab, J. (1987). The effects of creative drama methods on mathematics achievement, attitudes and creativity. (Doctoral dissertation, West Virginia University, 1987). Dissertation Abstracts International, 48-10A, $2538 .$. 
Satterwhite, J. H. (1991). Developing creativity through songwriting in secondary education composition classes (Doctoral dissertation, Middle Tennessee State University, 1991). Dissertation Abstracts International, 52-11A, 3978.

Schwandt, T. A. (1997). Qualitative inquiry: A dictionary of terms. Thousand Oaks, CA: Sage Publications.

Silber, F. \& Hes, J. P. (1995). The use of songwriting with patients diagnosed with Alzheimer's disease. Music Therapy Perspectives, 13 (1), 31.

Silberman, C. E. (Ed.) (1973). The open classroom reader. New York: Vintage.

Skaught, B. J. (1987). Songwriting should be taught in your gifted program. The Gifted Child Today. 10, 40-41.

Smith, J. A. (2000). Singing and songwriting support early literacy instruction. The Reading Teacher, 53 (8), 646-648.

Sowell, E. J. (1996). Curriculum: An integrative introduction. Columbus, $\mathrm{OH}$ : Prentice-Halll, Inc.

Torrance, E. P. (1966). Torrance tests of creative thinking. Bensenville, IL: Scholastic Testing Service.

Torrance, E. P. (1967) Creative teaching makes a difference. In J. C. Gowan, G. D. Demos \& E. P. Torrance (Eds.), Creativity: Its educational implications (pp. 173-188). New York: John Wiley \& Sons.

Torrance, E. P. (1965). Rewarding creative behavior: Experiments in classroom creativity. Englewood Cliffs, NJ: Prentice-Hall.

Tucker, A. (1981). Music and the teaching of reading: A review of the literature. Reading Improvement, 18 (1), 14-19.

Ungerleider, J. H. (1987). Raising consciousness about the nuclear threat through music (Doctoral dissertation, University of Massachusettes, 1987). Dissertation Abstracts International, 49-03A, 476.

Vygotsky, L.S. (1978). Tool and symbol in child development. In M. Cole, V. John-Steiner, S. Scribner, \& E. Souberman (Eds.), Mind in society: The development of higher psychological processes (pp. 19-30). Cambridge, MA: Harvard University Press. 
Walker, J. (1995). Music therapy, spirituality and chemically dependent clients. In R. J. Kus (Ed.), Spirituality and chemical dependency (pp. 145-166). New York: Haworth.

Wiersma, W. (1995). Research methods in education: An introduction $\left(6^{\text {th }}\right.$ ed.) Needham Heights, MA.: Allyn \& Bacon. 
Appendix A:

Interview Schedules 


\section{Interview Schedule A: Classroom teachers}

(The interview will begin with an explanation of the purpose, and statements that participation is voluntary and participants' anonymity will be maintained.)

1. What was your role in the songwriting process? (Did you do anything to prepare the students? Will you be doing anything to follow up the experience?)

2. How do you think your students responded to the songwriting experience(s)?

3. What types of student learning, if any, did you observe taking place?

4. What were some of the students' attitudes before, during and after the session(s)?

5. How do you see the songwriting process fitting into your curriculum?

6. Do you have any comments on the way the songwriting instruction was presented, or on working with the professional songwriter?

7. Are there any other comments you would like to make?

Thank you for your participation in this interview. 


\section{Interview Schedule B: Songwriting consultants}

(The interview will begin with an explanation of the purpose, and statements that participation is voluntary and participants' anonymity will be maintained.)

1. What were your goals for the session(s), and how well do you feel that they were met?

2. How do you think the students responded to the songwriting session(s)?

3. What types of student learning, if any, did you observe taking place?

4. What were some of the students' attitudes before, during and at the close of the session(s)?

5. How do you see the songwriting process fitting into an elementary curriculum?

6. Do you have any comments on your process of working with the students or the classroom teacher(s), or how the residency was structured?

7. Are there any other comments you would like to make?

Thank you for your participation in this interview. 


\section{Interview Schedule C: Class focus groups}

(The interview will begin with an explanation of the purpose, and statements that participation is voluntary, will not affect any grades, and participants' anonymity will be maintained.)

1. Class, l'd like for you to tell me about writing your song(s). (How did it feel to write a song?)

2. Were you comfortable with the process? (Why or why not?)

3. Did you learn anything while songwriting? (What did you learn?)

4. Did you notice a change in anyone's attitude? (What kinds of changes?)

5. Does anyone think they might continue writing songs on their own, and if so, why? Had anyone ever written a song before?

6. What was it like to work with a professional songwriter?

7. Are there any other comments the group would like to make?

Thank you for your participation in this interview. 


\section{Appendix B:}

Summary of Songwriting Pedagogy by Site 


\section{Summary of Songwriting Pedagogy by Site}

\section{Site One}

Paul, a professional songwriter, musician and performer, spent one or more 45-minute sessions in approximately 35 different classrooms in two schools, grades K-7. During that time, he guided each group through brainstorming topics and ideas for a song, creating a story or montage of related images, and building the song, line by line. He stressed creative and divergent thinking, and the use of figurative language. Paul created most of the melodies and guitar accompaniment for the songs on the spot, beginning while the lyrics were still in process, and the sessions concluded with singing a fully or partially completed song into his recorder. Many of the songs were integrated into a subsequent school-wide production incorporating multiple art forms, and several of the songs were selected for later production of a recording, to be performed by professional musicians. Funding for the residency was obtained by the school through a state arts grant.

\section{Site Two}

Pam, a professional songwriter and experienced elementary school teacher, visited several of the 42 participating classrooms (grades K-5) each day during her three-school residency, spending approximately seven 45-minute sessions in each classroom. She began by introducing students to a variety of styles of musical recordings and their accompanying art designs. Her songwriting process began with brainstorming topics for songs and creating a 
word bank of related ideas and associated rhyming words. Next, the students would formulate a list of action ideas and sequence those ideas into the song, line by line, drawing from details and rhymes collected earlier. Lower grades wrote class songs; in grades $3-5$, students worked in groups to write several songs per class. Upon completion of the lyrics, Pam would play different musical styles on her guitar, from which the children would select the one they preferred for their song. She created most of the melodies and accompaniment, incorporating student melodic ideas whenever possible. The series of songwriting classes concluded with recording the finished song and students creating individual cover designs for a personal copy of the tape, and was followed up later with a school-wide performance. Funding for the residency was provided through a partnership between the school system and a local arts agency.

\section{Site Three}

The songwriting instruction at this site was presented through a collaboration with the Country Music Hall of Fame in a program called "Words and Music" which teams up professional songwriters in the Nashville area with interested teachers in nearly fifty different schools in the region. Instructional materials were provided by the museum for the classroom teacher to teach the process of lyric writing to the students. (The teacher I observed taught fourth and fifth grade gifted students; however, the program included participation from regular education, special education, content area specialists and music teachers, primarily in grades 4-12.) The lyric writing process taught to the 
students included analyzing songs and identifying the elements of a song and characteristics of a good song before writing. Jean, the teacher I observed, integrated the materials from the "Words and Music" kit into her creative writing curriculum, and covered concepts of character, setting, plot, etc., as well. Students independently planned, wrote, revised, and submitted the lyrics for one or more songs to designated professional songwriters, who selected the lyrics for several songs and set them to music. The class later met with the songwriter at the museum and heard the finished songs, which were recorded for them. At the end of the school year, selected songs from all the ones written through the program that year were performed by the co-writers in a concert at the museum. The only costs of participation for the schools were expenses related to their field trip.

\section{Site Four}

This K-5 Maryland school is one of hundreds of elementary and middle schools participating in the "Creating Original Opera" program sponsored by the Metropolitan Opera Guild of New York. A pair of teachers, one music and one regular education, participated in a week-long summer training program and received curriculum materials for teaching students how to write, produce and perform an original opera. The process, carried out over the period of an entire school year, integrated writing, musical, and technical activities into the regular curriculum. The performance I attended was produced by fourth and fifth grade students, but the program is not limited to those grade levels. In this program, the songwriting began with the identification of theme and thesis, followed by 
characters, setting, and possible conflicts. A story line was developed in narrative and dialogue, musical moments were identified, and student composers (who have practiced composition) worked from song concepts to write appropriate melodies, which were then arranged with harmonic structures by an adult accompanist. Writers and composers then teamed together to write the lyrics for the songs, considering character traits, the setting, and any other pertinent information. Simultaneously, other students were developing set and costume designs, public relations and publicity, and documenting the process. Two public performances culminated the year's work, and were videotaped for the school archives and interested families. The cost of participation for schools in this program is a modest financial expense and a huge commitment of time and dedication. 


\section{Appendix C:}

\section{Song Topics Grouped by Theme}


Table C1. Topics of group songs from two schools at Site One by theme.

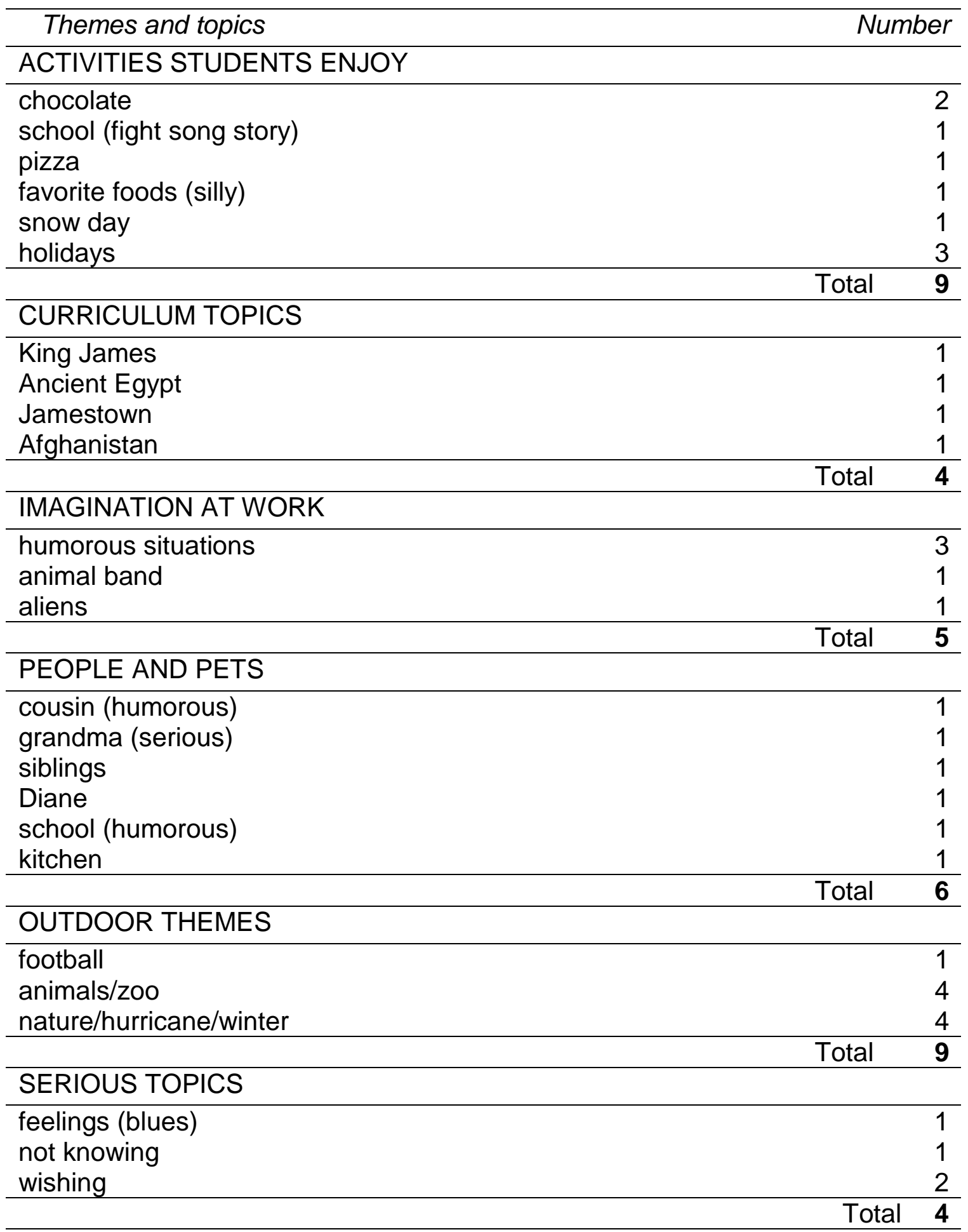


Table C2. Topics of group songs from two schools at Site Two by theme.

\begin{tabular}{lrr}
\hline \multicolumn{1}{c}{ Themes and topics } & Number \\
\hline ACTIVITIES STUDENTS ENJOY & 3 \\
\hline camping, horseback riding & 10 \\
music, TV and movie themes & 1 \\
school (positive) & 6 \\
sports & 3 \\
vacation/holidays & Total & $\mathbf{2 3}$ \\
\hline & & 3 \\
\hline CURRICULUM TOPICS & Total & $\mathbf{3}$ \\
\hline bats, zoos, dinosaurs & & \\
\hline & & 6 \\
\hline IMAGINATION AT WORK & Total & $\mathbf{1 0}$ \\
\hline adventure/mystery & \\
aliens/space & 3 \\
\hline PEOPLE AND PETS & 1 \\
\hline animals & 7 \\
friends & & 2 \\
pets & & \\
\hline & & 1 \\
\hline OUTh attitude & Total & $\mathbf{1 3}$ \\
\hline nature & Total & $\mathbf{1}$ \\
\hline
\end{tabular}


Table C3. A sampling of song topics from schools at Site Three.

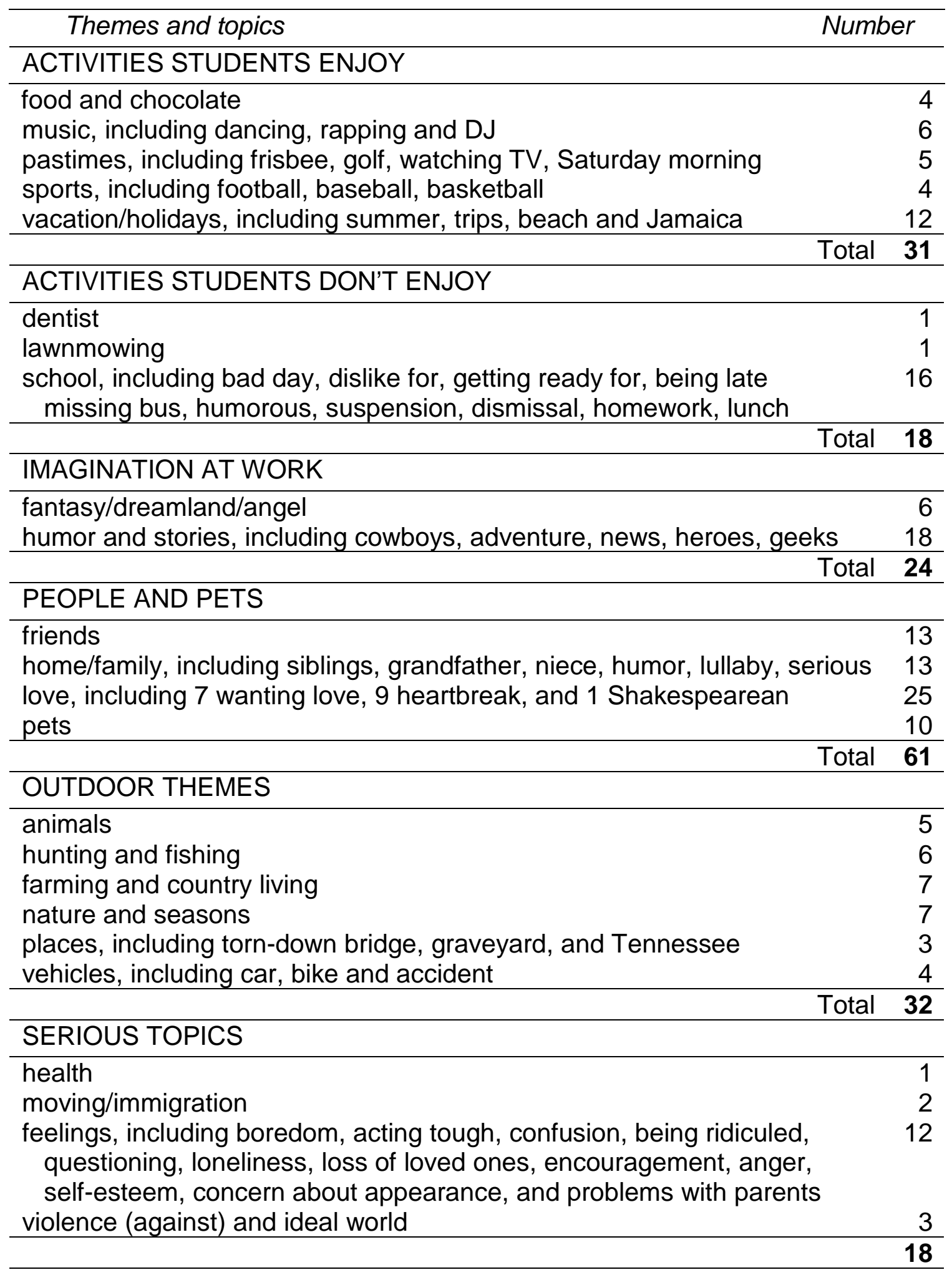




\section{Appendix D:}

National Standards for Arts Education

Relating to the Songwriting Process 


\section{National Standards for Arts Education Relating to the Songwriting Process}

\section{Music (K-4) Content Standard \#3}

Improvising melodies, variations, and accompaniments

\section{Achievement standard}

Students improvise short songs and instrumental pieces, using a variety of sounds, including traditional sounds (e.g., voices, instruments), nontraditional sounds available in the classroom (e.g., paper tearing, pencil tapping), body sounds, (e.g., hands clapping, fingers snapping), and sounds produced by electronic means (e.g, personal computers and basic MIDI devices, including keyboards, sequencers, synthesizers, and drum machines).

\section{Music (K-4) Content Standard \#4}

Composing and arranging music within specified guidelines

\section{Achievement standard}

Students create and arrange short songs and instrumental pieces within specified guidelines (e.g., a particular style, form, instrumentation, compositional technique). 


\section{Music (K-4) Content Standard \#9}

Understanding music in relation to history and culture

\section{Achievement standard.}

Students identify various uses of music in their daily experiences and describe characteristics that make certain music suitable for each use.

\section{Reference:}

Consortium of National Arts Education Associations. (1994). National Standards for Arts Education [On-line]. Available: http://artsedge.kennedy-center.org/ professional_resources/standards/nat_standards_main.html 


\section{About the Author}

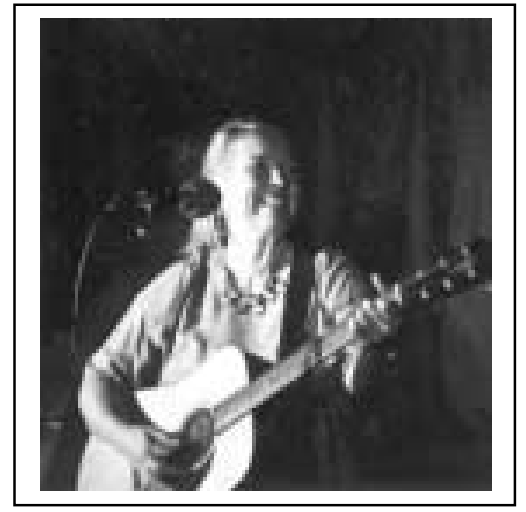

Sally dhruvá Stephenson is an artist-educator with a wide range of experience in both fields. As an educator, she has taught students from the ages of preschool through graduate students. College courses she has taught include "Early Childhood Education," "Creative Experiences in Early Childhood," "Integrating the Arts in the Elementary Classroom," and "Literacy and the Young Child." She has also supervised student teachers in the field. Her public school teaching experience includes Head Start, kindergarten, elementary gifted, and community education. Outside of the classroom, Stephenson's artistic interests include music, theatre, photography and textile arts. A founding member of the Landmark Players in central West Virginia, she has credits in acting; directing; costume, mask and make-up design; sound, lighting and set design; and publicity. Her original play, "For the Duration: WV Memories of the War Years" toured state-wide in conjunction with a Smithsonian exhibit of WWII home front memorabilia. She has performed with several musical ensembles and, at the time of this writing, performs solo as a singer-songwriter. Her original songs have been published on the recordings "Stories and Songs of Creative Creatures," "Musicians for the Met," "Angel Patrol," and "Jammer Without a Band." She is also a published photographer. This dissertation represents the merging of her professional and personal interests (song 15). 